Boletín de la Sociedad Geológica Mexicana

VOLUMEN 62, NÚM. 1, 2010, P. 55-100

\title{
Los minerales de colección como recurso económico en países en vías de desarrollo
}

\author{
Joan Carles Melgarejo*1, Marc Campeny ${ }^{1}$, Joaquim Sanz ${ }^{2}$, Carles Curto ${ }^{3}$, \\ Joan Viñals ${ }^{4}$
}

${ }^{1}$ Departament de Cristal·lografia, Mineralogia i Dipòsits Minerals, Facultat de Geologia, Universitat de Barcelona c/ Martí i Franquès s/n 08028 Barcelona Catalunya, España.

${ }^{2}$ Departament d'Enginyeria Minera i Recursos Naturals, Escola Politècnica Superior d'Enginyeria de Mines de Manresa, Universitat Politècnica de Catalunya Avinguda Bases 61-73 08242 de Manresa Catalunya, España.

${ }^{3}$ Museu de Ciències Naturals de Barcelona (Geologia) Ajuntament de Barcelona/ICUB. Parc de la Ciutadella s/n 08003 Catalunya, España.

${ }^{4}$ Departament de Ciències dels Materials i Enginyeria Metal·lúrgica, Facultat de Química, Universitat de Barcelona. c/ Martí i Franquès 1, 08028 Barcelona Catalunya, España.

* joan.carles.melgarejo.draper@ub.edu

\begin{abstract}
Resumen
El coleccionismo de minerales es una actividad en expansión. El alto nivel de demanda de minerales y de sus derivados posibilita la creación de microempresas en países en vías de desarrollo que, con muy poca inversión de capital, pueden facilitar el desarrollo de áreas rurales sin producir apenas impacto en el medio natural. Un aspecto muy importante para la supervivencia de estas microempresas es que el material tenga la calidad adecuada para su óptima comercialización, cosa que no ocurre en la actualidad con la mayor parte del material que procede de los países en vías de desarrollo. En este trabajo se proporcionan, de forma ilustrada, los criterios que se deben usar para identificar el tipo de material que puede ser interesante para ser comercializado, así como los mecanismos de tratamiento de los minerales desde su lugar de extracción hasta el punto de venta.
\end{abstract}

Palabras clave: mineralogía popular, coleccionismo, microempresa, países en vías de desarrollo.

\begin{abstract}
Mineral collecting is a growing activity. The high demand for minerals and their derivatives has resulted in the creation of microcompanies around the mineral trade in developing countries. This activity could facilitate the development of rural areas with no need of a large capital investment and with minimal environmental impact. The high quality of their products is the most important aspect for the survival of these micro-companies, but nowadays the material that comes from developing countries does not always arrive in the best condition. In this essay the basic criteria are provided for identifying the kind of minerals that are interesting enough to be commercialized, and also the procedures recommended for commercializing them from the place where they are extracted to their point of sale.
\end{abstract}

Key words: popular mineralogy, collecting, micro-companies, developing countries 


\section{Introducción}

Actualmente hay miles de personas de todo el mundo, de todas las edades y posición social, que coleccionan minerales. Es difícil saber el número de aficionados a esta ciencia en todo el mundo, pero pueden llegar a ser más de 100.000 personas en Europa y bastantes más en los Estados Unidos de América. Posiblemente en el resto del mundo haya una cifra similar. De hecho, el número de coleccionistas crece cada año y se extiende no solamente en los países más desarrollados sino que también empiezan a aparecer colecciones importantes en países en vías de desarrollo o en países con economías emergentes.

La forma de obtener las piezas de las colecciones es muy variada. En primer lugar, los coleccionistas pueden obtenerlas a partir de la recolección propia en el campo o en las minas. El perfil del recolector de minerales en los países desarrollados es el de una persona que realiza esta labor como afición en horas de ocio y clasifica y prepara las muestras en su tiempo libre.

Muchos coleccionistas también obtienen muestras mediante intercambios de sus piezas con las de otros coleccionistas o, muy comúnmente, a partir de la compra. Esta compra se puede realizar directamente a los mineros o a otros coleccionistas, pero casi siempre se realiza mediante la compra al detalle en pequeñas tiendas especializadas, en ferias de minerales o por Internet.

A causa de este hecho, se ha generado un cierto mercado de minerales, actualmente muy globalizado, y que cuenta con decenas de miles de persones que viven directamente o indirectamente de él.

La elevada demanda de minerales de colección plantea la posibilidad de que se busquen y extraigan más muestras en otros lugares del mundo donde todavía no ha surgido una sensibilidad en torno a este mercado. Efectivamente, esta demanda facilita que las comunidades pequeñas puedan encontrar fuentes complementarias de ingresos, a partir de la comercialización de productos minerales locales. Este tipo de extracciones es, por definición, artesanal, por la cual cosa muy probablemente no podría ser rentable para las empresas mineras clásicas, sino solamente para microempresas.

Por otro lado, se debe tener en cuenta que a los minerales recolectados se les puede dar dos tipos de valor añadido: (1) una preparación para resaltar los aspectos que más interesan del ejemplar y (2) una lapidación o talla para fabricar objetos ornamentales o joyas.

En los países en vías de desarrollo la recolección puede ser un mecanismo de desarrollo de pequeñas microempresas en el medio rural. Sin embargo, en estos países generalmente se desconoce este tipo de recurso y la manera de llevar a cabo las labores relacionadas. Por otro lado, en algunos de los países donde ya se comercializan minerales de colección a menudo existe falta de criterio a la hora de valorar correctamente las piezas, o acerca de cómo tratarlas de manera correcta durante los procesos de recolección, limpieza, almacenamiento o exportación. Ello conlleva el deterioramiento de las piezas y, por tanto, la reducción de su valor.

El objetivo central de este trabajo es proporcionar a estas pequeñas comunidades los conocimientos básicos para recoger, conservar y comercializar minerales de colección.

\section{Tipos de colecciones de minerales}

Existen diferentes tipologías de colecciones de minerales en función del criterio utilizado para seleccionar las piezas que las integran.

a) Estética. Es la más común; el coleccionista procura obtener ejemplares vistosos, generalmente bien cristalizados, de buen tamaño y bonitos colores (Figura 1).

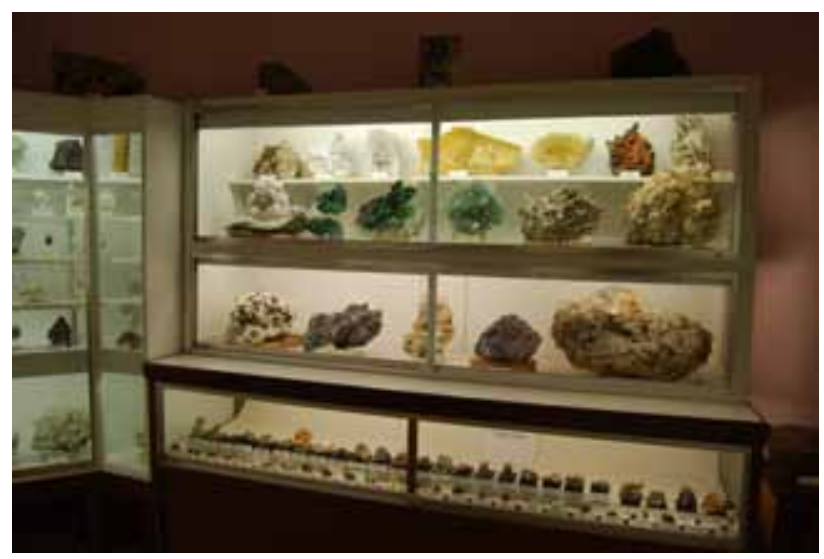

Figura 1. Colección de minerales seleccionada por la estética de las muestras

b) Sistemática: El coleccionista intenta obtener el máximo número de especies y variedades minerales, tanto comunes como raras, de entre las cerca de 4500 especies reconocidas en la actualidad (Figura 2). Es un tipo de colección con base científica y se utiliza en las exposiciones públicas de los grandes museos de Ciencias Naturales. Obviamente, en la medida de lo posible, el gestor de la colección tenderá a presentar en exposición las piezas más grandes, mejor cristalizadas y más estéticas de cada mineral. Sin embargo, como muchas de las especies son raras, a menudo solamente se pueden obtener muestras de muy pequeñas dimensiones. Ello abre la puerta a un tipo de coleccionismo especializado en especimenes de dimensiones reducidas.

c) Por ámbito geográfico: Hay coleccionistas que se especializan en los minerales que se encuentran en una localidad concreta o en un país determinado y que procuran hacerse con todas las especies que se encuentran en ellos, con sus diversas variedades de formas y colores (Figura $3)$. 


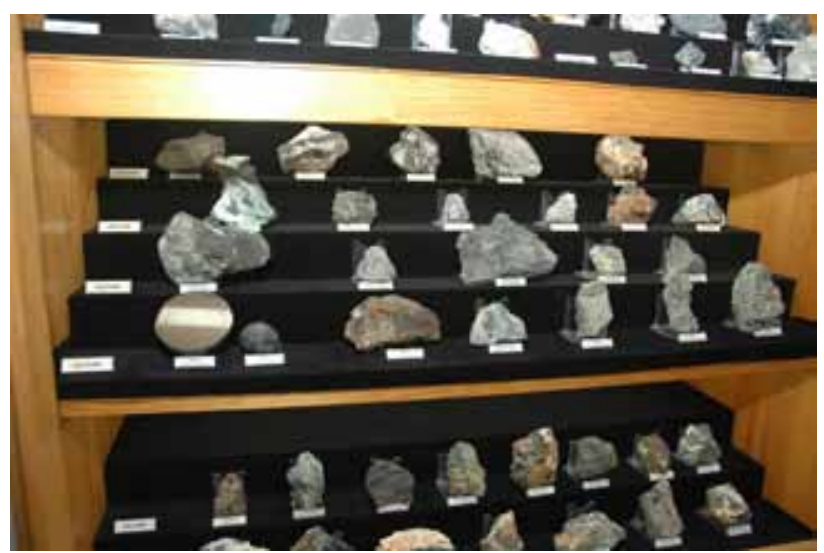

Figura 2. Colección de minerales ordenada por la clasificación sistemática de las muestras, en este caso, por sulfuros.

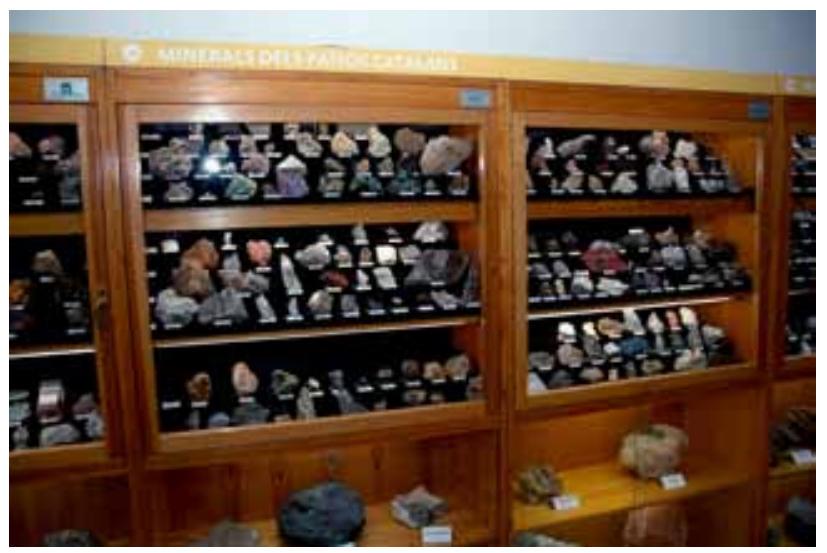

Figura 3. Colección de minerales de muestras de un país, en este caso, los Països Catalans.

d) Por especie. Un coleccionista puede interesarse exclusivamente en los numerosos aspectos que puede presentar una única especie mineral. De hecho, existen algunos minerales, como el cuarzo, la calcita o la fluorita, que pueden presentar una amplia variedad de formas y colores, de manera que una colección por especie puede agrupar una gran cantidad de ejemplares diferentes. Un ejemplo de esto lo constituye el Museo del Guix (Museo del Yeso) de Vilobí del Penedès, en Cataluña.

e) Por afinidad química. Algunos coleccionistas se especializan en sólo ciertos grupos de minerales, como los minerales radioactivos (Figura 4) o los minerales de elementos de las tierras raras.

f) Por fluorescencia. Muchos aficionados aprecian los minerales que son intensamente fluorescentes a la luz ultravioleta. En estos casos, se pueden mostrar los minerales cambiando las condiciones de iluminación (Figura 5): con luz natural, con luz ultravioleta de longitud de onda corta y con luz ultravioleta de longitud de onda larga.

g) Meteoritos. El coleccionismo de meteoritos es muy popular y hay miles de coleccionistas en todo el mundo. Aún así es un tipo de coleccionismo complicado, porque se

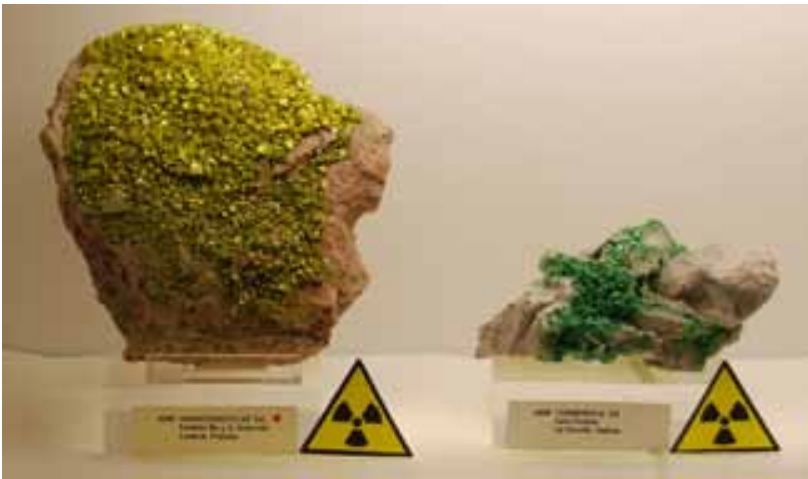

Figura 4. Colección de minerales especializada en minerales radiactivos.

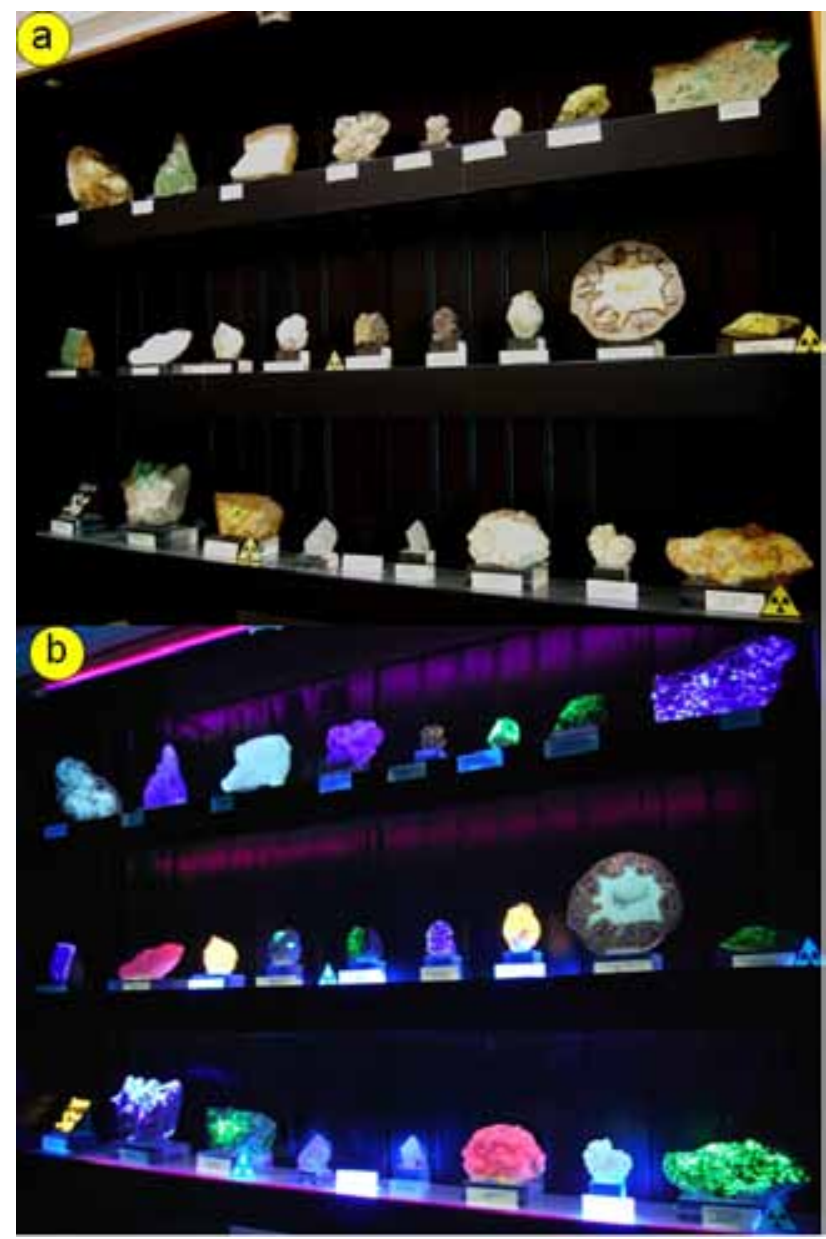

Figura 5. Colección de minerales especializada en minerales fluorescentes. a) Bajo luz natural; b) la misma colección observada con luz ultravioleta

trata de materiales muy raros y de muy difícil catalogación. Por estas razones, los precios de los meteoritos son muy elevados. A su vez también existe un riesgo muy elevado de que se hagan falsificaciones. Generalmente los meteoritos se venden a peso, ya sea por gramos o miligramos. Existen meteoritos que tienen origen o composición muy 
raros, de modo que unos pocos miligramos pueden llegar a costar miles de euros.

Existen diversas formas de colección de meteoritos. En primer lugar, está el coleccionismo de meteoritos enteros. Por lo comentado anteriormente, esta es una opción muy cara, y a más, poco atractiva ya que la superficie externa de los meteoritos acostumbra a presentarse parcialmente fundida o muy alterada, y su aspecto no es demasiado llamativo (Figura 6).

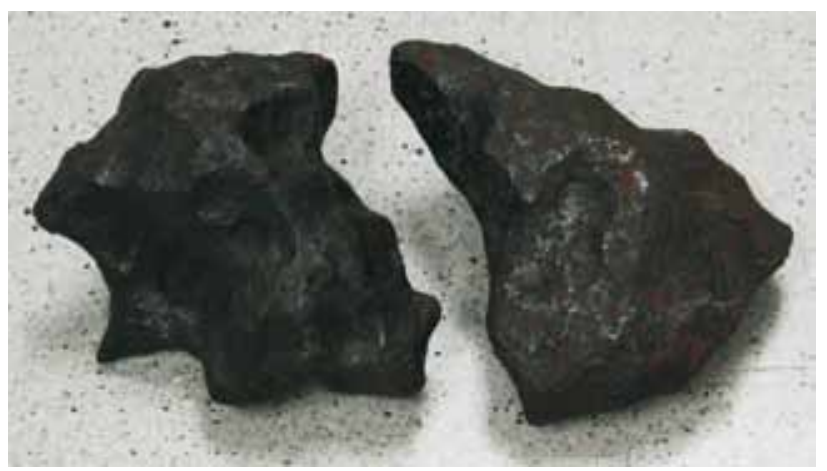

Figura 6. Piezas de meteoritos de gran tamaño. Campo del Cielo, Argentina.

Esta opción es esencial cuando se quieren mostrar las texturas externas del meteorito, como por ejemplo las abrasiones que ha sufrido al atravesar la atmósfera.

También existe la opción de coleccionar finas secciones pulidas demeteoritos. Deestamanera, elcoleccionistaahorra peso (y, por tanto, costes) y dispone de una superficie fresca en la cual se puede observar la textura interna de la roca y su mineralogía.

Una última forma de coleccionarlos es a partir de láminas delgadas estándar de 30 micras de grosor, en las que los minerales se pueden observar a través del microscopio de luz transmitida. Esta modalidad posibilita descubrir una amplia gama de colores, pero implica la necesidad de disponer de un microscopio, opción que no siempre es posible.

\section{Tipos de muestra en función de su tamaño}

Algunos coleccionistas o científicos prefieren muestras en las cuales se vea solamente el mineral y otros prefieren que también se aprecie la roca o los minerales acompañantes, lo que implica poder disponer de muestras que permi- tan visualizar numerosos minerales a la vez. Ello determina que, a igualdad de calidad del mineral que interesa, cuanto más grande sea la muestra más alto será su precio.

Según el argot de los coleccionistas, se utilizan los siguientes términos para clasificar los minerales en función de su tamaño (Tabla 1):

a) Pieza grande de vitrina, o bloque (cabinet, en inglés; abreviatura HS). Se trata de muestras de grandes dimensiones, de hasta varios decímetros, que permiten que sus propiedades puedan ser apreciadas desde unos metros de distancia (Figura 7). Es la típica pieza de museo y puede tener valores muy elevados.

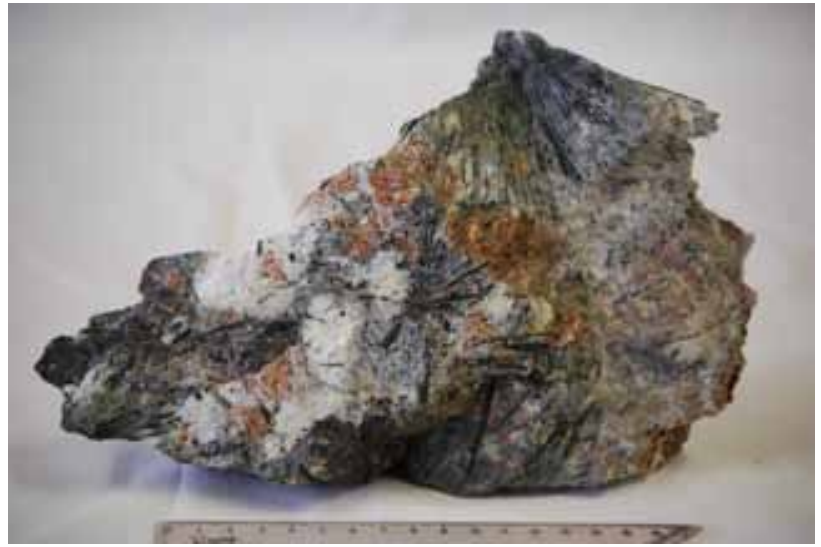

Figura 7. Pieza de museo de grandes dimensiones. Destacan cristales radiales oscuros de egirina (verde) en una matriz más clara. Khibiny, Península de Kola, Rusia.

b) Pieza de vitrina pequeña, muestra de mano (small cabinet, en inglés; abreviatura SC). Es de dimensiones más reducidas que la anterior, del tamaño de la palma de una mano humana o menor $(5-10 \mathrm{~cm}$.), pero puede apreciarse aún en el interior de una vitrina, sobretodo si se coloca en primera fila (Figura 8). También puede ser presentada en pequeños cajones. Es un tamaño de muestra muy apreciada, pero que evidentemente no alcanza precios tan elevados como la anterior, hecho que facilita su comercialización a un nivel más popular.

c) Miniatura (miniature, en inglés; abreviatura, $\mathrm{MN}$ ). Se trata de muestras pequeñas, de dimensiones parecidas a las de una pelota de ping-pong, de pocos centímetros (3-5, Figura 9). Es un tipo de pieza ideal para colecciones personales que se guardan en cajones y adquiribles a precios generalmente asequibles.

d) Uña (thumbnail, en inglés; abreviatura, TN). Muestra con una matriz de pequeñas dimensiones $(2-3 \mathrm{~cm}$.), del

Tabla 1. Clasificación de las medidas de los minerales.

\begin{tabular}{lccccc}
\hline \multicolumn{1}{c}{ Nombre } & $\begin{array}{c}\text { Micromount } \\
\text { (micromontaje) }\end{array}$ & $\begin{array}{c}\text { Thumbnail } \\
\text { (tamaño de la uña) }\end{array}$ & $\begin{array}{c}\text { Miniature } \\
\text { (miniatura) }\end{array}$ & $\begin{array}{c}\text { Small Cabinet } \\
\text { (muestra de mano) }\end{array}$ & $\begin{array}{c}\text { Cabinet } \\
\text { (bloque) }\end{array}$ \\
\hline $\begin{array}{l}\text { Medidas de la matriz } \\
\text { Abreviación }\end{array}$ & $0,5 \mathrm{~mm}-2 \mathrm{~cm}$ & $2-3 \mathrm{~cm}$ & $3-5 \mathrm{~cm}$ & $5-10 \mathrm{~cm}$ & $>10 \mathrm{~cm}$ \\
\hline
\end{tabular}




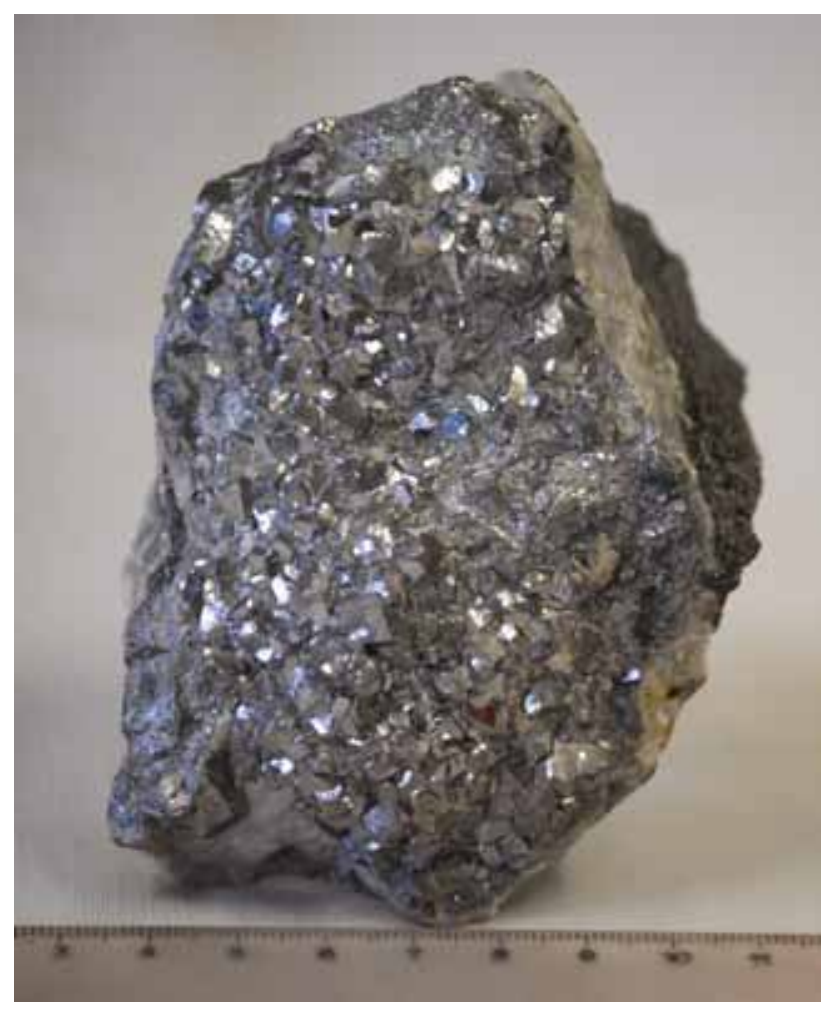

Figura 8. Pieza típica de vitrina con agregados de cristales de skutterudita. Bou Azzer, Marruecos.

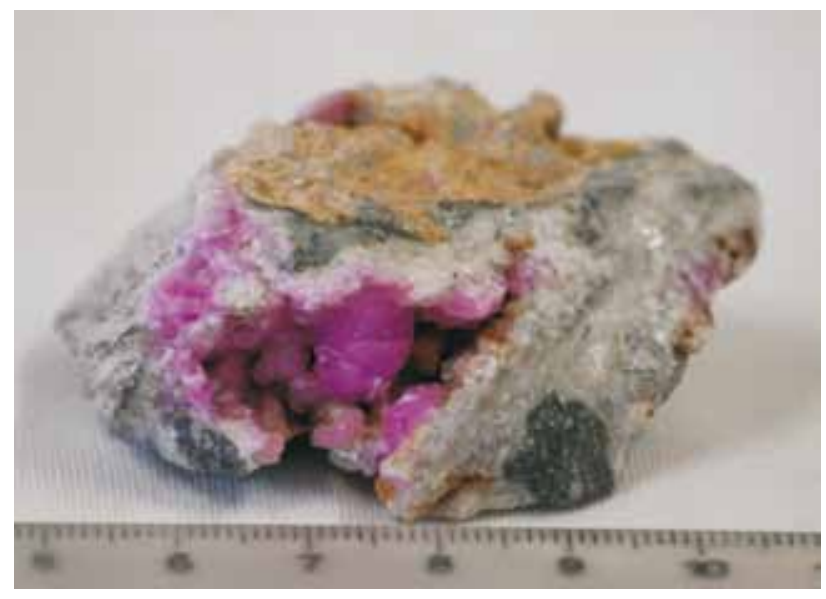

Figura 9. Pieza de tamaño miniatura. Esferocobaltita de Bou Azzer, Marruecos.

tamaño de una uña o una moneda, y en la que los cristales del mineral que interesa tienen dimensiones generalmente milimétricas o centimétricas de cristales (Figura 10). Generalmente es un tipo de pieza pensada para colecciones personales que se guardan en cajones y presenta precios casi siempre asequibles por el coleccionista de nivel medio.

e) Micromontaje (Micromount, en inglés; abreviatura, MM) Muestra pequeña (1-20 mm), compuesta de cristales

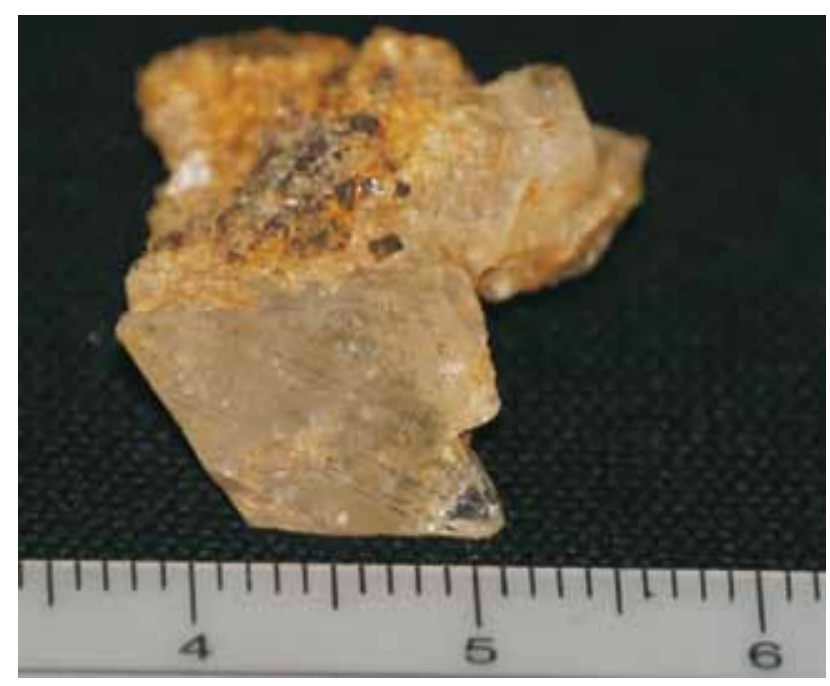

Figura 10. Pieza del tamaño de la uña. Hialofana de Busovaca, Bosnia y Herzegovina.

muy pequeños pero perfectos, con o sin matriz, que se disponen montados sobre un soporte (generalmente de plastilina o silicona, pero también soportes más finos) de manera que los minerales de interés quedan orientados hacia el observador para mostrar sus propiedades (Figura 11).

Él éxito que tienen los micromontajes entre los coleccionistas de minerales se basa en el poco espacio que ocupan (hecho que permite que una colección sistemática de muchos miles de ejemplares ocupe un espacio relativamente muy reducido) y en que los cristales más pequeños acostumbran a ser los más perfectos y bonitos. De todas formas, los micromontajes tienen el inconveniente de que necesitan de medios especiales (lupas binoculares) para ser apreciados adecuadamente.

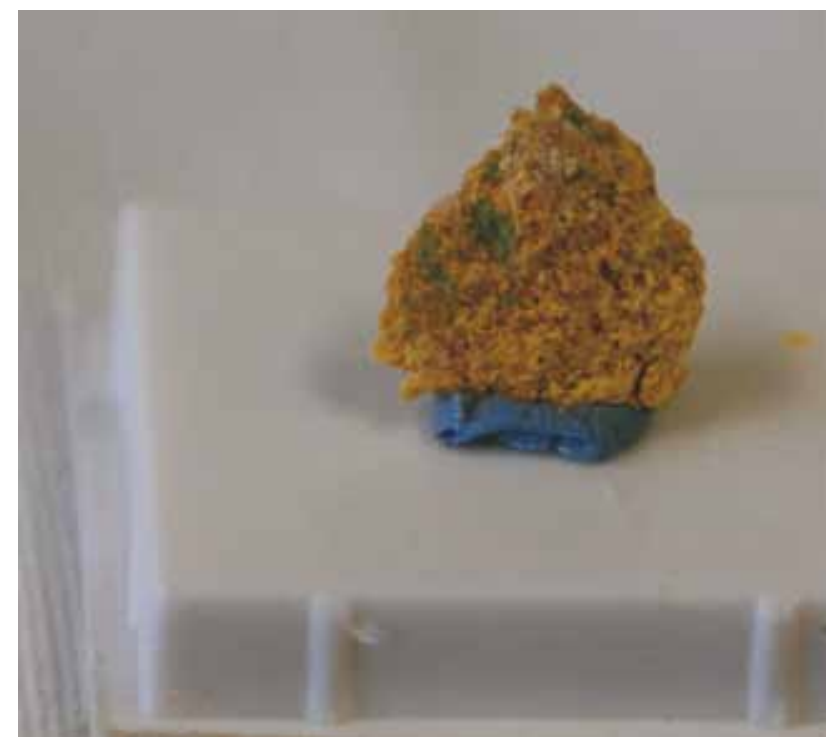

Figura 11. Micromontaje de conicalcita (verde) sobre una matriz de goethita (amarillo). El conjunto está montado sobre un soporte de plastilina. 


\section{Tipo de muestra en función de la posición del mineral en la pieza}

Se pueden distinguir numerosas posibilidades en función de la posición del mineral en la muestra. Todas ellas pueden tener interés en función de las diferentes cualidades del mineral.

a) Cristal flotante (abreviatura SXL; floater, en inglés). Se trata de un cristal individual que exhibe todas sus caras cristalinas. En estos casos, para que tenga una valoración máxima es importante que el cristal esté bien terminado en todas sus caras de manera que se parezca a las formas cristalinas ideales del mineral (Figura 12). En el caso que el cristal estuviera originalmente implantado sobre una superficie, las caras por donde el cristal estaba adherido a la roca no serán perfectas y presentaran fracturas en su base. Pero en el caso en que el cristal estuviera incluido en una matriz que pudiera desaparecer fácilmente, pueden aparecer cristales enteros de una gran belleza y muy preciados.

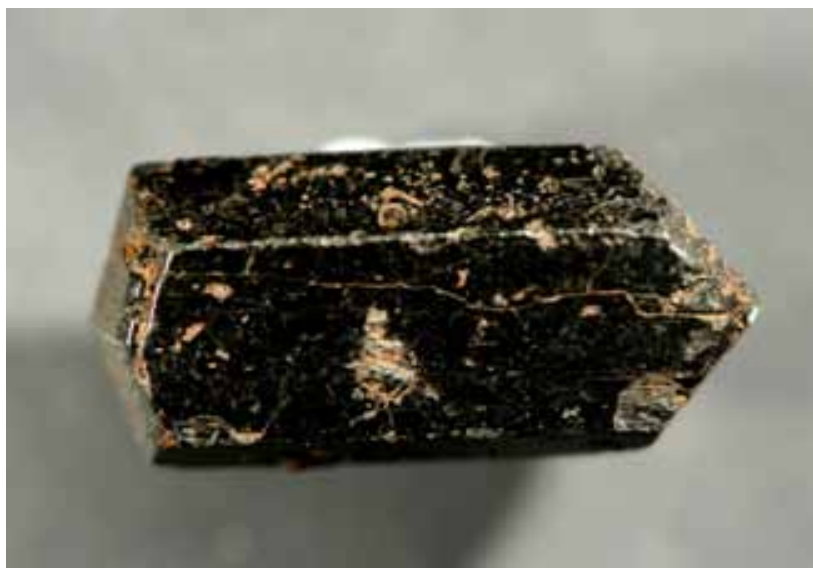

Figura 12. Cristal idiomórfico de hornblenda de hábito prismático. Tenerife (Canarias)

b) Cristales agregados (abreviatura AGG; aggregates, en inglés). Se trata de cristales agrupados de la misma especie, generalmente interpenetrados, sin matriz, en los que se puede apreciar la mayoría de las caras cristalinas (Figura 13). Pueden tener aspectos muy complejos y ser de gran belleza sea cual sea la dirección desde la que se contemplan, de manera que pueden llegar a tener precios muy elevados.

c) Cristales incluidos (abreviatura XL). Se trata de cristales que han crecido en el interior de una roca y que, por tanto, aparecerán englobados en una matriz rocosa al romperse ésta (Figura 14). En ocasiones, puede ser interesante conservar los cristales dentro de la matriz y no extraerlos, porque el conjunto puede presentar una estética adecuada o porque expresa la forma natural de presentarse los cristales.

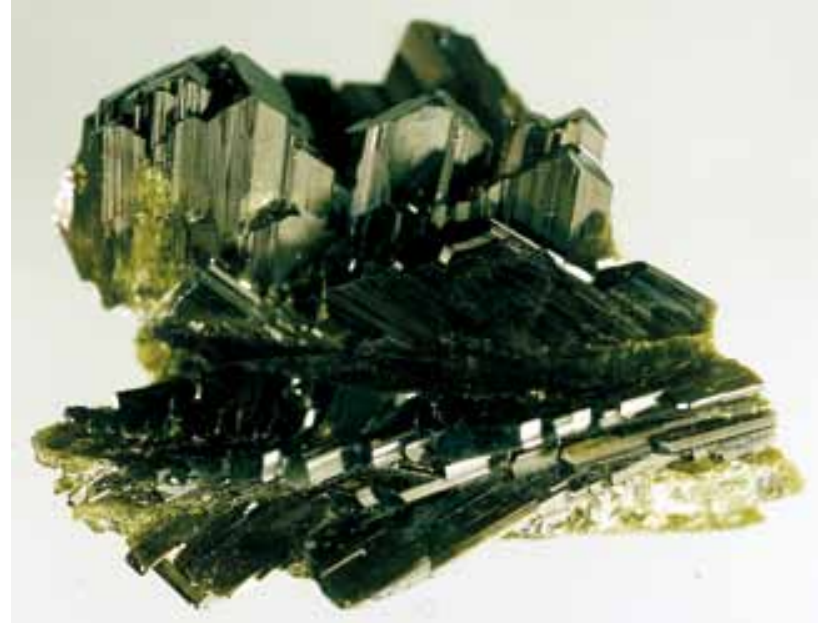

Figura 13. Agregados radiales de cristales de epidota. Baluchistán, Pakistán.

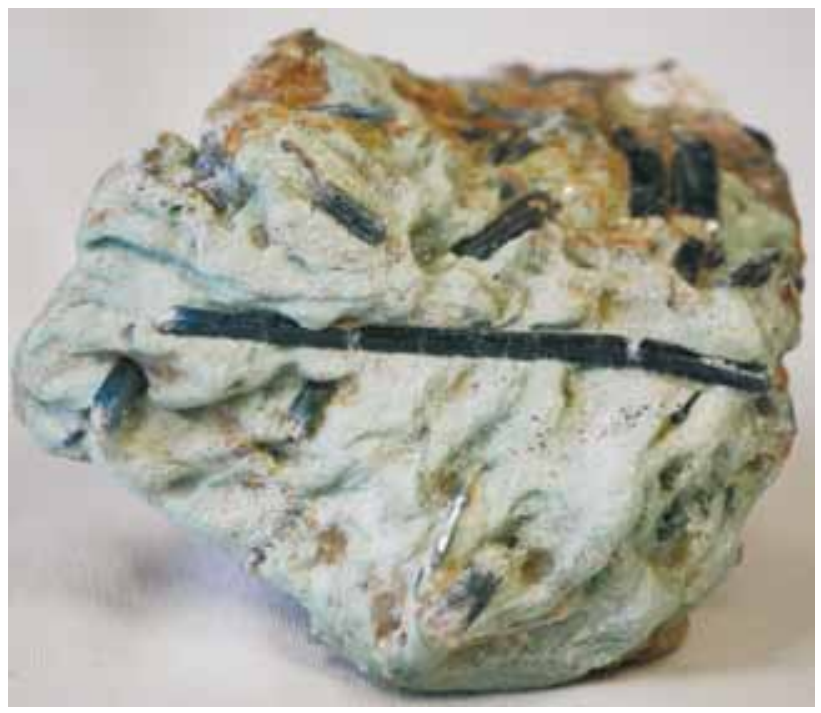

Figura 14. Cristales de cianita (oscuro) incluidos en una matriz de micas blancas. Urales, Rusia.

d) Cristales implantados (abreviatura XL). Se trata de cristales que han crecido de manera más o menos aislada sobre superficies (Figura 15). Es importante que los cristales estén lo más enteros y completos posible aunque, evidentemente, la parte del cristal que esté adherida a una superficie irregular será también irregular y, por tanto, estos cristales no acostumbran a estar completos. Por otro lado, los cristales que crecen sobre superficies planas interfieren con los cristales vecinos, de manera que los agregados cristalinos llegan a tener superficies irregulares y poco vistosas. En general, cuanto más separados estén los cristales entre sí, mejor desarrolladas estarán sus caras y mejor estética presentará la muestra.

e) Drusa (druse, en inglés). Es una variante de agregación de cristales implantados, en la cual los cristales crecen sobre las superficies más o menos planas de grietas de la 


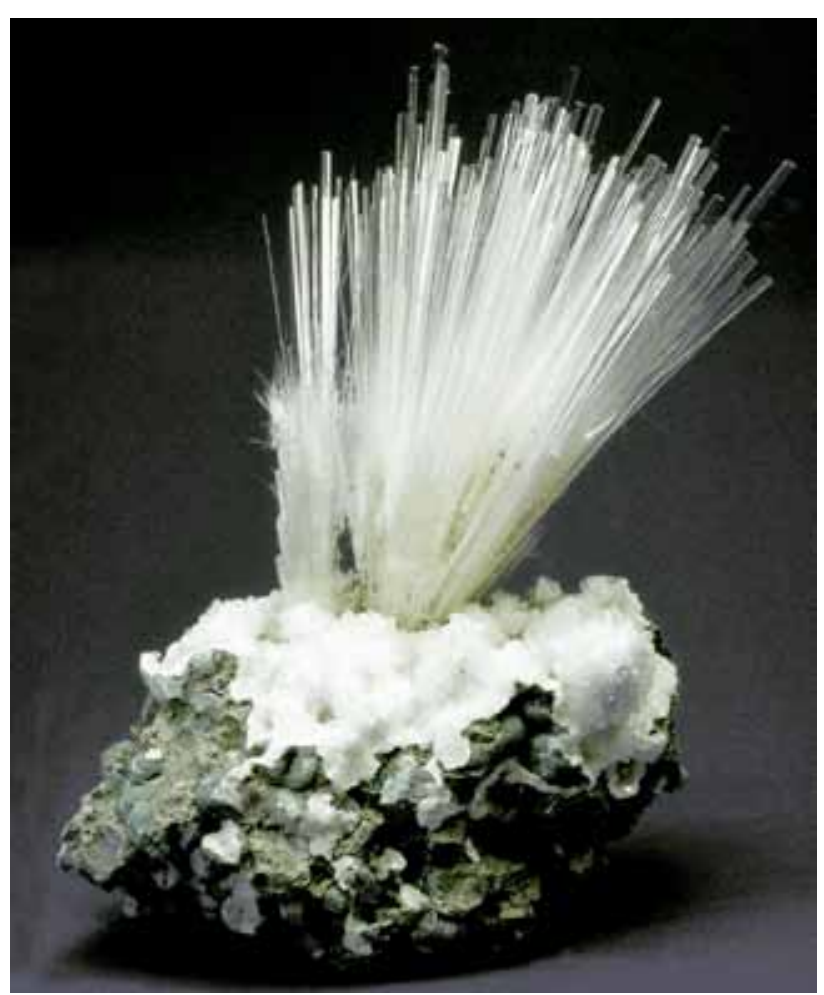

Figura 15. Cristales aciculares-radiales de mesolita implantados sobre basalto. Poonah, India.

roca, recubriéndola de un tapiz denso de cristales en los que estos tienden a crecer de forma más o menos perpendicular a la superficie de soporte (Figura 16).

f) Geoda. (abreviatura CAV, geode en inglés). Es una variante de agregación de cristales implantados en la cual éstos crecen sobre las superficies de una cavidad esferoidal en una roca, recubriéndola de un tapizado denso de cristales en el cual los cristales tienden a crecer de forma más o menos perpendicular a la superficie de soporte (Figura 17). Las geodas deben quedar abiertas al máximo de manera que permitan visualizar el conjunto de la cavidad. Algunas geodas, como las de las amatistas de Brasil, presentan enormes dimensiones, de tamaño métrico, y son extensivamente utilizadas en decoración en todo el mundo.

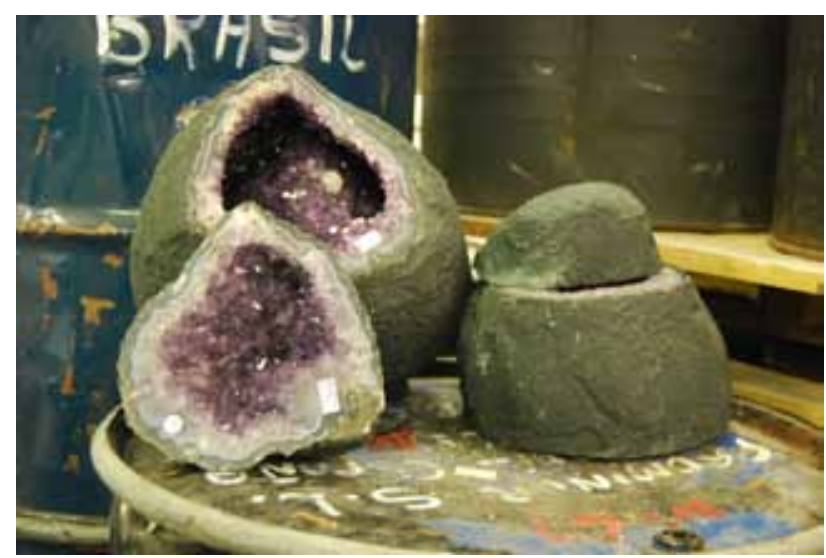

Figura 17. Cristales de amatista (morado) de Brasil que tapizan geodas en basalto alterado de color verde Las geodas han sido serradas para mostrar mejor las cristalizaciones.

g) Agregados fibrosos (abreviatura F). Agregados de cristales en forma de fibras. A menudo crecen paralelos entre sí y más o menos perpendicularmente a una superficie (Figura 18), aunque también pueden hacerlo de manera

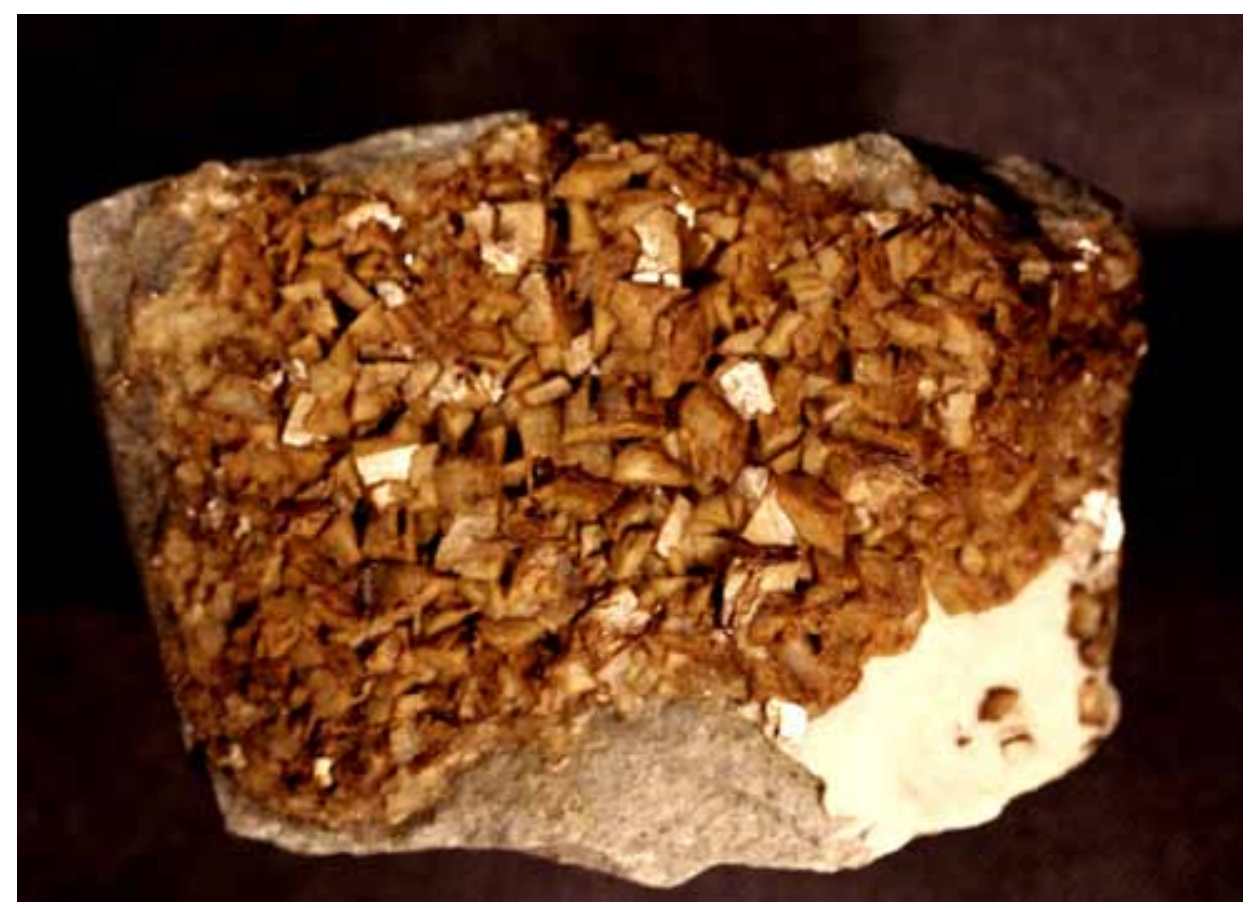

Figura 16. Drusa de cristales de ankerita (marrón). Bellmunt del Priorat, Cataluña. 


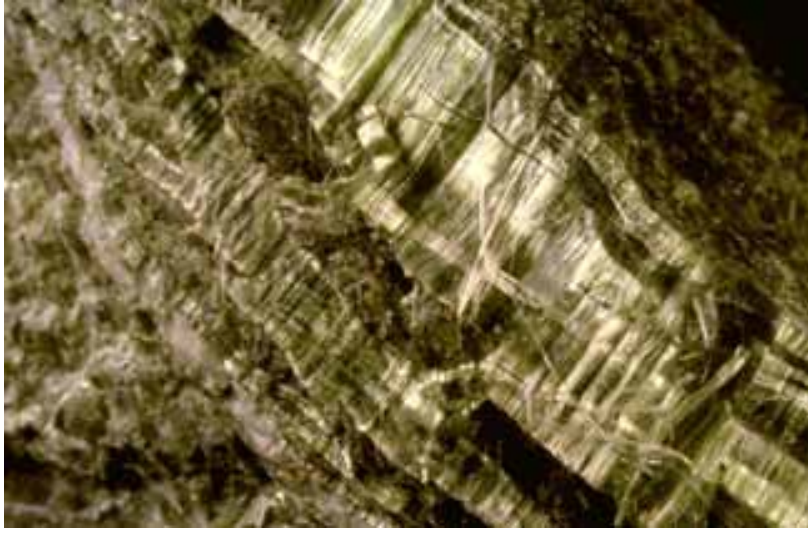

Figura 18. Agregados fibrosos de crisotilo, paralelos entre sí y perpendiculares a las paredes de una veta. Gualba de Dalt, Cataluña.

desorientada. Muchos de estos minerales fibrosos tienen brillo sedoso cuando se encuentran en fibras dispuestas paralelamente y a menudo son flexibles y se pueden hilar fácilmente. $\mathrm{Si}$, a más, son fáciles de tejer, incombustibles e inatacables por los ácidos pueden ser utilizados en la fabricación de asbesto o amianto. Un ejemplo típico es el crisotilo, o los amiantos de anfíboles (riebeckita, antofilita, tremolita, etc.). Algunos agregados fibrosos desorientados tienen aspecto de cartón mojado ("cartón de montaña").

Debe tenerse presente que los minerales fibrosos, como el crisotilo y muchos minerales del grupo de los anfíboles, pueden ser cancerígenos (típicamente por inhalación de partículas por vía respiratoria), de manera que se deben tratar con precaución. Se recomienda manipularlos en lugares bien ventilados, para evitar la inhalación de fibras de amianto.

h) Agregados radiales (abreviatura R; en inglés radial aggregates). Se trata de crecimientos de cristales de forma alargada y que comparten un vértice del cual irradian (Figura 19). Este tipo de crecimientos da formas muy espectaculares cuando el tamaño de los cristales es grande. Generalmente este tipo de agregado lo forman cristales implantados sobre otros.

i) Agregados en rosa (o en roseta). Los constituyen cristales en forma lenticular, laminar o tabular que, interpenetrándose, acaban tomando la forma de una flor (Figura 20). El mejor ejemplo de ello es el yeso ("rosas del desierto"), pero también pueden tener esta forma la barita y la hematites.

j) Agregados esferulíticos (abreviatura $\mathrm{S}$; spherulite, spherulitic aggregates en inglés). Son cuerpos compactos de forma esférica, por lo general fibrosos-radiales internamente, y que acostumbran a crecer implantados sobre cavidades de la roca (Figura 21).

k) Agregados en lazo (abreviatura, BT; en inglés, bow-tie aggregates). Se trata de cristales de forma tabular curvados, agregados de forma casi radial, con un centro común. Los presentan a menudo algunos minerales como la estilbita (Figura 22) y la prehnita.

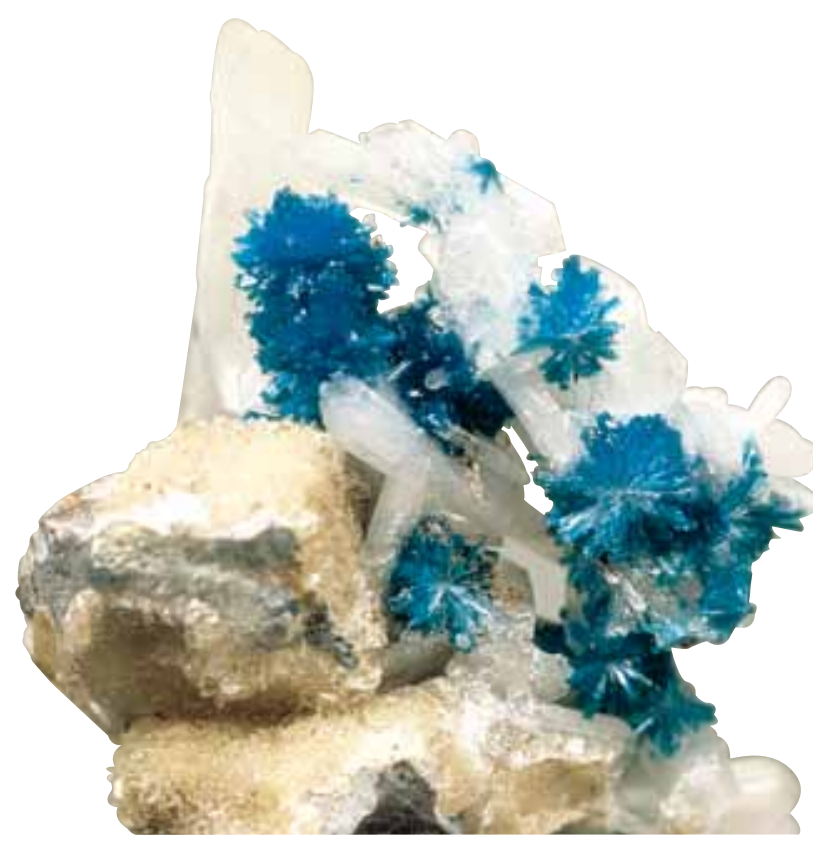

Figura 19. Agregados aciculares-radiales de cavansita (azul) implantados sobre estilbita (blancos). Poonah, India.

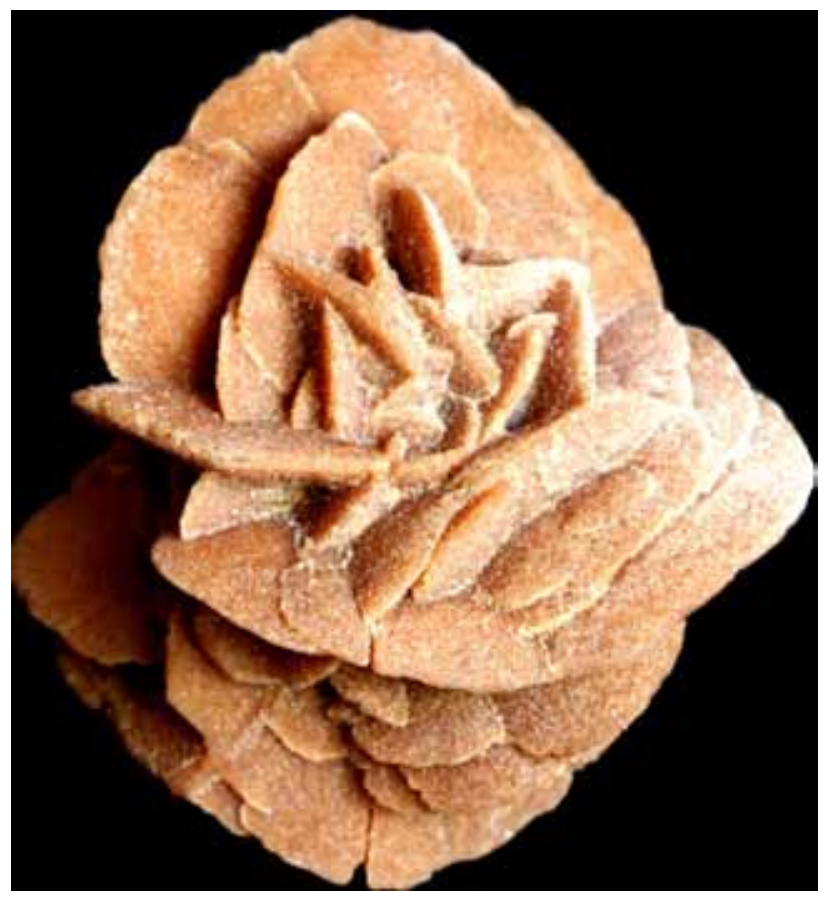

Figura 20. Rosa del desierto de yeso. Argelia.

l) Agregados botrioidales (abreviatura, B; en inglés, botryoidal aggregates). Se trata generalmente de crecimientos esferulíticos que crecen sobre una superficie y que interfieren con sus vecinos de una manera parecida a como lo hace la espuma del jabón (Figura 23). También se llaman reniformes. Esta forma de presentarse es muy típica de minerales formados en condiciones supergénicas, 


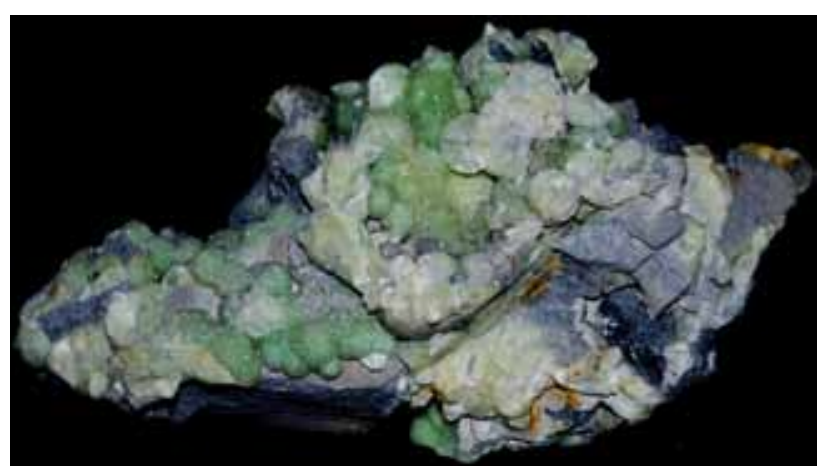

Figura 21.Agregados esferulíticos de wavellita de color verde, Arkansas, EUA. En la parte fragmentada se aprecian crecimientos radiales de cristales de color blanco.

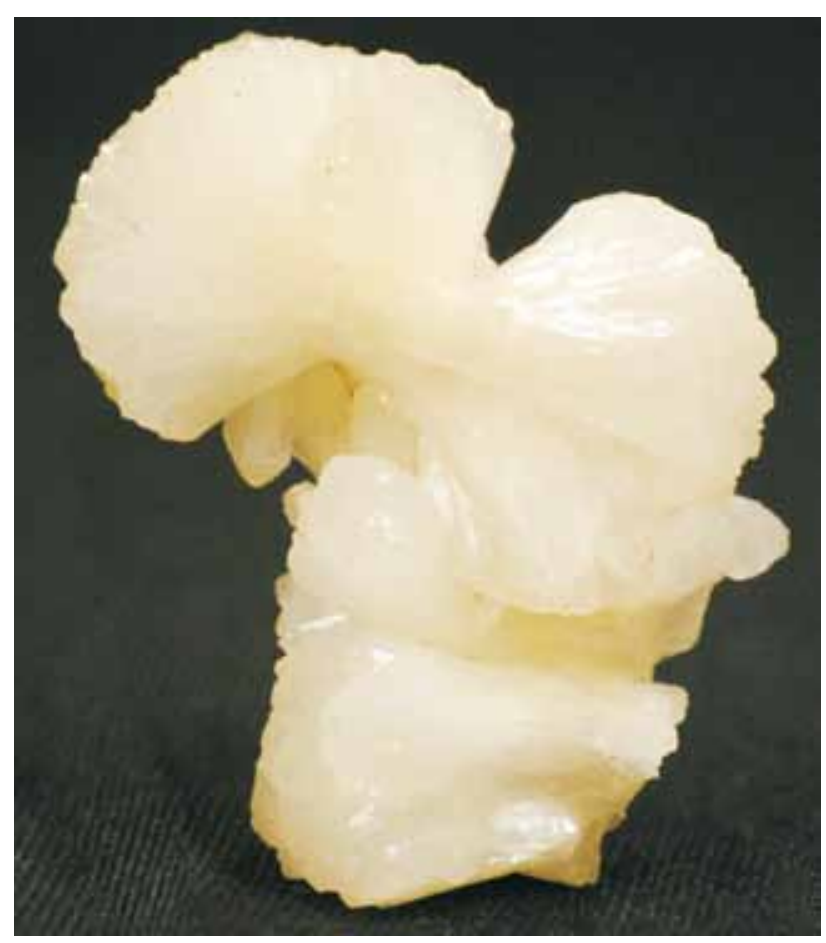

Figura 22. Agregados en lazo de la estilbita. Poonah, India

como muchos óxidos e hidróxidos, la malaquita y otros minerales.

m) Agregados escamosos. Los presentan los minerales de estructura laminar y que tienen, por tanto, aspecto foliáceo, como por ejemplo las micas (Figura 24) o las cloritas, cuando sus cristales se agrupan. Casi siempre estos cristales se disponen de forma subparalela entre ellos, de manera que el conjunto presenta un brillo satinado, aterciopelado o nacarado.

n) Agregados esqueléticos. Lo presentan algunos minerales en que los cristales no han desarrollado completamente las caras, pero si las aristas, de manera que tienen la apariencia de esqueletos (Figura 25). Existen ejemplos muy vistosos en algunos metales nativos, pero también en las sales.

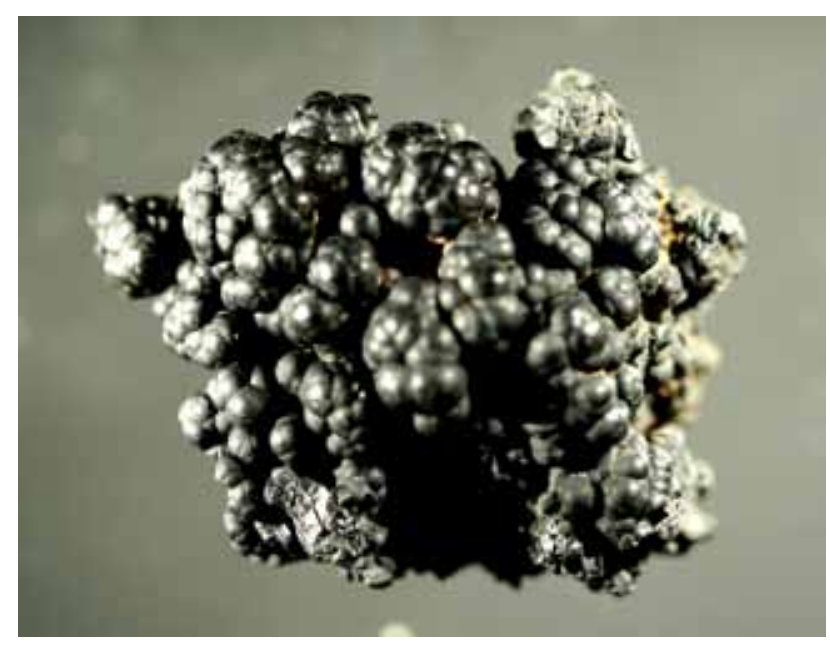

Figura 23. Agregados botroidales de romanechita. Imini, Marruecos

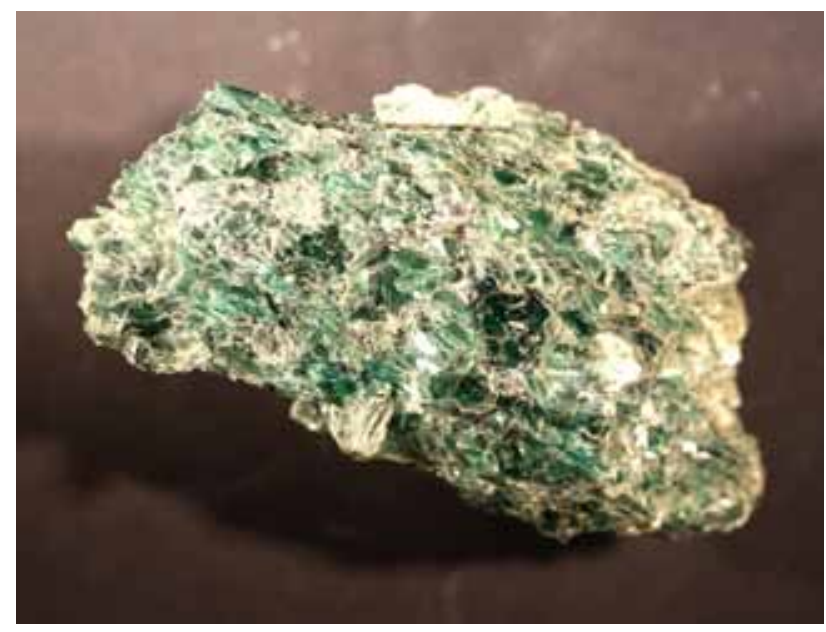

Figura 24. Agregados escamosos de mica fuchsita de color verde. Brasil.

o) Agregados arborescentes. Es un caso extremo del ejemplo anterior, de manera que los agregados forman cuerpos que recuerdan ramas de árboles (Figura 26). Los pueden presentar la plata, el oro, el cobre y algunos otros minerales. Son formas muy delicadas pero muy decorativas.

p) Agregados filiformes. Se trata de cristales muy alargados y altamente caracoleados sobre sí mismos. Son muy típicos del oro y de la plata (Figura 27).

q) Dendritas (abreviatura, D; en inglés, dendrites). Se trata de crecimientos arborescentes (de manera similar a las ramas de un árbol), pero desarrollados en forma de películas sobre las grietas de las rocas. Los más comunes son los constituidos por óxidos de manganeso (Figura 28). Aunque se trata de un material muy común, a veces estos minerales pueden "dibujar paisajes" sobre la roca base $\mathrm{y}$, por tanto, pueden dar figuras altamente decorativas $\mathrm{y}$ preciadas. 


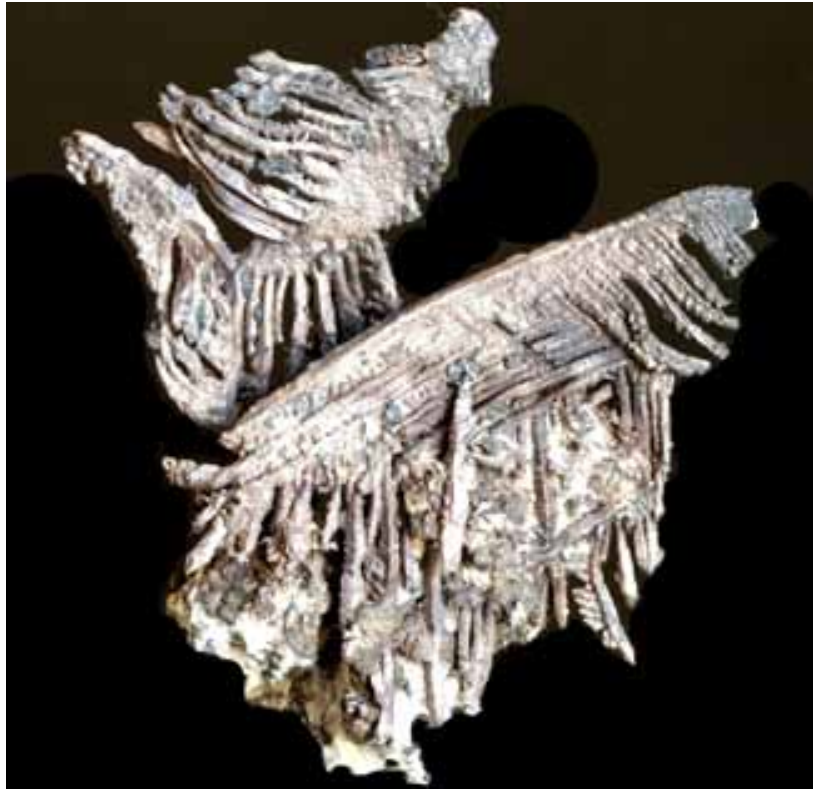

Figura 25. Agregados esqueléticos de plata nativa.

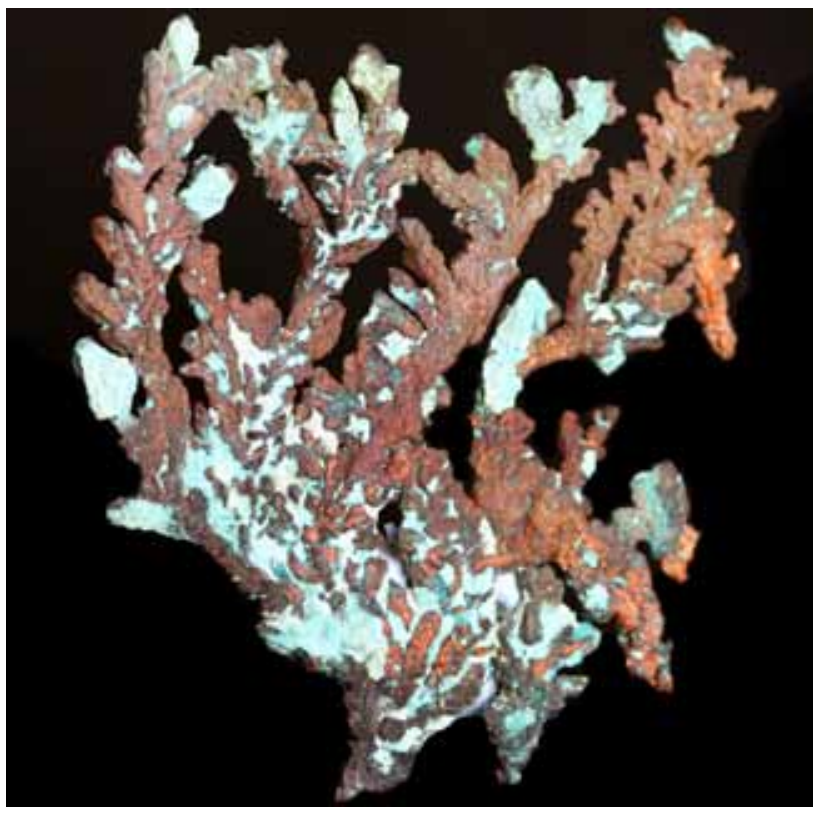

Figura 26. Agregados arborescentes de cobre nativo.

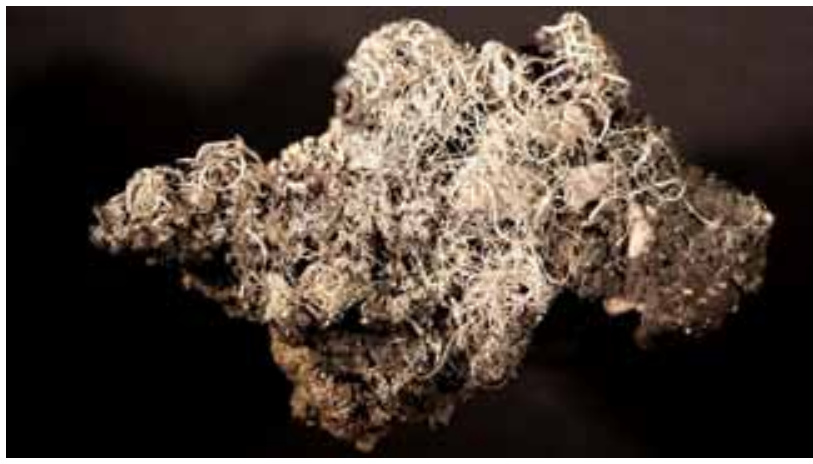

Figura 27. Agregados filiformes de plata nativa. Imichil, Marruecos

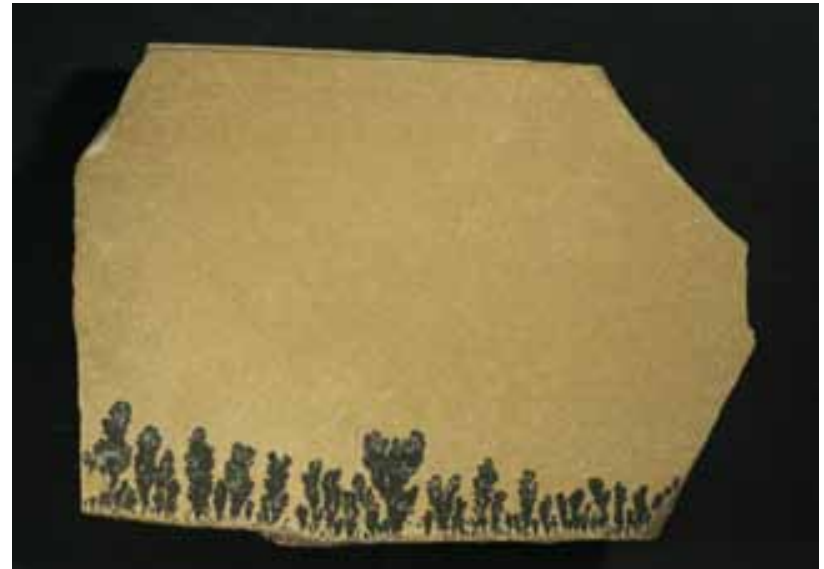

Figura 28. Dendritas de pirolusita (negro) sobre roca caliza.

r) Agregados cristalinos granulares (abreviatura XLN). Generalmente se trata de agregados brillantes, de aspecto de terrones de azúcar, pero a menudo sin caras geométricas bien definidas (Figura 29). No son demasiado apreciados a menos que se trate de minerales muy raros y que solamente aparezcan en esta forma.

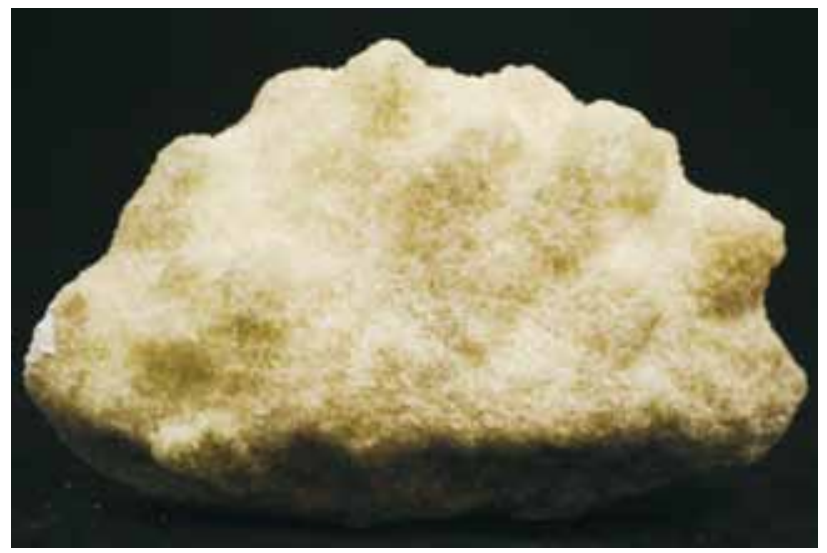

Figura 29. Agregados cristalinos granulares de kaliborita. Sallent, Cataluña.

s) Agregados masivos (abreviatura M; en inglés, massive aggregates). Se trata de agregados compactos de cristales de granulometría muy fina, imperceptibles hasta bajo lupa binocular. Sus granos son tan finos que el brillo de la muestra es casi mate (Figura 30). Este tipo de muestra se vende a precios muy bajos, independientemente de la medida que tenga, siempre que sea un mineral relativamente corriente; así y todo, la rareza del mineral puede hacer que se venda a un buen precio.

t) Agregados pulverulentos (abreviatura P; en inglés, powder aggregates). Se trata de mineral en polvo o granitos muy pequeños, de brillo mate. Muchas veces estos minerales son inestables, por lo cual se preservan en tubitos o cajitas de plástico (Figura 31). Este tipo de muestra sólo es aceptada cuando se trata de minerales extremadamente raros; en caso contrario, no posee ningún tipo de cuota de 


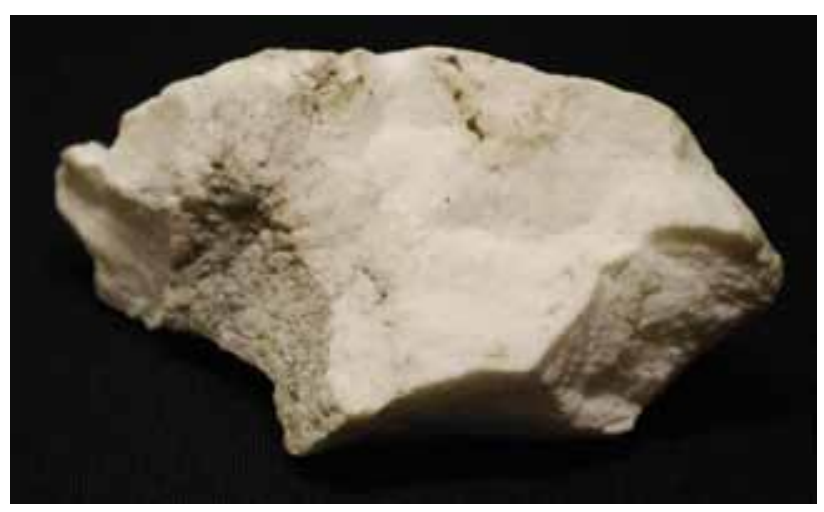

Figura 30. Agregados macizos de pandermita. Emet, Turquía.

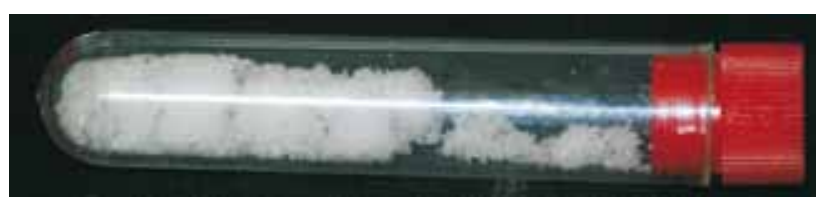

Figura 31. Agregados cristalinos polvorientos de hexahidrita. Cueva de las Maravillas, Calatayud, Teruel, España.

mercado.

u) Nódulo (abreviatura, N; en inglés, nodule). Se trata de un cuerpo de forma más o menos esferoidal, compuesto generalmente de cristales muy pequeños, invisibles a simple vista, o bien por minerales amorfos; internamente acostumbra a presentar brillo mate. No acostumbran a ser demasiado preciados, a menos que presenten formas curiosas y buen color (Figura 32), o a menos que presenten geodas o fracturas repletas de cristales.

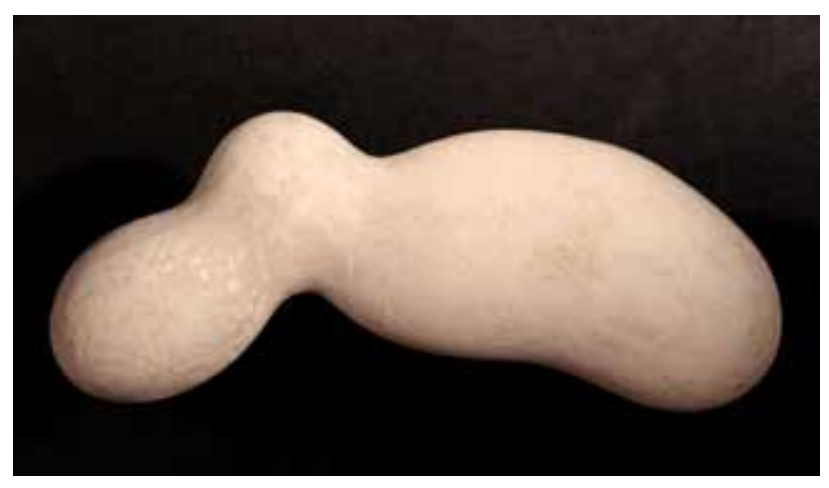

Figura 32. Nódulo de ópalo de la variedad menilita. Las Minas, Albacete.

\section{Criterios para determinar el valor de las piezas}

El valor de las piezas puede variar, como cualquier objeto, según las oscilaciones del mercado y su precio debe estipularse a partir de una relación entre la oferta y la demanda. A nivel general, el valor de las piezas aumenta cuanto mayor sea la perfección de los cristales y en ausencia de daños en el proceso de extracción y preparación, de su posición y estética, dimensionalidad, de su color, transparencia y brillo y de su rareza.

Como regla general, a igualdad de calidad las muestras más valiosas son las más grandes, pero a veces muestras más pequeñas pueden llegar a tener también precios muy elevados.

\subsection{Cristalización}

El valor de las piezas aumenta con los siguientes aspectos relacionados con la cristalización:

Forma cristalina del cristal. Algunos minerales tienden a estar cristalizados en una forma determinada. Por eso, cuando se hallan cristalizados en otras formas menos comunes estos ejemplares pueden tener más valor (Figura $33)$.

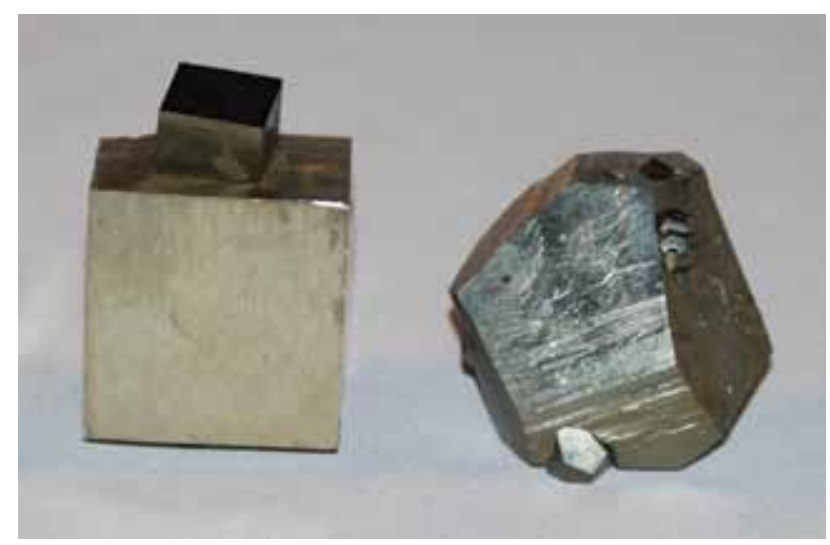

Figura 33. Formas cristalinas diferentes de la pirita: la de la izquierda es más común y la de la derecha, más rara.

Complejidad del cristal. Los cristales más complejos y ricos en caras son a menudo los más apreciados, ya que posibilitan un juego de reflejos más grande que si son sencillos (Figura 34).

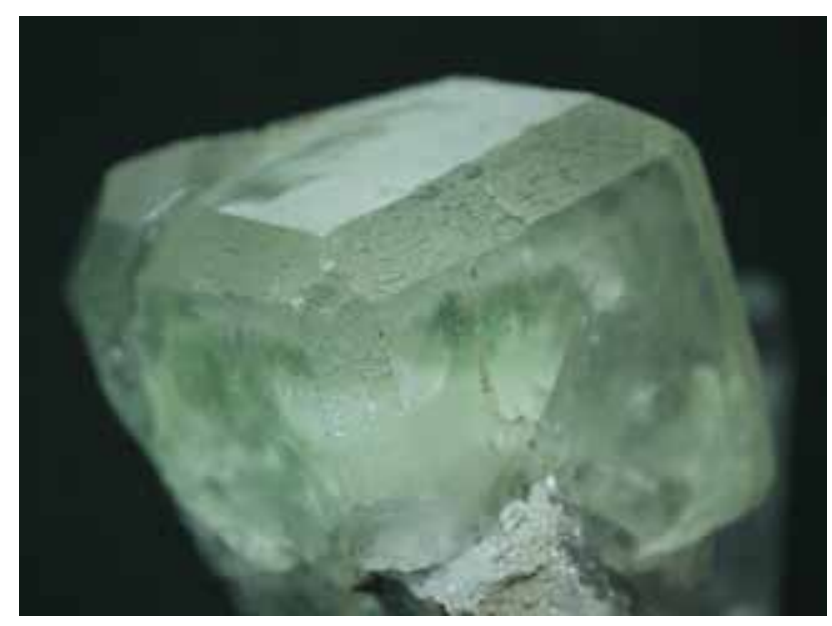

Figura 34. Cristales cúbicos de fluorita con las aristas biseladas. China. 
Perfección del cristal. Como norma general, cuanto más perfectas sean las caras y aristas de los cristales, más valor tendrá una pieza. Si el cristal está suelto, es importante que tenga todas las caras y aristas completas pues, de lo contrario, pierde valor. Si el cristal está en una matriz, es importante que se vea el máximo número de cristales perfectos y, de ser posible, con el máximo número de caras (Figura 35). Ello implica que en ocasiones deba eliminarse matriz o recubrimientos que oculten parte del cristal que interesa mostrarse.

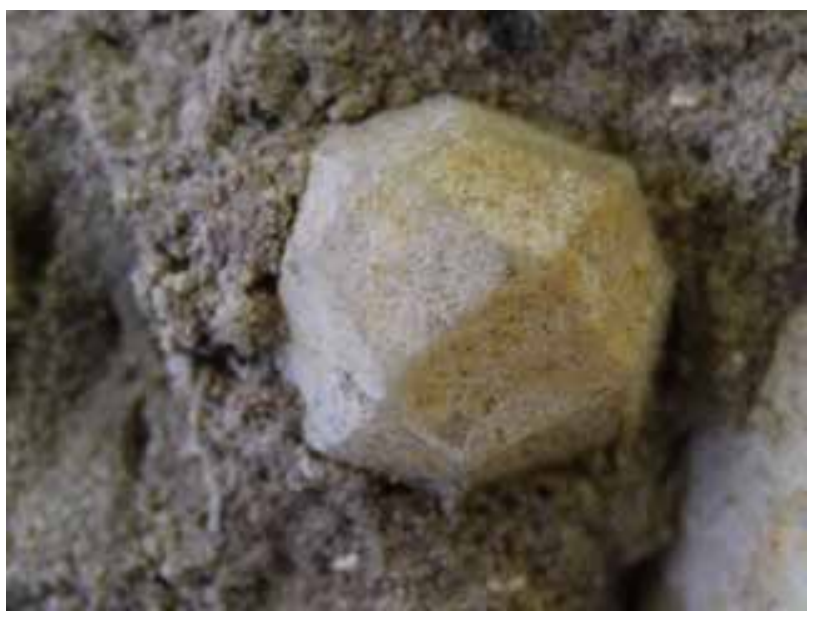

Figura 35. Cristal de leucita incluido en roca volcánica. Roccamonfina, Italia.

Aspecto de la superficie de las caras. No siempre los cristales presentan caras planas y aristas rectas. Las caras $\mathrm{y}$ aristas pueden estar curvadas sin que el cristal se haya deformado, como en el caso de la dolomita o del corindón; en otros casos, las caras pueden estar estriadas (estrías de crecimiento o maclado, Figura 36).

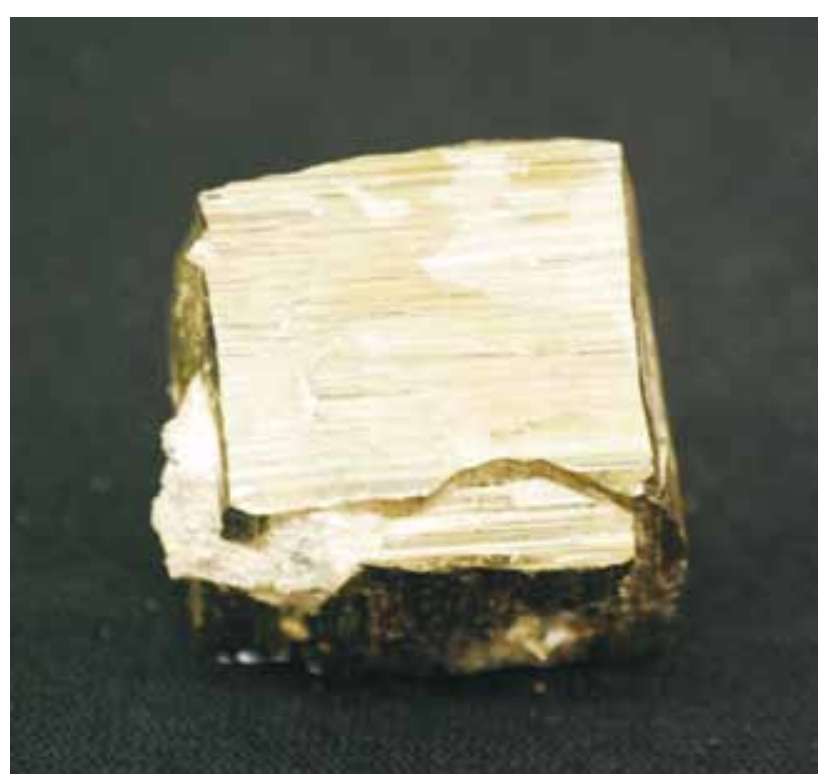

Figura 36. Cristales cúbicos de pirita con las caras estriadas.
Finalmente, algunos cristales pueden tener diferentes tipos de figuras geométricas sobre las caras, o bien éstas pueden tener signos de disolución, depresiones (tolvas, Figura 37), figuras helicoidales u otras figuras. Si estas figuras están bien preservadas, la muestra puede ganar interés.

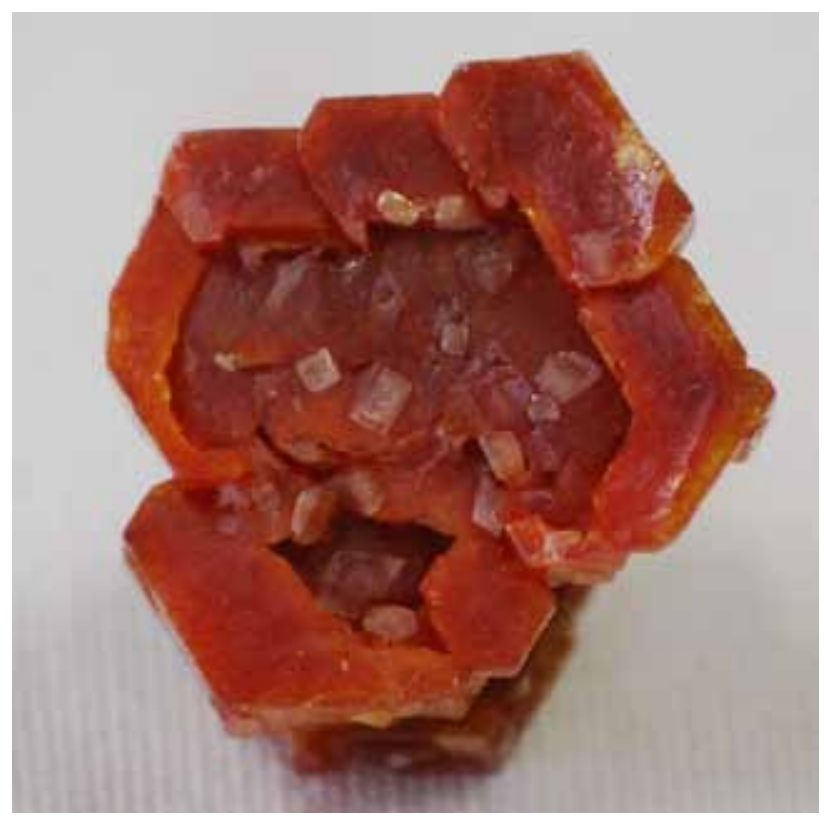

Figura 37. Cristales de vanadinita con aspecto de tolva. Mibladen, Marruecos.

Cristales deformados. Algunos cristales pueden tener formas muy complejas, producto de procesos de cristalización también bajo circunstancias complejas. Algunas formas singulares, particularmente las que tengan parecidos con otros objetos, pueden proporcionar un valor añadido a la pieza. Algunos cristales pueden tener caras o aristas complejamente curvadas e incluso evidencias de deformación (Figura 38).

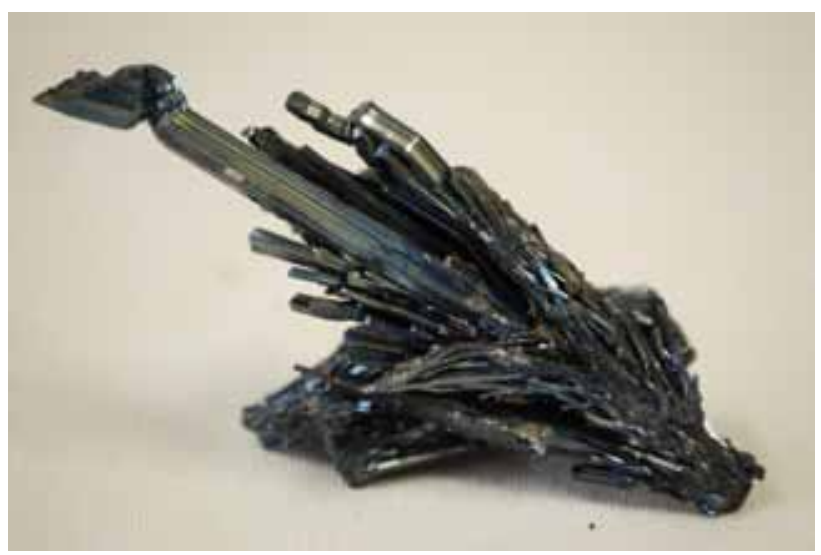

Figura 38. Cristales de estibina en agregados radiales; en varios cristales se aprecia la curvatura de las aristas y las caras. China. 
Sobrecrecimientos. A menudo los minerales cristalizan en diferentes etapas, de manera que los cristales formados en una primera etapa pueden quedar recubiertos por los cristales formados en la segunda. Cuando en dos etapas diferentes cristaliza el mismo mineral, pero en condiciones diferentes, puede ser que haya cambios importantes en la forma o en el color del mineral. En estos casos, el segundo cristal en formarse tiende a desarrollarse manteniendo la misma orientación que el cristal que actúa de base, de manera que aparecen formas muy caprichosas. Un caso típico es el del cuarzo en cetro (Figura 39).

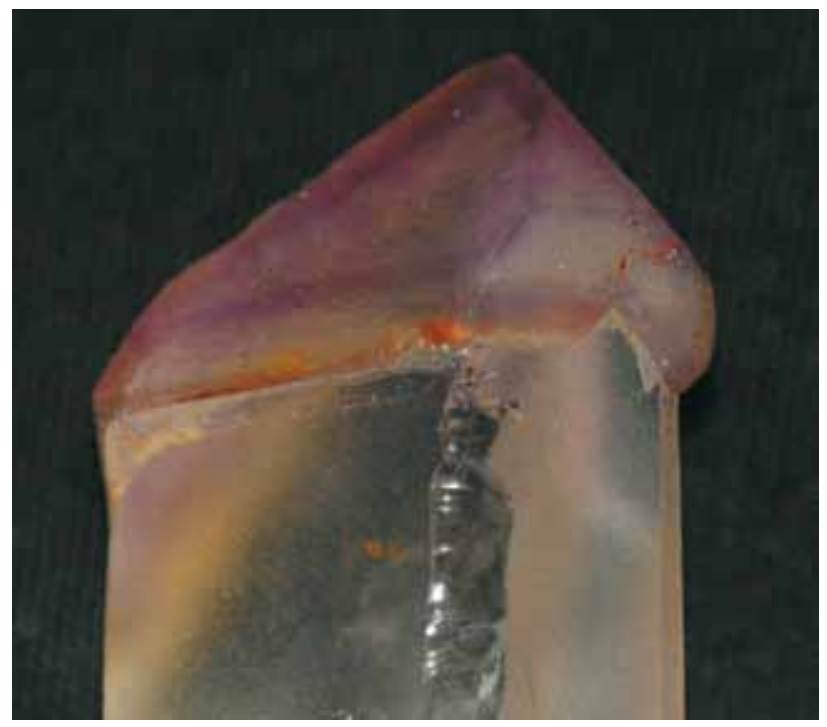

Figura 39. Cristales de cuarzo incoloro sobrecrecido por cuarzo amatista formando un crecimiento en forma de cetro. Brasil.

Maclas. Los cristales pueden estar maclados. Una macla (en inglés twin) es el crecimiento simultáneo de dos o más cristales gemelos. Los cristales maclados bien desarrollados son muy apreciados. Hay muchos tipos de maclas, como por ejemplo las simples (de dos cristales) o las múltiples (de más de dos cristales). Por otro lado, según cual sea la forma de la macla, hay las maclas de yuxtaposición (Figura 40) y las maclas de compenetración (Figura 41). Cuando las maclas de yuxtaposición son múltiples se habla de maclas polisintéticas (Figura 42); en el caso de maclas de compenetración múltiples se habla de maclas cíclicas (Figura 43).

Tamaño. En general, a igualdad de perfección, cuanto más grande es un cristal mayor es su valor (Figura 44). Aun así, el factor que pesa más en el valor de la pieza es su perfección.

\subsection{Ausencia de daños en las piezas}

El daño de cualquier tipo en las piezas hace que estas pierdan valor. Los daños pueden ser de varios tipos:

Cristales rotos. Durante los procesos de extracción o transporte puede ser que en una pieza haya cristales

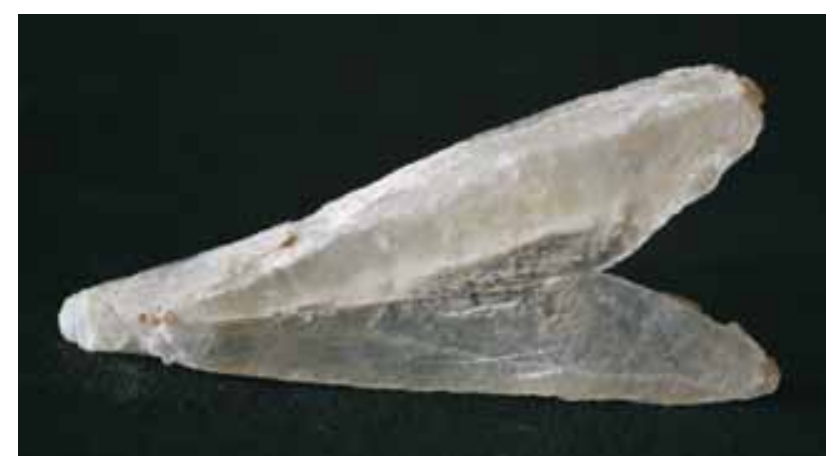

Figura 40. Maclas de yuxtaposición simple de yeso, en forma de punta de flecha.

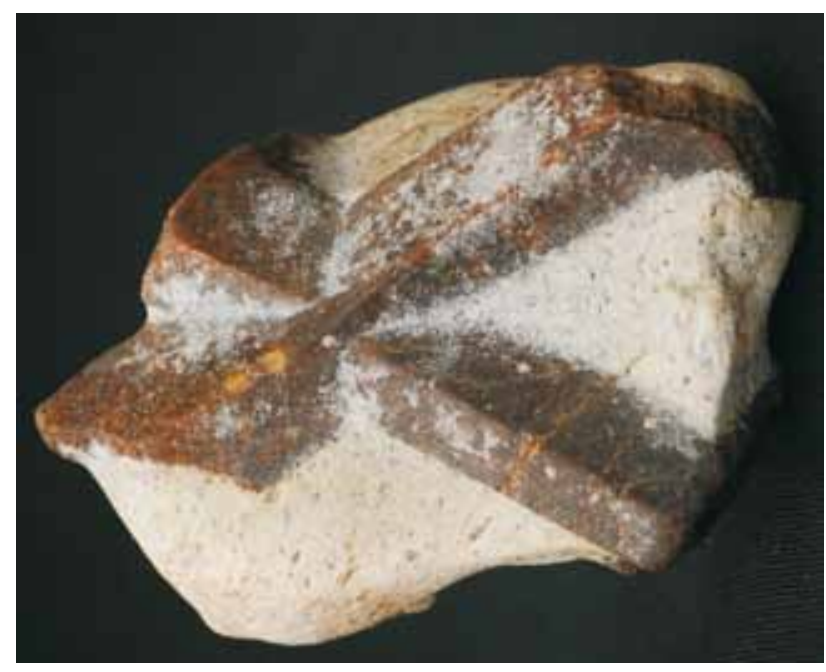

Figura 41. Maclas simples de compenetración de estaurolita en forma de cruz de San Andrés. Keivy, Kola, Rusia.

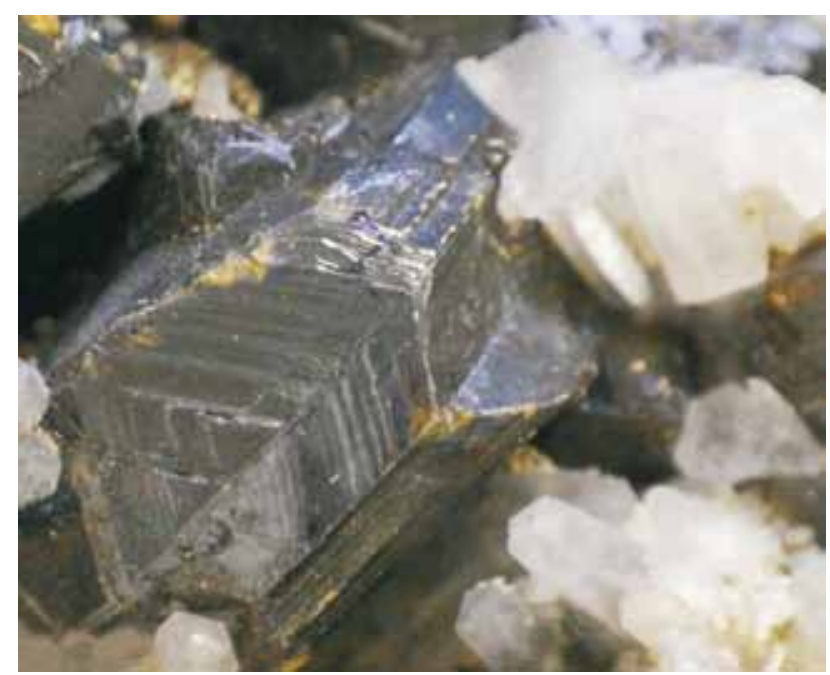

Figura 42. Maclas polisintéticas de esfalerita. Trepca, Kosovo.

que se rompan (Figura 45). Cuando en una muestra hay muchos cristales, si los cristales rotos son muchos y/o se encuentran en zonas críticas de la muestra (por ejemplo, al centro), se reduce su belleza y la muestra pierde valor. 


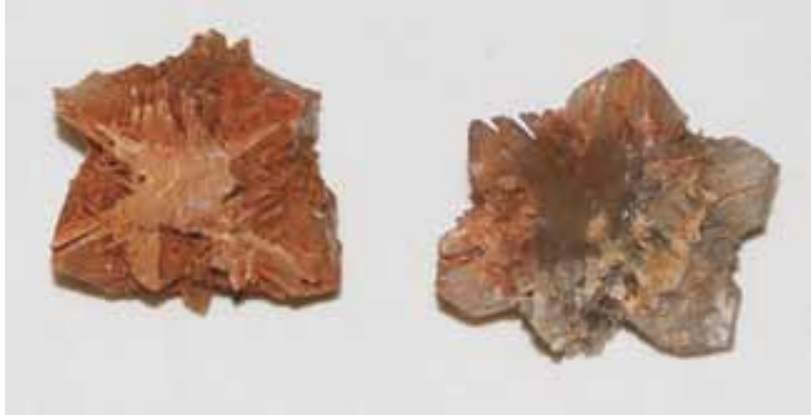

Figura 43. Maclas múltiples de compenetración de aragonita. Velilla de Medinaceli, Guadalajara, España.

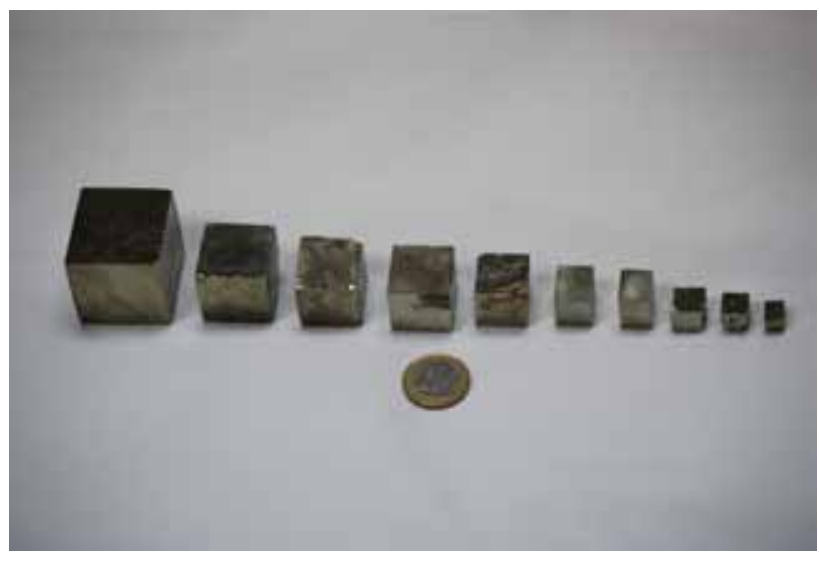

Figura 44. Cristales de pirita de forma similar y de diferentes tamaños. Ambasaguas, La Rioja, España.

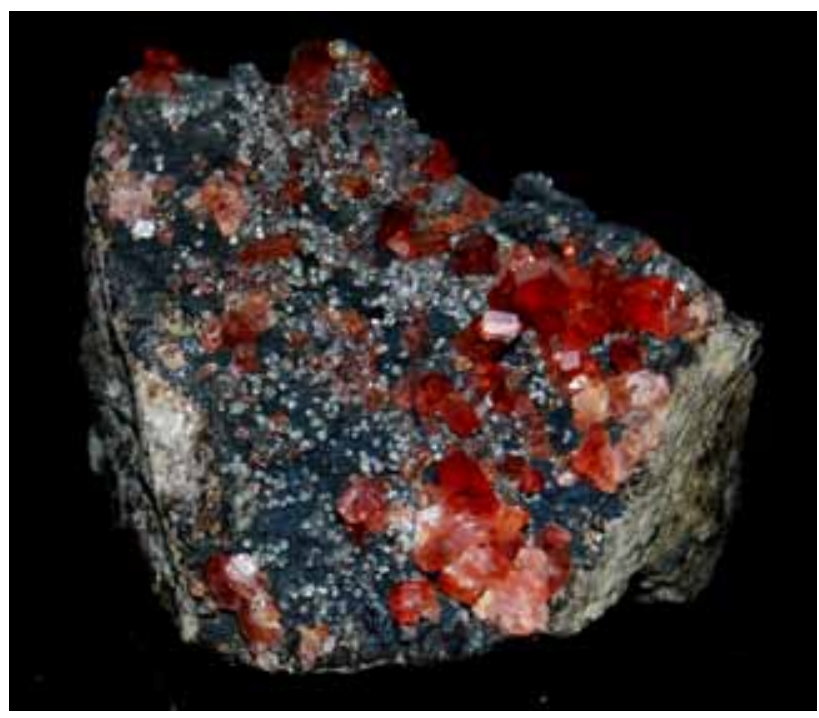

Figura 45. Muestra con cristales de rodocrosita (rojo). Los de alrededor están rotos, cosa que resta valor a la pieza. Perú.

Golpes. Es un factor crítico que depende directamente del recolector. Pueden producirse durante la extracción del mineral, durante el almacenamiento o durante el transporte. La presencia de golpes en la superficie expuesta de una muestra reduce exponencialmente su precio y puede quitarle todo su valor (Figura 46, 47).
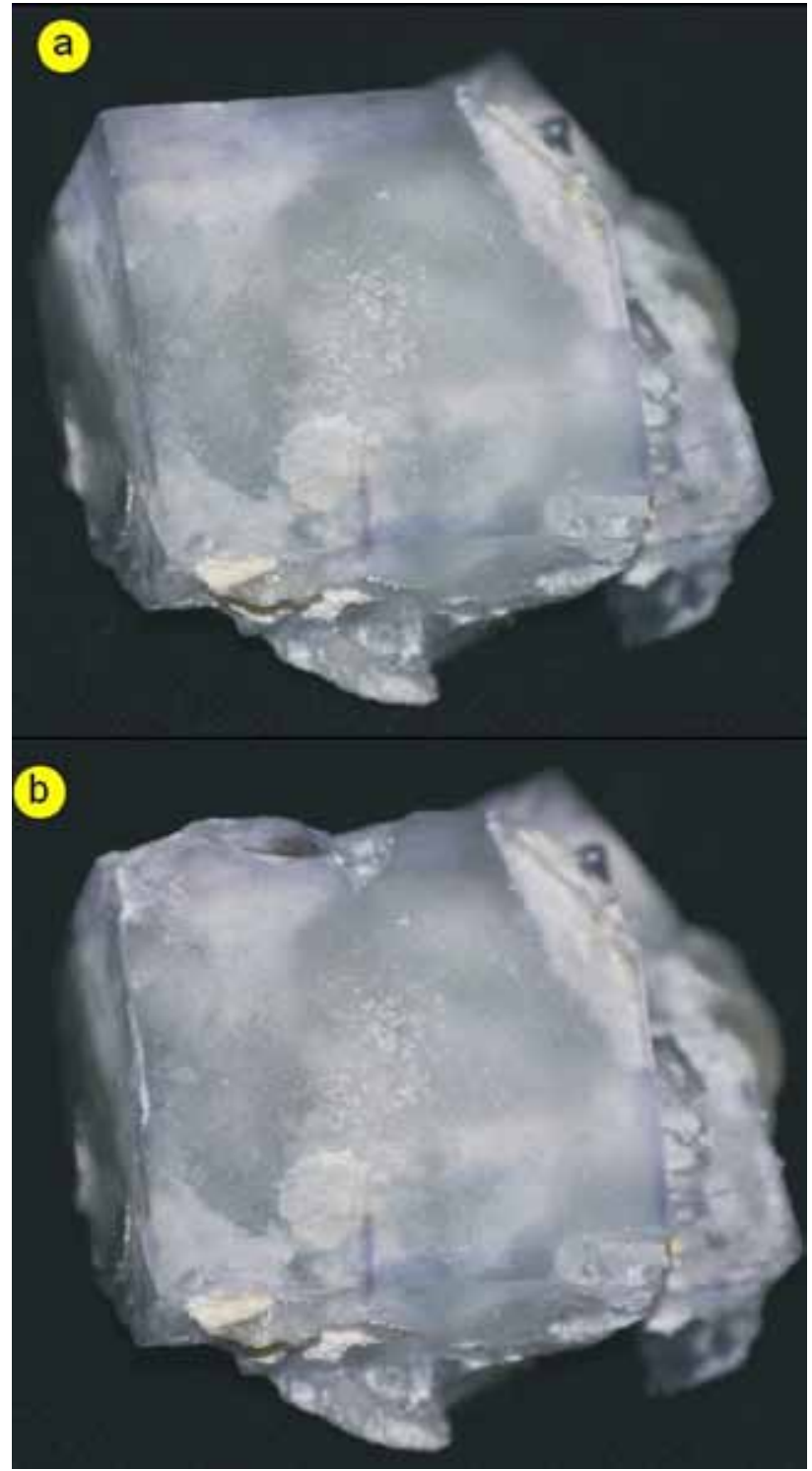

Figura 46. a) Cristal cúbico de fluorita b) el mismo cristal con los vértices y aristas rotas que le restan todo su valor.

Rayas. Se producen también por tener poco cuidado durante la extracción o transporte del mineral. Son igual de graves que el caso anterior.

Decoloración. Algunos minerales son muy sensibles a la luz, de manera que por exposición a una luz intensa pueden sufrir reacciones químicas catalizadas por la luz (reacciones fotolumínicas). A causa de estas reacciones la superficie del mineral puede adquirir pátinas, perder color u oscurecerse. Son ejemplos algunos minerales de plata, y muy particularmente las platas rojas (serie pirargiritaproustita), minerales que se ennegrecen rápidamente por la exposición a la luz. El rejalgar, de color rojo sangre, se transforma en agregados pulverulentos de pararejalgar de color amarillo (Figura 48) y la vanadinita se oscurece y pierde brillo. Por tanto, como precaución, es mejor guardar los minerales bien envueltos (por ejemplo, con papel de 


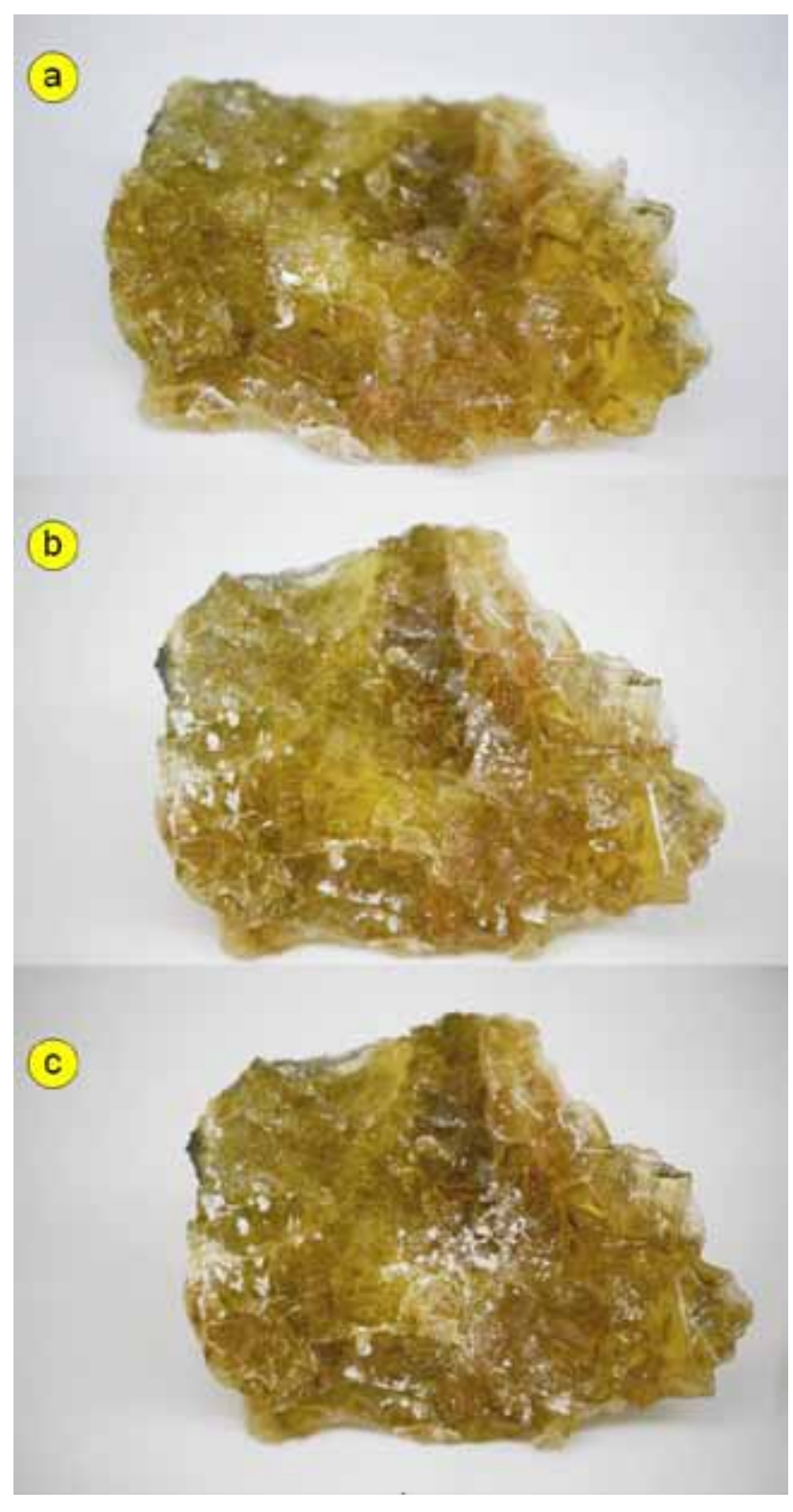

Figura 47. Pérdida progresiva del valor de una drusa de fluorita: arriba, máxima calidad, en el centro, pérdida por golpes alrededor; abajo, pérdida total por golpes en el centro.

aluminio o con un paño negro) y en lugares oscuros, para prevenir la pérdida de color.

Reacciones químicas ambientales. Una cierta cantidad de minerales tienen un dominio de estabilidad reducido, particularmente en condiciones ambientales. De esta manera, muchas sales (particularmente sulfatos, nitratos, cloruros, boratos) pueden hidratarse o deshidratarse fácilmente, de manera que se forman nuevos minerales por efectos de estas reacciones. Los nuevos minerales típicamente son microcristalinos, de tamaño de grano muy fino y, a menudo, pulverulentos (Figura 49). De esta manera, algunos minerales de estas características, inicialmente formados como cristales de gran tamaño y belleza, transparentes y brillantes, se convierten en masas pulverulentas,

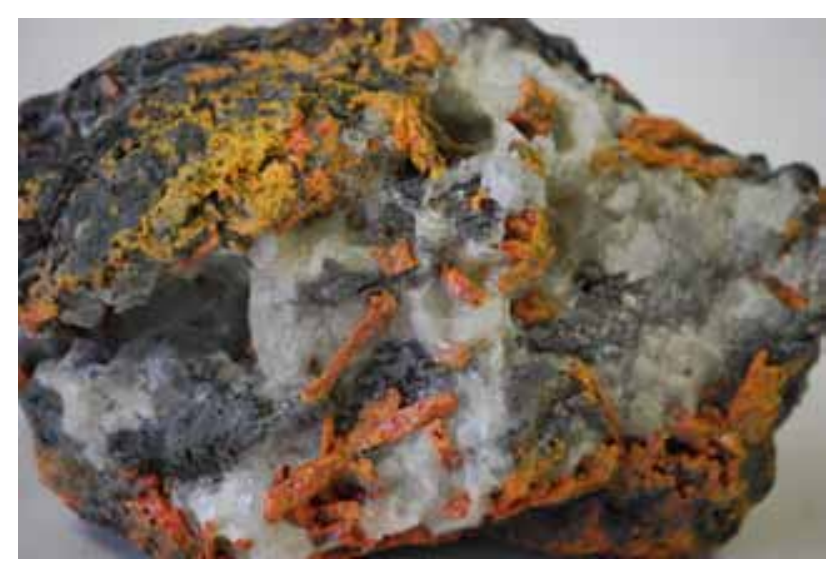

Figura 48. Cristales de rejalgar, inicialmente de color rojo sangre intenso, que se han descolorido por mantener la muestra poco protegida de la luz.

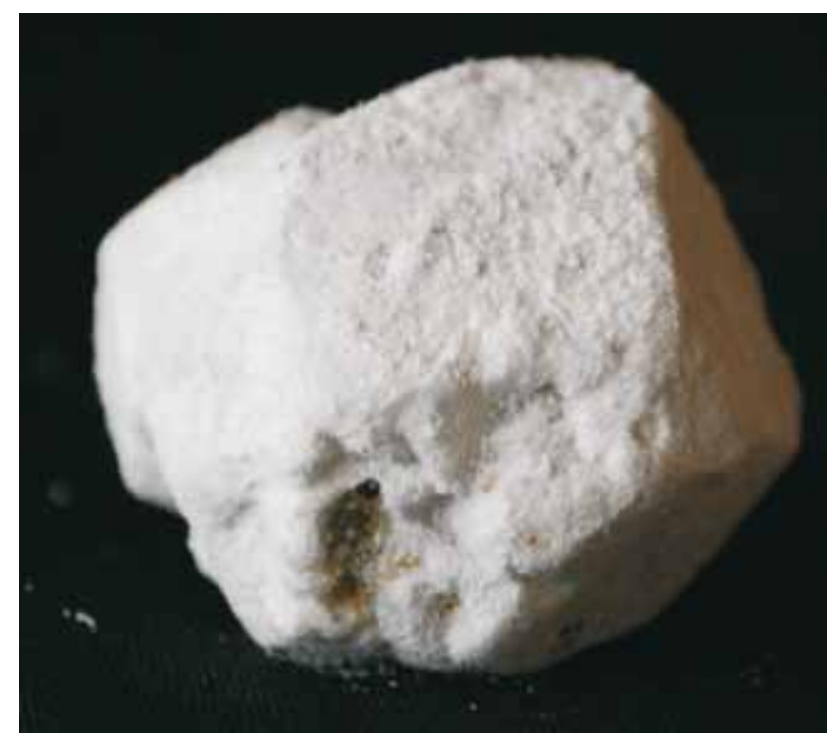

Figura 49. Cristales de hanksita que se han alterado a una masa criptocristalina y polvorienta de color blanco.

frágiles y sin ningún interés. En algunos casos, para impedir estas reacciones, es suficiente con barnizar la muestra o mantenerla dentro de una caja herméticamente cerrada; en otros casos, es imprescindible mantener la muestra herméticamente cerrada en recipientes al vacío o rellenos de gases nobles.

Otros minerales salinos son delicuescentes y pueden perder y reabsorber parte de su agua de cristalización, de manera que pueden quedar deshechos dando lugar a una salmuera.

\subsection{Color de las piezas}

Es una de las propiedades más importantes de las piezas desde el punto de vista de la comercialización y ayuda mucho a su venta.

Intensidad y tonalidad de color. Como norma general, 
los minerales con los colores más vivos son generalmente los más agradables a la vista y preferidos por el gran público, de manera que tienen los precios más elevados (Figuras $50,51$ y 52$)$.

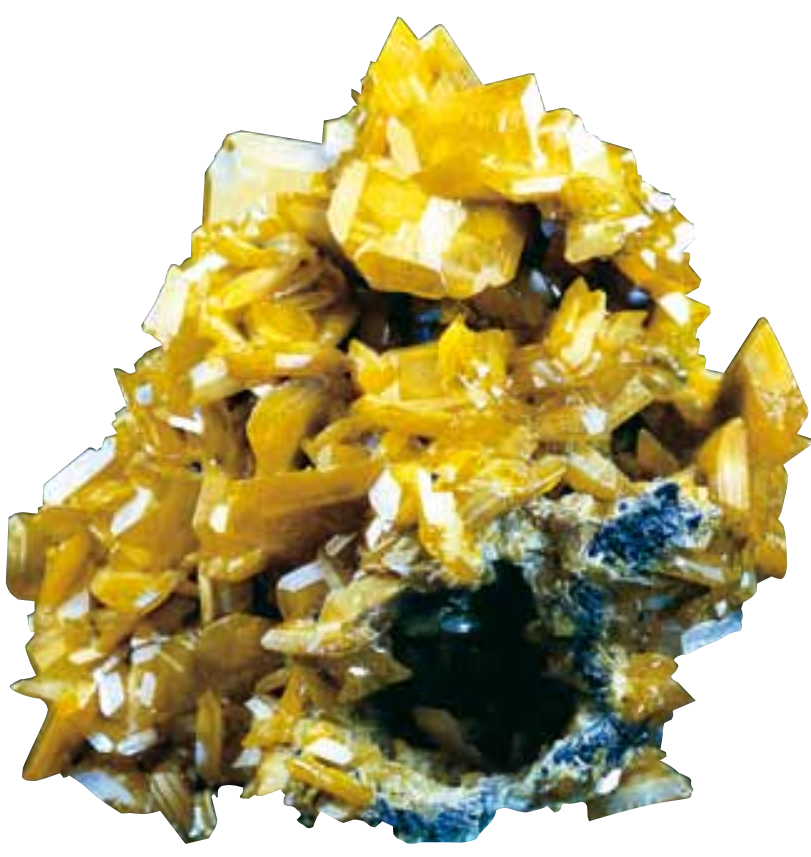

Figura 50. Cristales tabulares de wulfenita, de color amarillo muy intenso. Marruecos

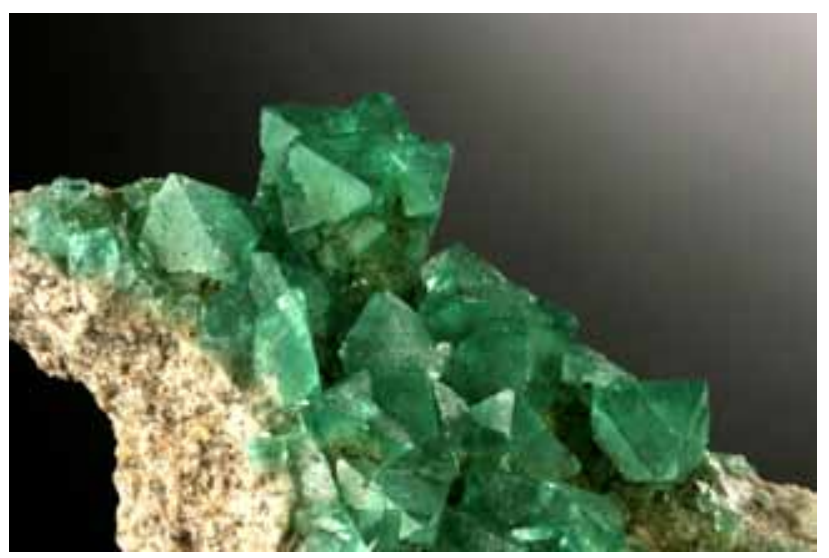

Figura 51. Cristales octaédricos de fluorita, de color verde. Mina Berta, Sant Cugat, Cataluña.

Dentro de la misma especie, un mineral puede presentarse incluso en el mismo yacimiento con diversas intensidades de color, de manera que a igualdad de calidad y tamaño de los cristales, los colores más intensos acostumbran también a ser los más preciados (Figura 53).

Por otro lado, un mismo mineral puede presentarse en diferentes coloraciones. En este caso, los colores más raros de este mineral pueden ser aún más valorados (Figura 54). Entre diferentes muestras de un mismo color, naturalmente, la más valiosa será aquella que tenga los colores más intensos.

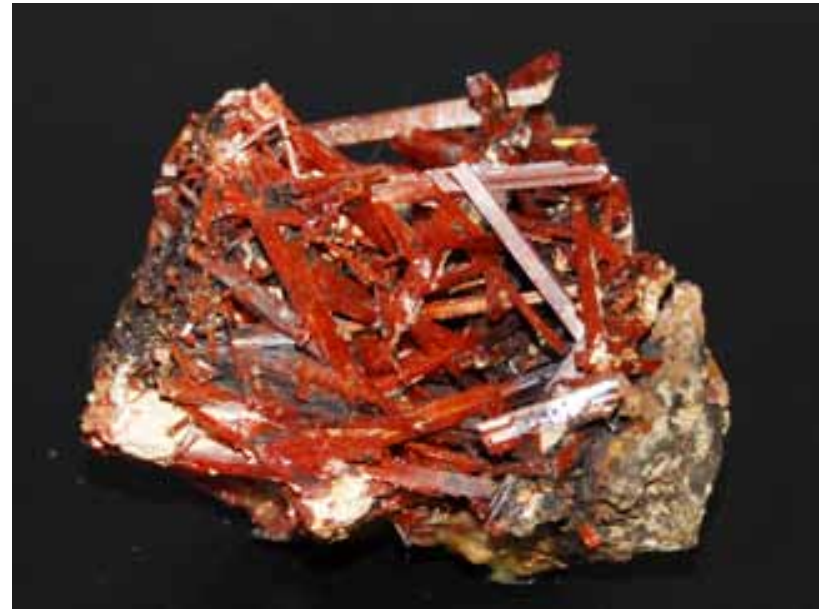

Figura 52. Cristales prismáticos de crocoíta de color rojo. Red Lead mine, Dundas, Tasmania.

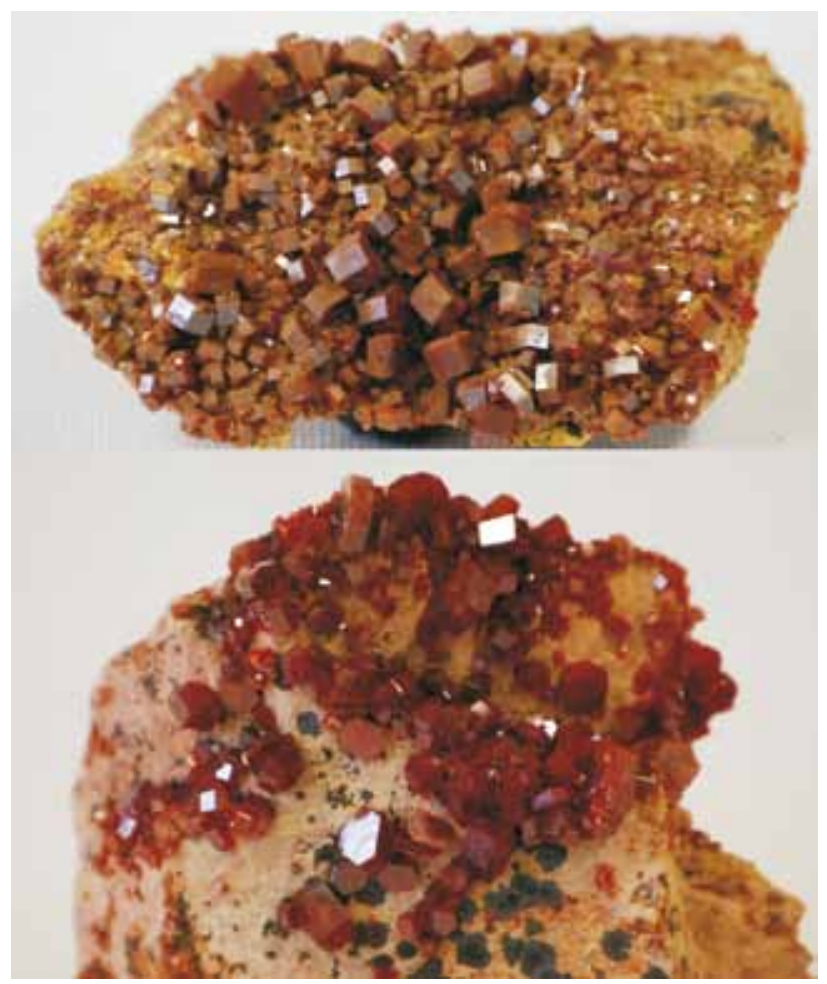

Figura 53. Cristales de vanadinita rojos con diferente intensidad de color. Los de la muestra inferior serían más apreciados.

Generalmente, las muestras más coloreadas se encontraran preservadas de los rayos solares, ya que muchos minerales pierden su color si reciben directamente la luz solar.

Dicroísmo. Algunos minerales, como por ejemplo la cordierita gema o la epidota, presentan la propiedad del dicroísmo, de manera que al girar sus cristales estos cambian de color (Figura 55). Ello es debido a la absorción diferencial de la luz en las diferentes direcciones del cristal. Este efecto puede dar preciosos efectos ópticos a las gemas talladas con este material en el caso que el cristal esté bien tallado. 


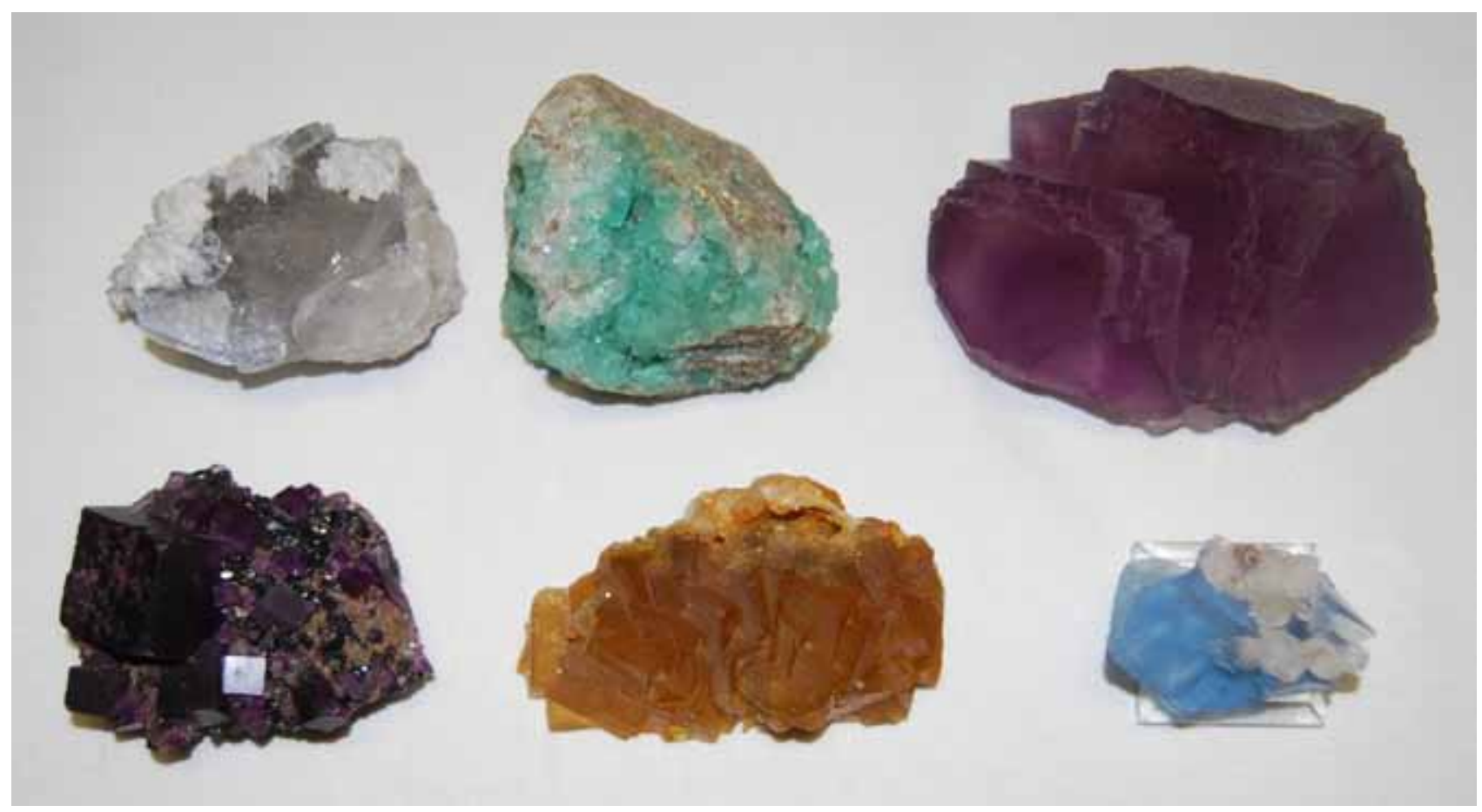

Figura 54. Algunos de los diferentes colores en que se puede presentar la fluorita, incluso en una misma localidad. El azul es el más raro.

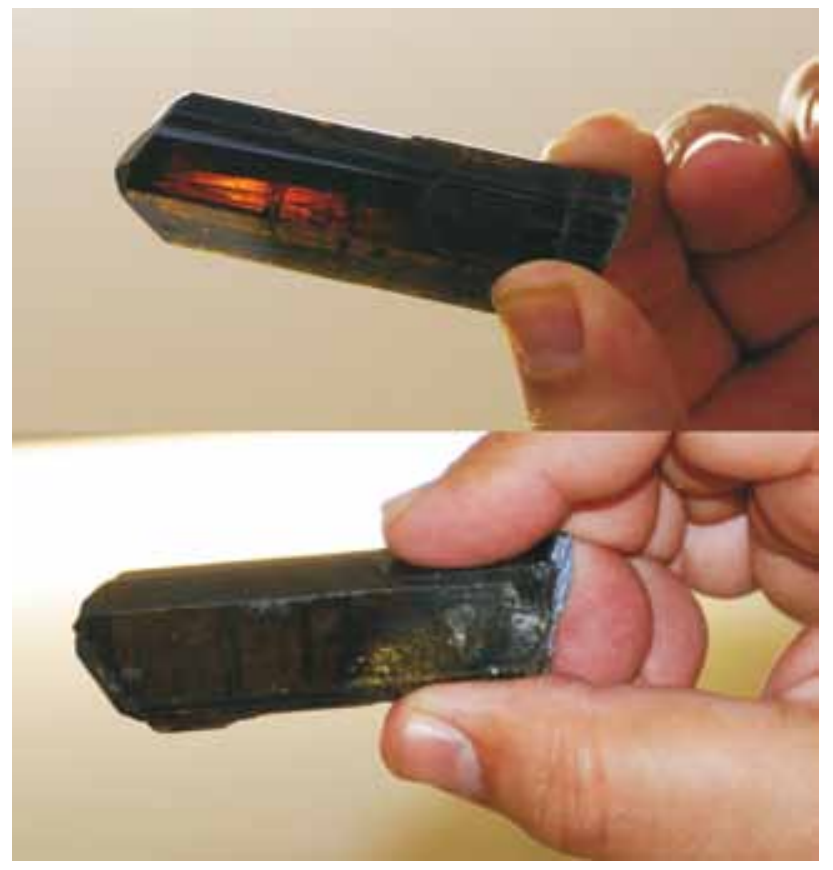

Figura 55. Cristales dicroicos de epidota, en los cuales se aprecia un cambio de coloración de marrón-rojizo a verde oliva al girar la muestra y observar por transparencia diferentes caras del mismo cristal. Baluchistán, Pakistán.

Pseudocromatismo. Algunas irregularidades microscópicas o submicroscópicas internas del mineral (como por ejemplo exsoluciones, pequeñas inclusiones, microfracturas, microesferulitas) pueden dispersar la luz produciendo un juego de colores muy espectacular conocido genéricamente como pseudocromatismo, que puede convertir el mineral en una gema muy apreciada. Este fenómeno lo presenta el ópalo noble, mientras que el ópalo común tiene un aspecto mucho más basto (Figura 56). También se puede dar en algunos feldespatos, como la labradorita (labradorescencia, Figura 57), la variedad adularia del feldespato potásico (adularescencia, piedra de luna), etc. El fenómeno puede ser más claro en muestras pulimentadas.

Variaciones de color en la muestra. Algunos minerales se pueden formar en diversos episodios y en cada episodio pueden presentar un color o brillo diferente. En ocasiones, este fenómeno puede conllevar a cambios de aspecto muy notable, que hacen que la muestra adquiera una gran belleza. Un buen ejemplo de ello pueden ser las ágatas, que no son más que una variedad de cuarzo de tamaño de grano muy fino (y que, por tanto, presentan brillo de cera), que han sido coloreadas de forma natural por diversas impurezas, y que en función de las diferentes impurezas tienen diferentes coloraciones distribuidas en bandas de forma concéntrica (Figura 58).

Modificaciones artificiales del color. El color original del mineral puede ser modificado artificialmente por los vendedores de minerales para dar un aspecto más atractivo a las piezas mediante tinciones con diferentes colorantes (Figura 59). Esto se realiza sobretodo con ágatas.

Las modificaciones del color también se pueden conseguir con tratamientos térmicos. Por ejemplo, por calentamiento de amatistas (de color violeta) de baja calidad se obtienen coloraciones de color ámbar (falso topacio). Estas variedades tratadas pueden ser utilizadas también como 


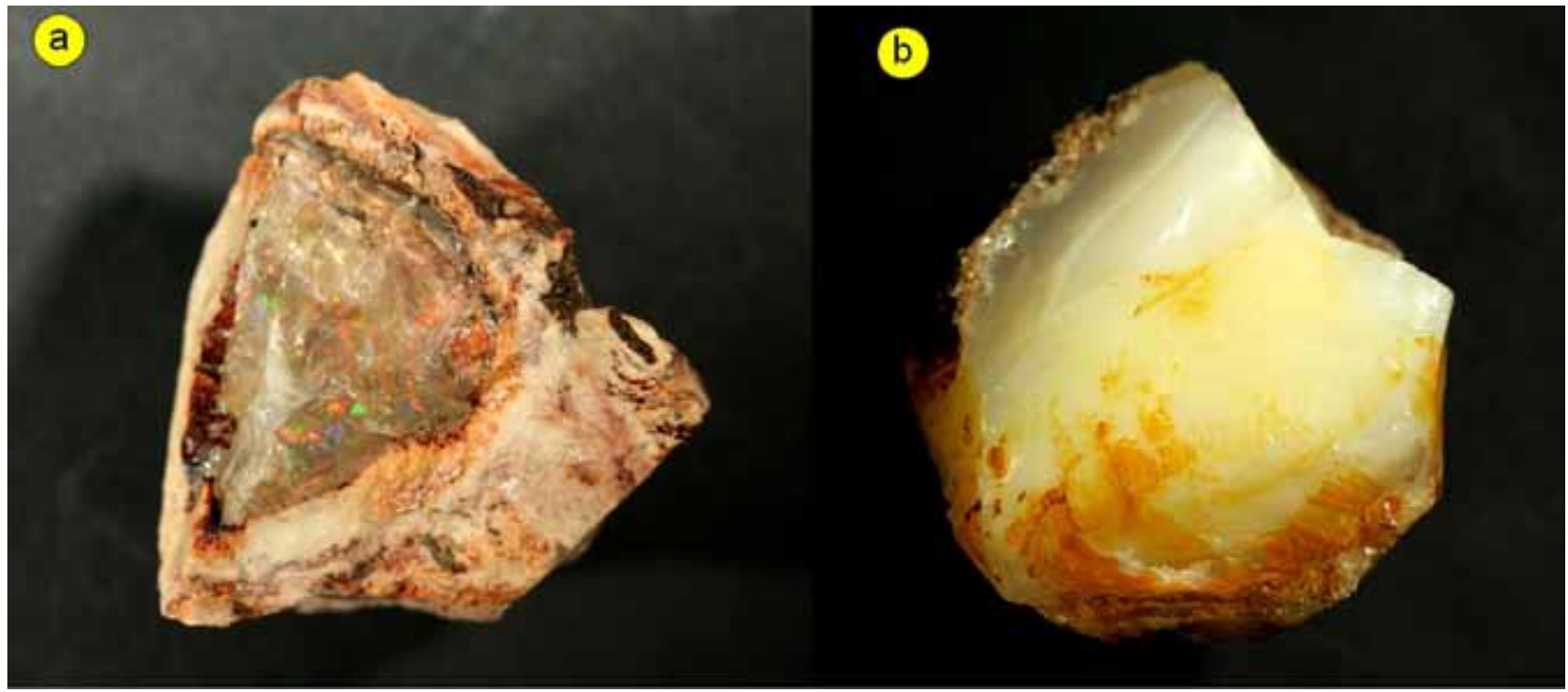

Figura 56. a) Pseudocromatismo que da un juego de colores en el ópalo noble de Australia (efecto de "arlequín”) b) Aspecto lechoso del ópalo común. Caldes de Malavella, Catalunya

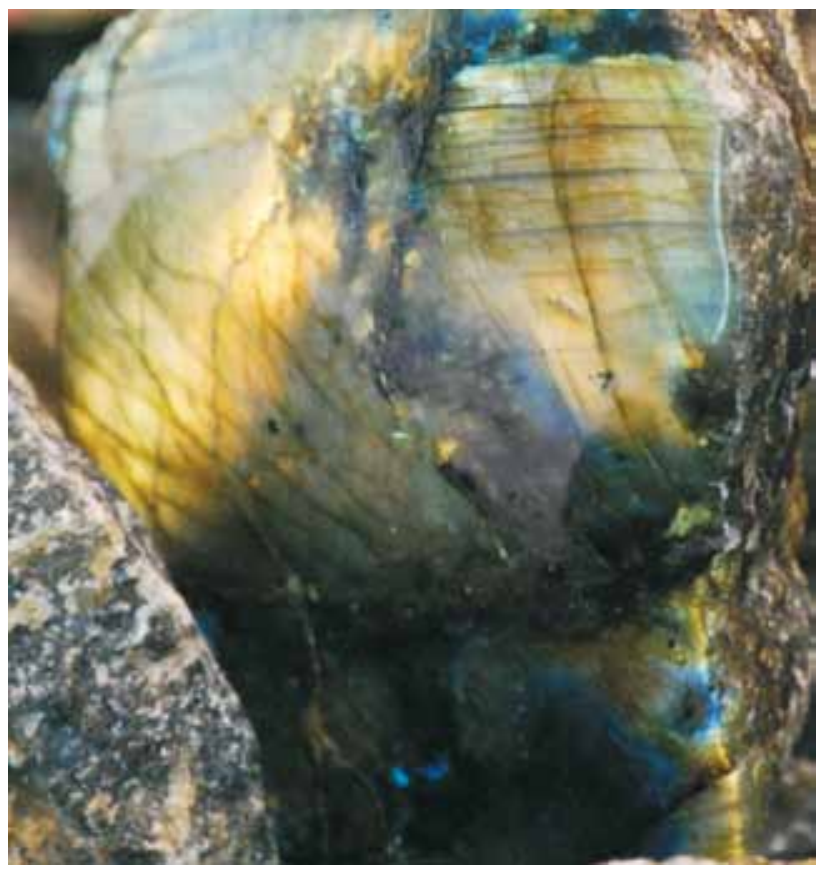

Figura 57. Efecto de juegos de color por pseudocromatismo sobre una superficie pulimentada de labradorita ("espectrolita") de Finlandia.

minerales de decoración (Figura 60) o bien como material de bisutería.

Aunque los ejemplares con el color modificado pueden ser mucho más espectaculares de cara al comercio de piezas de decoración para el gran público, se debe tener presente que los coleccionistas de minerales rechazan ampliamente esta práctica. En cualquier caso, si la muestra está teñida se debe indicar y de ninguna manera se puede vender como si fuera una muestra natural, ya que esto estaría considerado como una estafa.

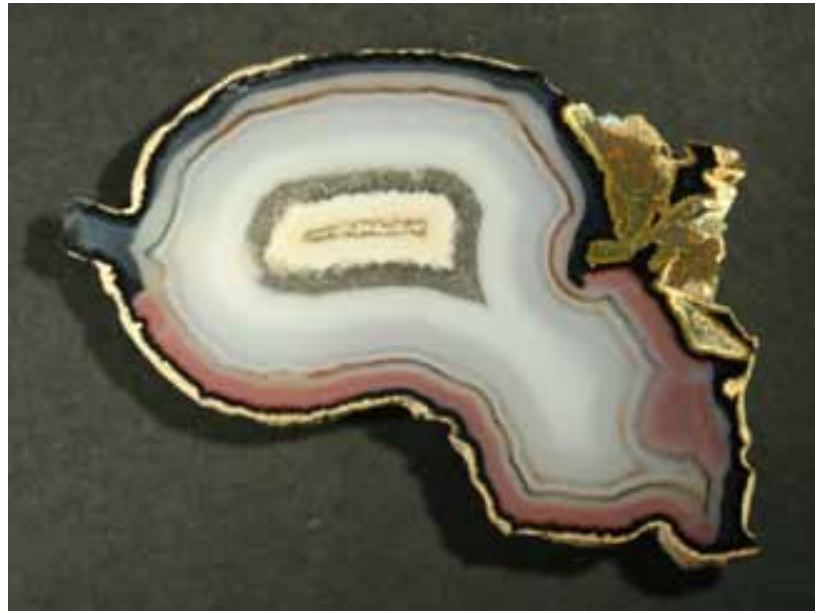

Figura 58. Crecimiento concéntrico en un ágata, en parte ya tallada y pulida.

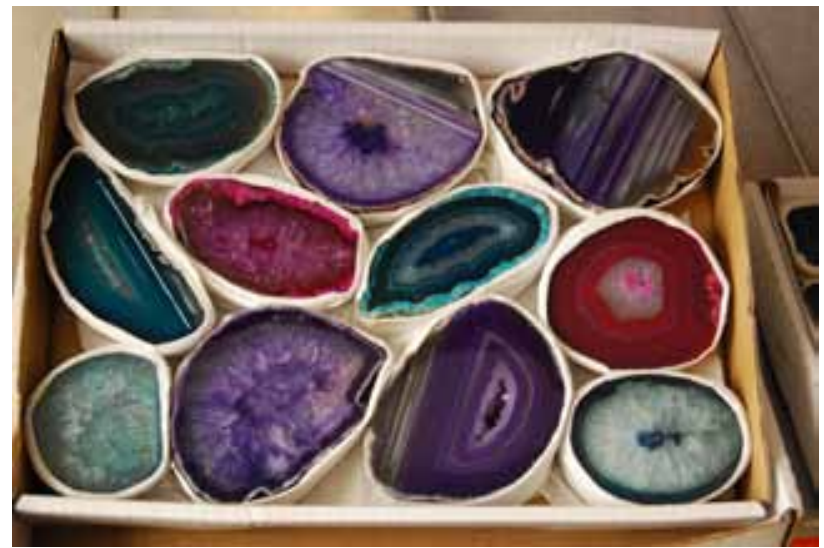

Figura 59. Colección de ágatas talladas, pulidas y teñidas con diferentes colorantes. 


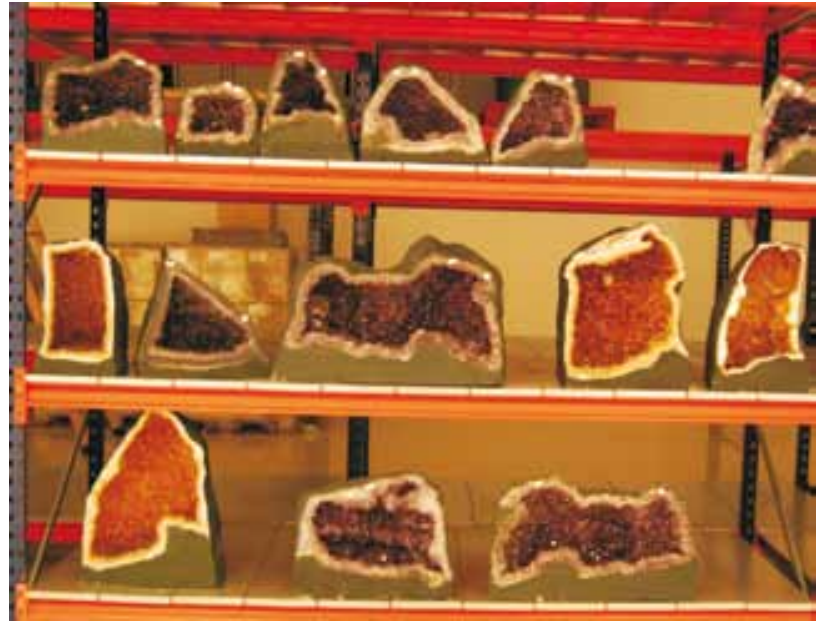

Figura 60. Geodas de amatista de color normal y con el color que se obtiene por calentamiento (falso topacio, de color ámbar).

\subsection{Pátinas}

Algunos minerales pueden tener finísimos recubrimientos peliculares de otros minerales (pátinas), que se forman generalmente por alteración de los minerales primarios. De una banda, las coloraciones de las pátinas enmascaran las coloraciones de los minerales originales, también les confieren coloraciones muy abigarradas o irisadas. Típicamente este fenómeno se da en minerales opacos (principalmente en sulfuros y óxidos).

Estos cambios de color pueden llegar a producir efectos de gran belleza. Tanto es así, que muchas veces este efecto es producido artificialmente para dar más valor a una pieza. De esta manera, las muestras de calcopirita irisada que se encuentran en el mercado han estado casi siempre generadas artificialmente a partir de un tratamiento de calcopirita vulgar con soluciones ácidas ricas en sulfato de cobre (Peacock ore, Figura 61).

\subsection{Zonación}

Algunos cristales pueden presentar zonación, eso es, variaciones importantes de coloración desde el centro de los cristales hacia su periferia o desde la base de los cristales hacia los extremos. Estos cambios de colores reflejan casi siempre cambios composicionales. Por tanto, estas variaciones hacen que una parte del cristal, con una cierta composición más inestable (por ejemplo, la parte central de los cristales de plagioclasa), sea más alterable que otra (en la plagioclasa, la parte externa).

Sea como sea, la zonación puede ocasionar bellísimos juegos de colores que incrementan mucho el precio del mineral. El cambio de coloración puede ser progresivo o brusco y la geometría de cada una de las zonas puede ser muy diversa (Figura 62).

Quizás, los minerales que presentan zonaciones más espectaculares son los del grupo de la turmalina. En este

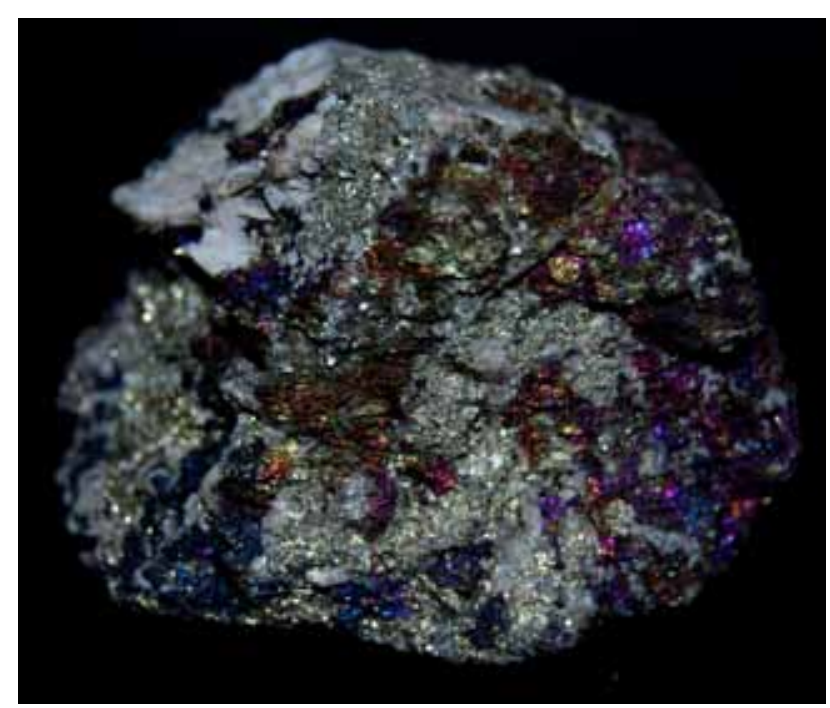

Figura 61. Calcopirita (amarilla, metálica) con pátinas muy coloreadas de bornita (lila, metálica) y covellina (azul). Butte, Montana, EUA.

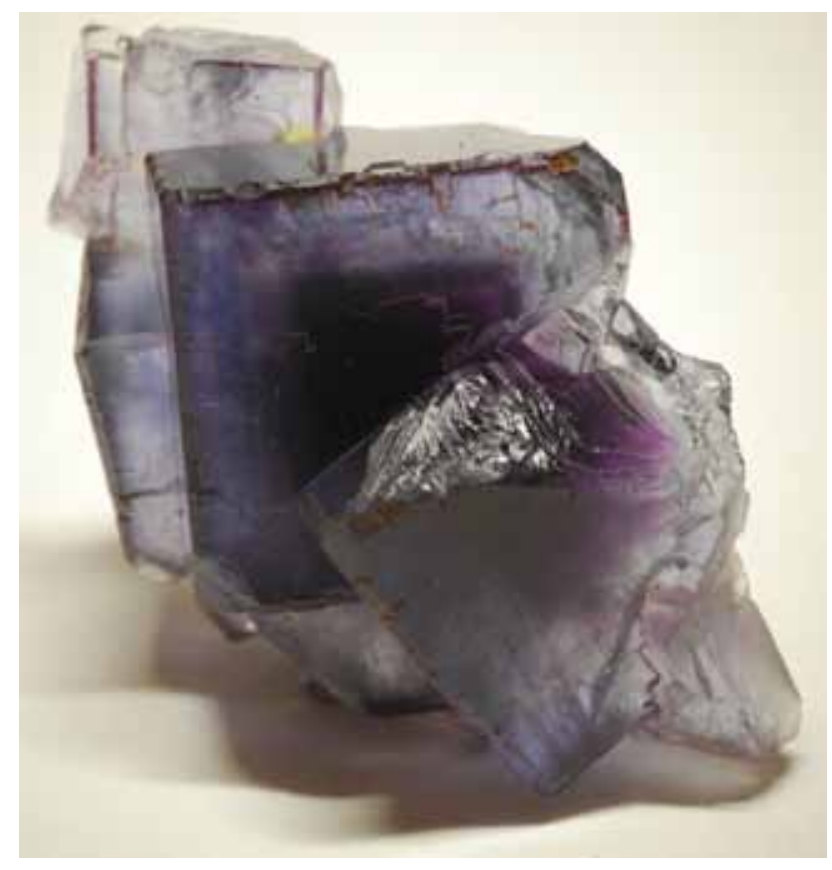

Figura 62. Cristales de fluorita zonada. A remarcar el cambio de color progresivo entre cada una de las zonas.

caso, la zonación acostumbra a ser concéntrica. De esta manera, en una loncha del cristal tallada perpendicularmente a su alargamiento se pueden apreciar bellísimos cambios de color, en una amplia gama (Figura 63). Una de las variedades más apreciadas es la conocida con el sobrenombre de turmalina sandía (en inglés, watermelon), llamada así por tener la parte externa del cristal verde y el núcleo de color rojo o rosado. Muchas turmalinas presentan cambios de color muy espectaculares también según la longitud del cristal, de forma complementaria o alternativa a la zonación concéntrica (Figura 64). 


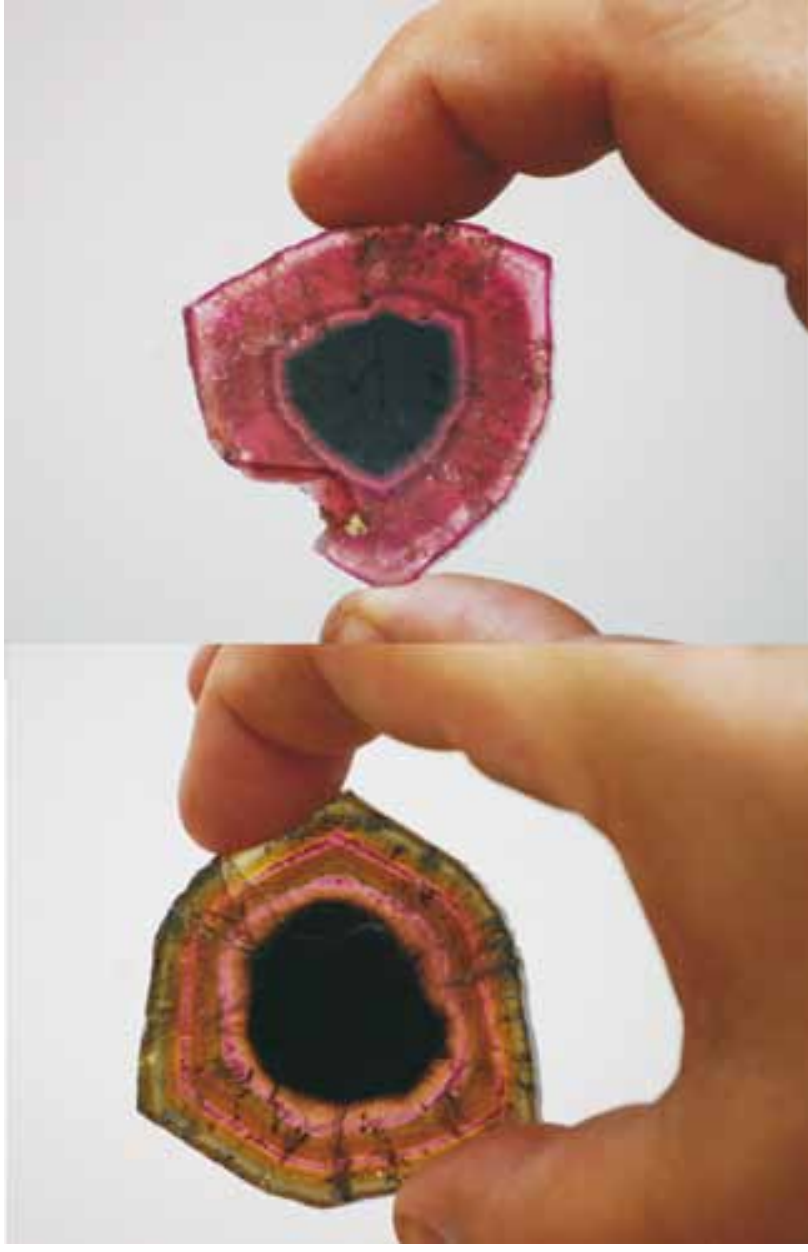

Figura 63. Secciones de turmalinas con zonaciones, con cambios muy fuertes de coloración. Brasil.

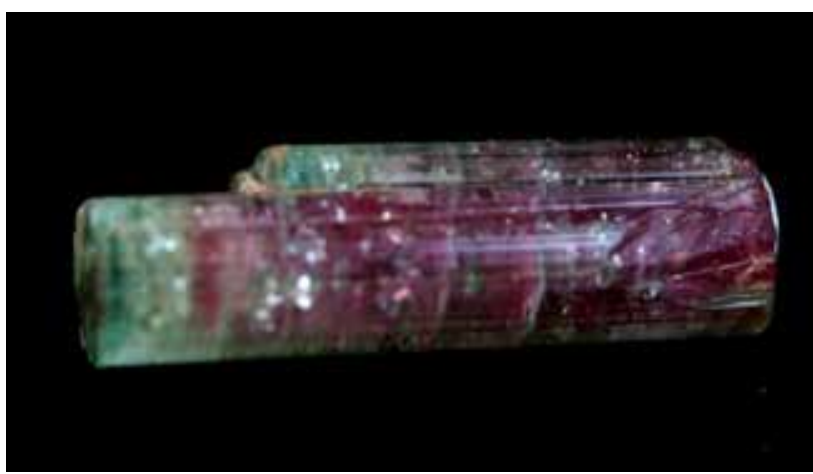

Figura 64. Variación del color de la turmalina elbaíta en el interior de un cristal, desde rosa a verde, en sentido longitudinal. Brasil.

\subsection{Transparencia}

En el caso de los minerales que pueden ser transparentes, la nitidez del mineral hace aumentar su valor. Los aspectos que pueden hacer disminuir el valor del mineral son inclusiones irregulares de otros minerales o fracturas (Figuras 65 y 66).

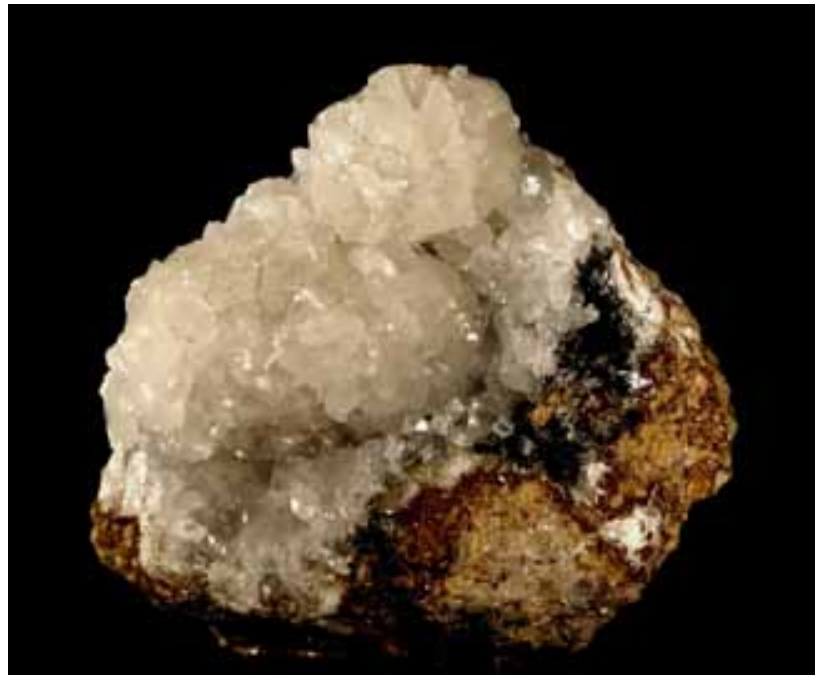

Figura 65. Agregados de cristales de calcita de muy poca transparencia.

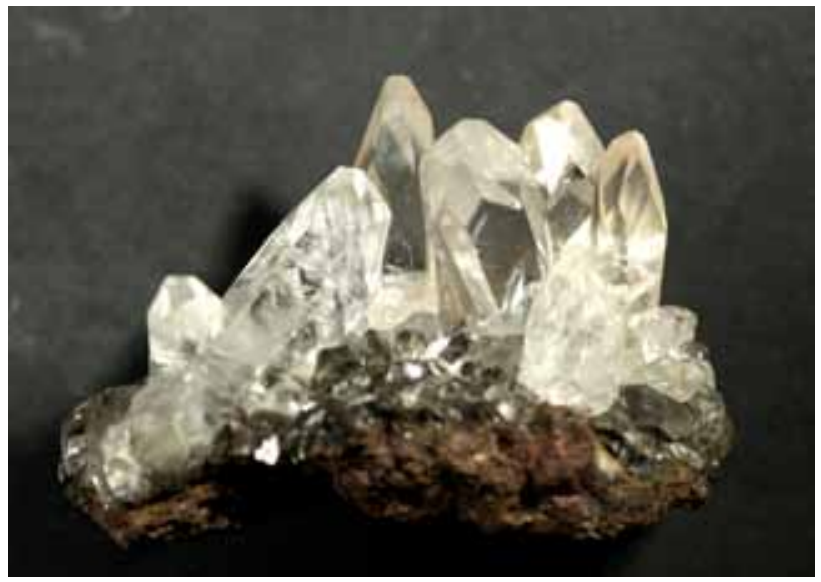

Figura 66. Cristales de calcita transparentes. Esta muestra podría ser más apreciada que la anterior, ya que los cristales quedan aislados y se aprecian mejor y además son transparentes.

\subsection{Inclusiones}

Determinadas especies presentan cristales incluidos dentro de un cristal más grande la misma especie. Cuando esto ocurre, y el mineral que encaja es transparente, la muestra es muy apreciada por los coleccionistas de minerales. Los cristales que se aprecian dentro otros cristales son conocidos como fantasmas (Figura 67).

Las inclusiones en el interior de un mineral pueden ser de partículas muy finas de otros minerales. En este caso, estas inclusiones pueden disponerse según los planos o ejes de simetría del mineral huésped, adoptando figuras geométricas. Un caso muy típico es el de la variedad de la andalucita conocida como quiastolita (Figura 68). La quiastolita era utilizada ya desde la Edad Media para elaborar tallas y recuerdos en el "Camino de Santiago", donde se la conocía por su nombre latino de lapis crucifer (piedra de cruz). También son ejemplos muy conocidos los 


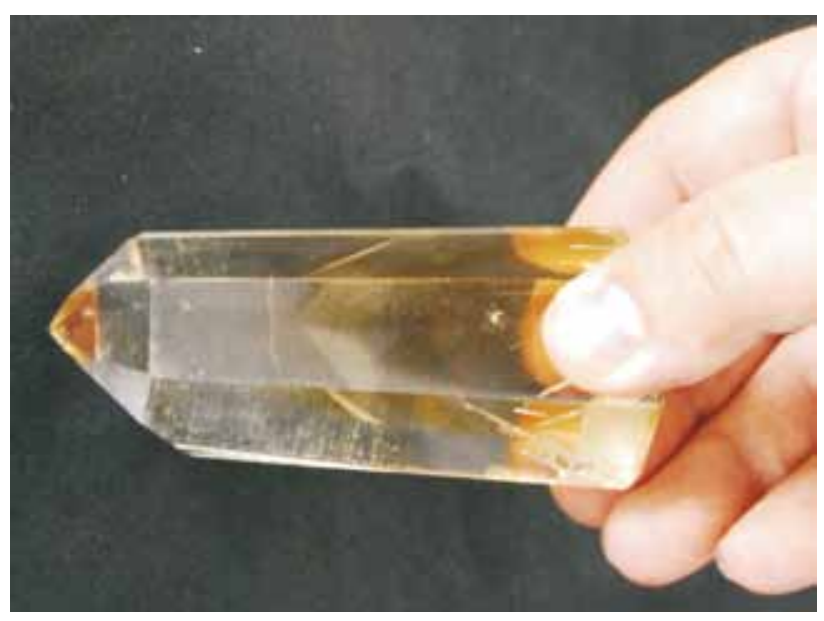

Figura 67. Cristal de cuarzo (pulimentado) con inclusiones de cuarzo más amarillento. Brasil.

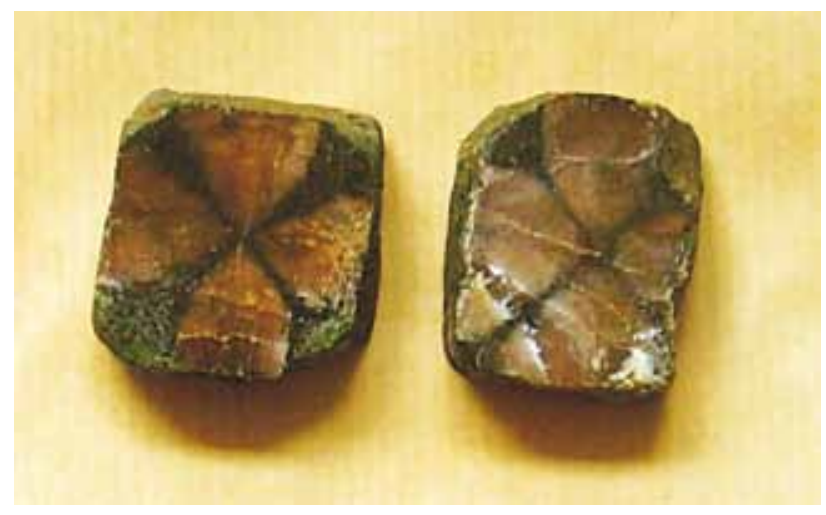

Figura 68. Inclusiones de materia orgánica de color negro dentro de cristales de andalucita de color rosado. Los cristales han sido tallados perpendicularmente al alargamiento. Estas variedades de andalucita que tienen inclusiones dispuestas en forma de cruz se conocen como "quiastolita". China.

"trapiches", especialmente en el caso del berilo, como en algunas esmeraldas de Colombia. Estas rarezas proporcionan también un valor añadido al mineral.

También son muy apreciados aquellos cristales que tienen inclusiones líquidas y gaseosas de tamaño apreciable. Este hecho se da, por ejemplo, en cristales de cuarzo de muchas localidades, que pueden atrapar inclusiones acuosas de tamaños que pueden llegar a escala centímétrica, en las que el agua está en parte líquida y en parte gaseosa (esta en forma de burbuja dentro del líquido). Estas burbujas gaseosas se mueven al girar el cristal (Figura 69).

\subsection{Brillo de las piezas}

Para que las muestras sean brillantes se necesita que los cristales tengan las caras cuanto más lisas sea posible. Si las caras son rugosas, el cristal pierde brillo y, en consecuencia, valor (Figura 70). En general, las muestras recogidas más cerca de la superficie están más expuestas al agua de lluvia y pueden estar parcialmente disueltas,

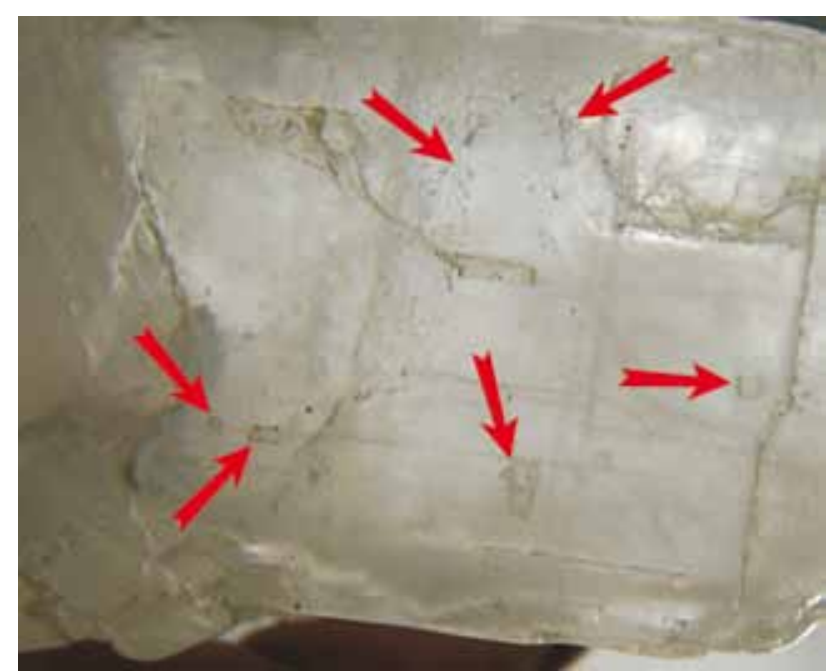

Figura 69. Inclusiones fluidas (líquido y vapor) de medida excepcionalmente grande (milimétrica) dentro de un cristal de halita. La posición de las inclusiones está señalada con las flechas rojas. Los Remolinos, Zaragoza, España.

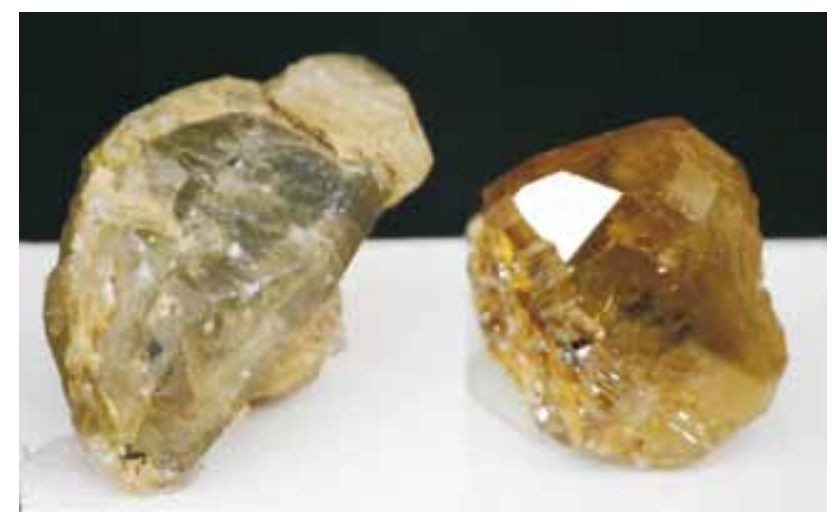

Figura 70. Cristales de cerusita con diferente grado de brillo de sus caras. La de la izquierda tiene las caras con un brillo muy mate; el de la derecha podría alcanzar precios más altos ya que sus caras son más brillantes. Mibladem, Marruecos.

por lo que tienden a ser menos brillantes. Los cristales mejores y más brillantes acostumbran a extraerse a algunos metros de profundidad. Normalmente los cristales de más calidad aparecen en el interior de cavidades del tipo drusa o geoda.

El brillo de las piezas puede ser modificado artificialmente a partir de determinados tratamientos. Un ataque con ácido, por ejemplo, puede modificar el brillo de la calcita, dándole un brillo graso que puede resultar bastante agradable para el coleccionista inexperto (Figura 71).

\subsection{Rareza}

Se pueden dar diferentes tipos de circunstancias que convierten a una pieza en una rareza. En primer lugar, una especie mineral puede ser muy rara y encontrarse en cantidades muy pequeñas en muy pocos lugares del mundo (Figura 72). 


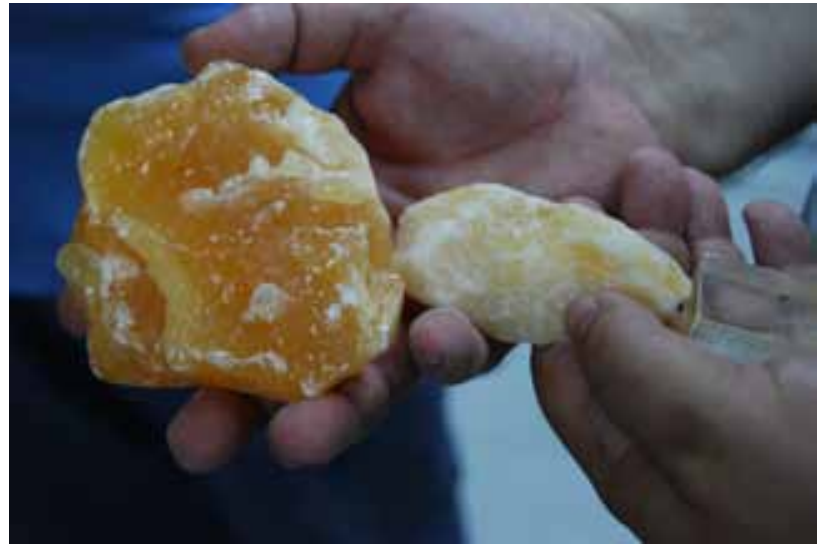

Figura 71. Muestra de calcita en estado natural (derecha) y la misma calcita atacada con ácido (izquierda). El ácido elimina los golpes, homogeniza la superficie y, por tanto, se aprecian mejor los colores; la brillantez queda también más acentuada.

Por otro lado, un mineral puede encontrarse generalmente en cristales pequeños y en un lugar se hallarse en cristales grandes. Por ejemplo, la azurita es muy común en costras de grano fino en yacimientos de alteración de cobre de todo el mundo, pero los grandes cristales de azurita son raros y por eso (y por su gran belleza) son muy apreciados. Los ejemplos más conocidos de cristales de azurita de buena calidad están en Namíbia y Marruecos (Figura 73).

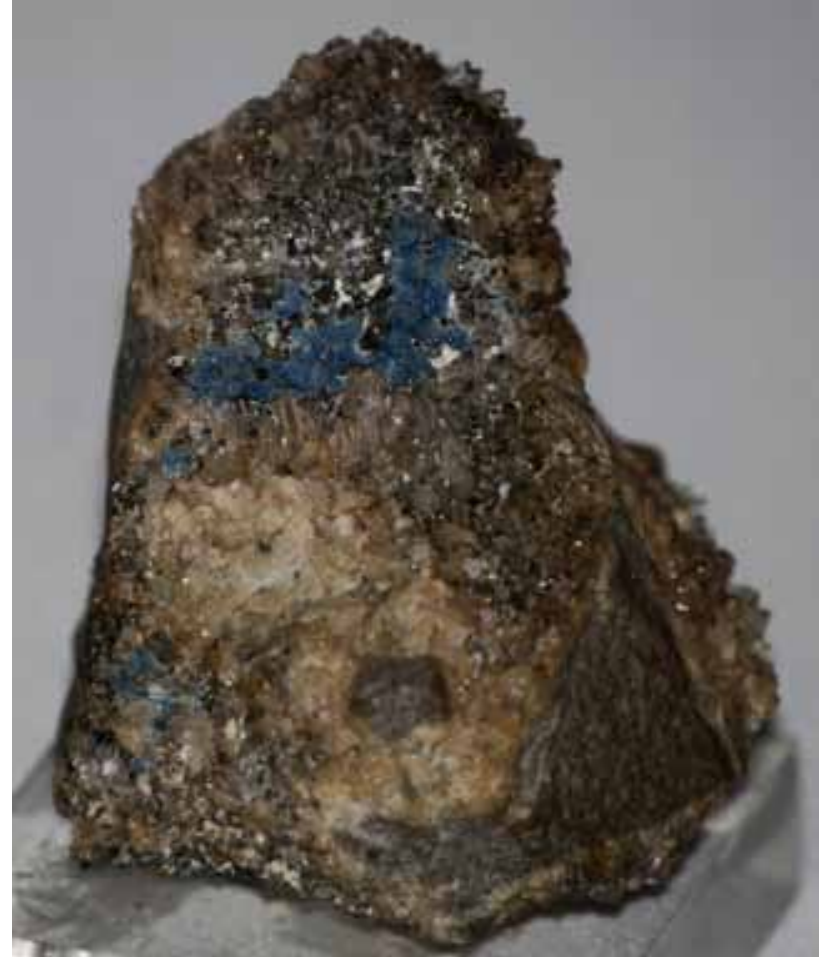

Figura 72. Un ejemplo de mineral raro: vauxita de Lallagua (Bolivia), en cristales azules implantados en cuarzo.
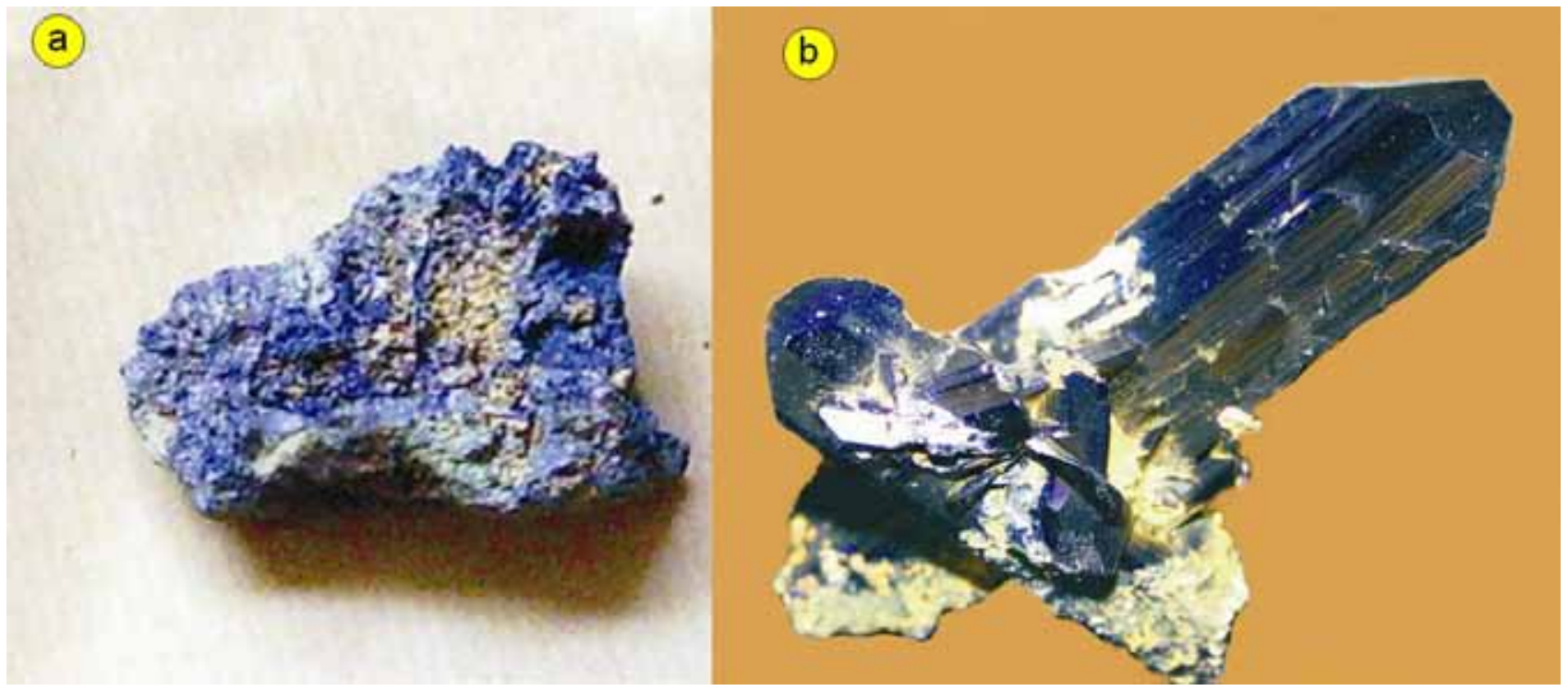

Figura 73. a) Costras de azurita microcristalina típica; b) cristales prismáticos muy bien definidos. Touisit, Marruecos

Otra posibilidad es que un mineral determinado, que generalmente presenta un color determinado, en un yacimiento se presente en un color excepcional. La diferencia de coloración puede deberse a que en este yacimiento haya uno o diversos elementos químicos que, añadidos excepcionalmente a la estructura del mineral, le den uno o varios colores anómalos. Uno de los mejores ejemplos lo proporcionan las coloraciones variadas de la smithsonita del Tsumeb (Namibia; Figura 74) en función de los elementos químicos acompañantes.

También puede presentar un interés adicional un mineral que generalmente cristaliza de una manera y que en un yacimiento concreto lo hace de otra (Figura 75). 


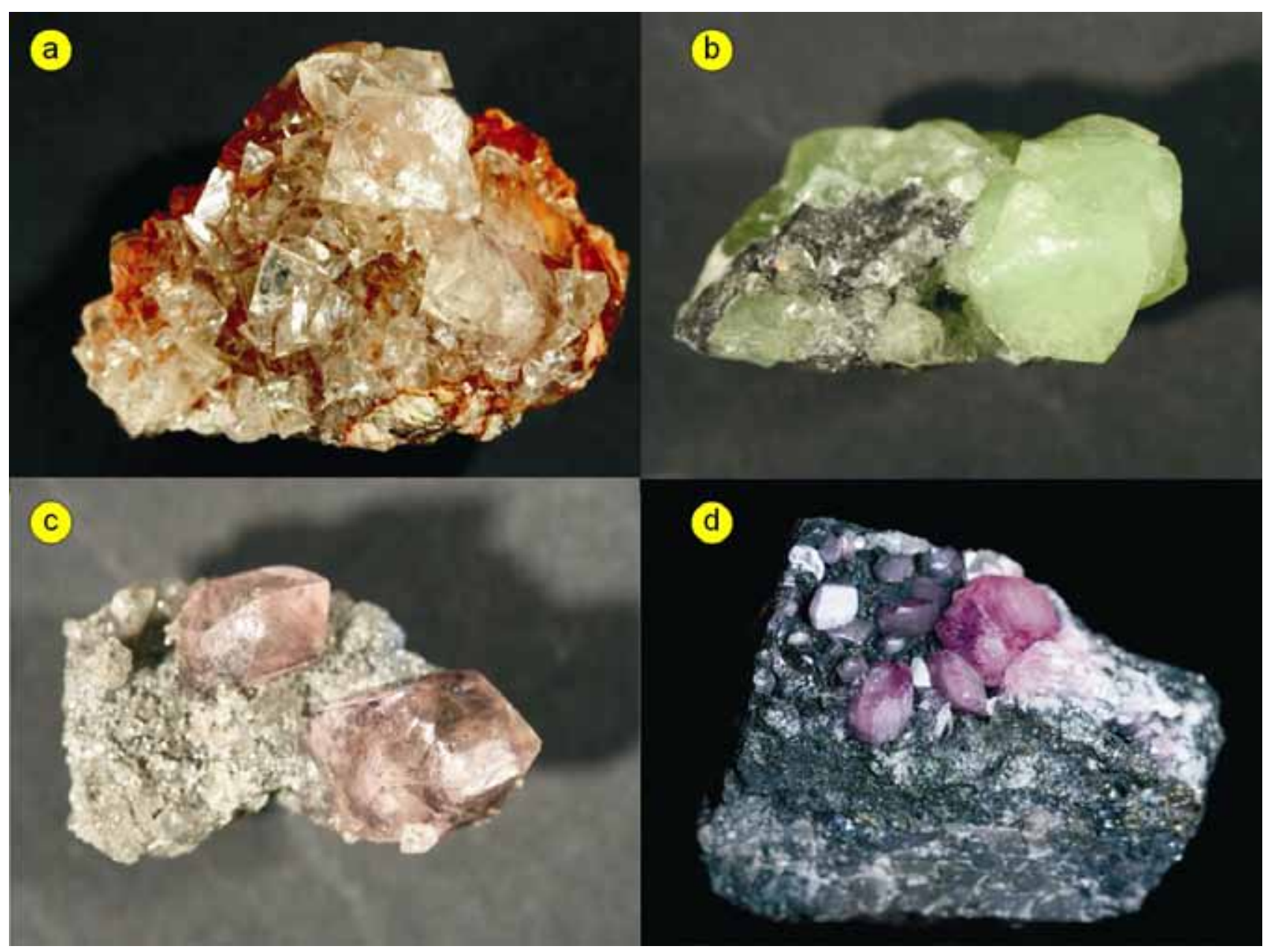

Figura 74. Variación de la coloración de la smithsonita en función de los elementos químicos anómalamente presentes en la estructura. a) Smithsonita pura (incolora); b) smithsonita verde rica en $\mathrm{Cu}$; c) y d) smithsonita rosa rica en cobalto. Tsumeb, Namibia.

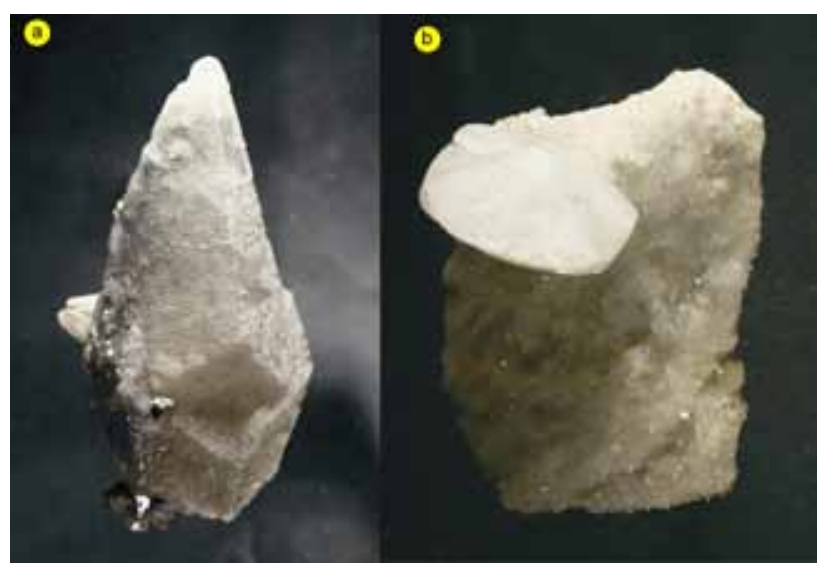

Figura 75. a) Cristales de calcita de aspecto escalenoédrico, muy comunes en todo el mundo; b) cristales de calcita de hábito lenticular, más raros.

Finalmente, en el caso de la gente que se dedica al coleccionismo por localidades, pueden ser interesantes las especies menos comunes en estos yacimientos, aunque sean muy comunes en otros yacimientos a nivel internacional.

\subsection{Estética de las piezas}

Aunque los aspectos intrínsecos de los minerales (color, forma, perfección de los cristales, etc.) son determinantes en la valoración de la muestra, la presencia que puede tener el conjunto de los agregados o el conjunto del mineral con su matriz también tiene un gran peso. De esta manera, pueden tener un atractivo especial aquellas formas de la roca de soporte que recuerden otras figuras naturales, como ahora paisajes, árboles, esculturas, etc. (Figura 76).

Por la misma razón estética, la presencia de elementos que rompan la regularidad de la muestra puede ayudar a mejorar la calidad del conjunto de la muestra (Figura 77).

La disposición de los cristales puede describir figuras geométricas que pueden recordar aspectos artificiales, como ahora letras, números, edificios, obres de arte, etc. (Figura 78 a 81).

\subsection{Visibilidad de los cristales}

En el caso que el interés de la muestra radique en la presencia de cristales de un mineral en concreto, la visibi- 


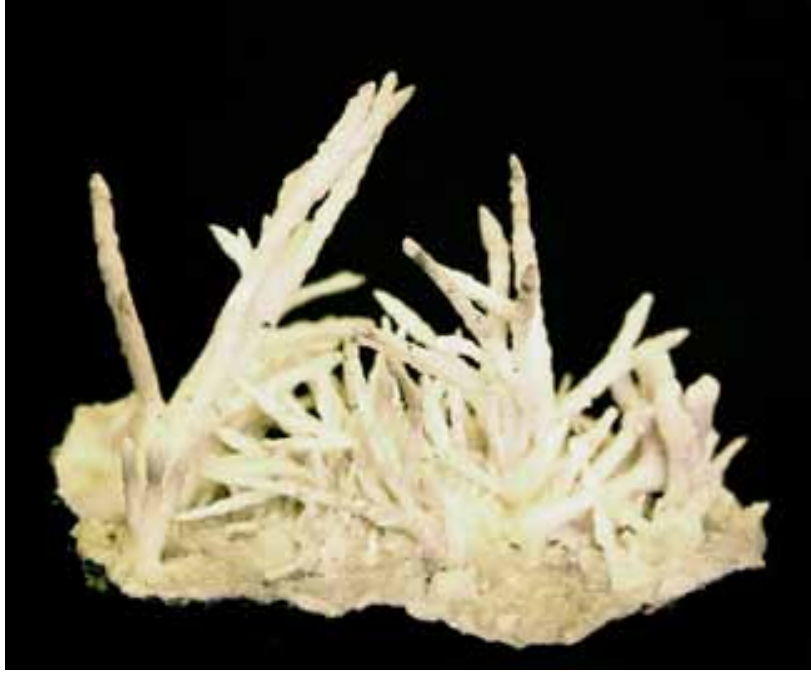

Figura 76. Aragonita de la variedad flos ferri, en agregados cristalinos de aspecto coralino. Laurion, Grecia.

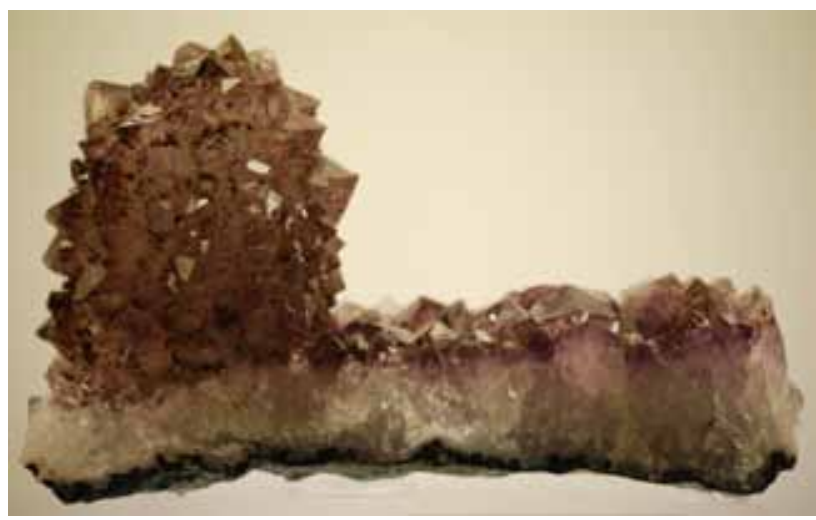

Figura 77. Curioso agregado de cristales de amatista con forma de piña que rompe la monotonía de una drusa plana del mismo mineral. Brasil

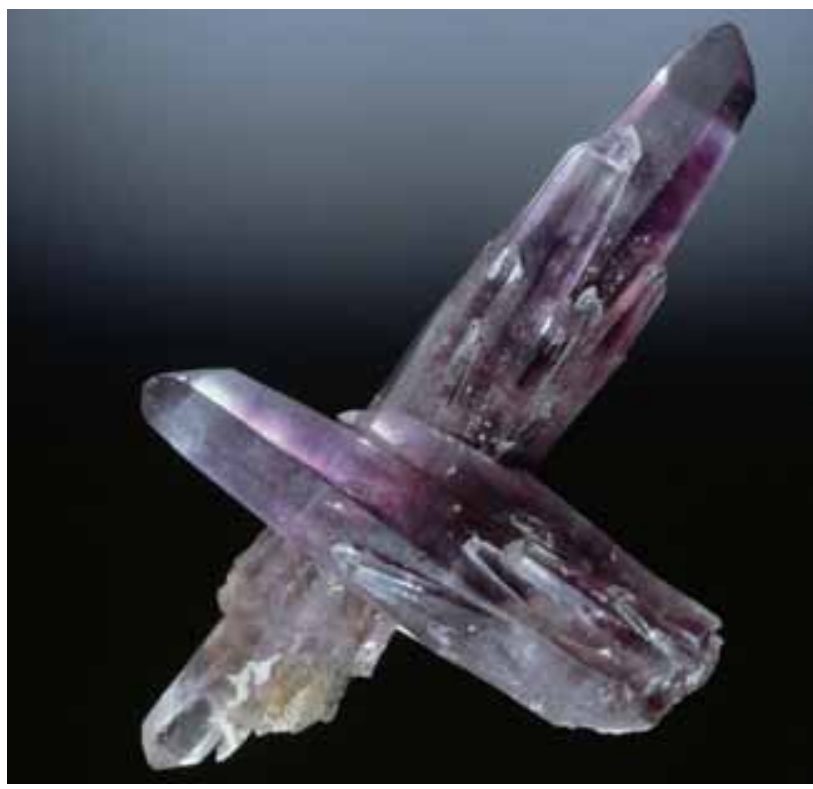

Figura 78. Cristales de amatista en forma de X, de muy buena estética, que permiten su contemplación desde muy diversas orientaciones.

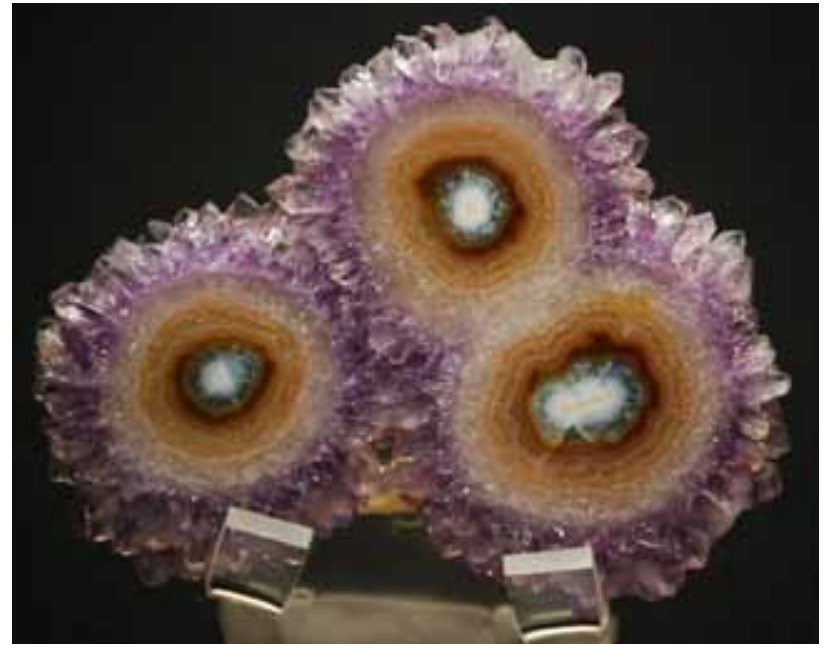

Figura 79. Cristales de cuarzo de la variedad amatista (de color morado) dispuestos de manera radial sobre crecimientos concéntricos de grano fino de cuarzo poco coloreado. Los crecimientos han estado coalescentes. La muestra ha estado serrada para mostrar la estructura interna. Brasil

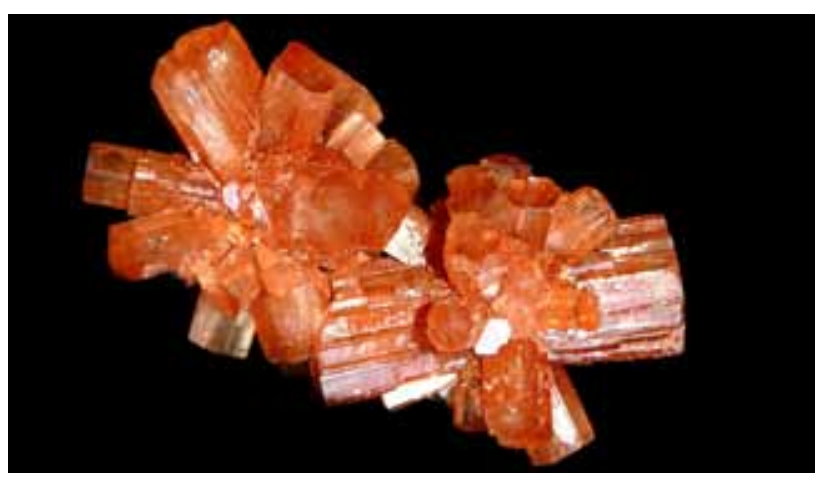

Figura 80 Aragonita en cristales columnares maclados, que forman agregados radiales en forma de piña. Como se puede apreciar, la muestra presenta la belleza de cada uno de los cristales se mire por el lado que se mire.

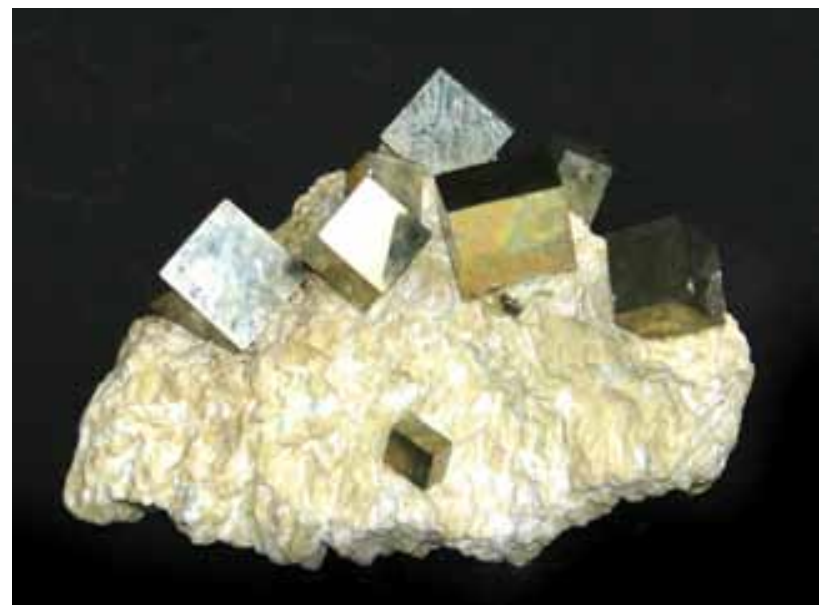

Figura 81. Pirita en cubos perfectos incluidos en matriz, de la que sobresalen casi totalmente; los cristales están orientados en muchas direcciones, garantizando variaciones de brillantez al girar la muestra. Navajún, La Rioja, España. 
lidad de estos cristales es un aspecto muy crítico a la hora de establecer el valor de la muestra.

En general, incluso más que el número de cristales en una muestra, es interesante que los cristales queden aislados y permitan ver en todo su esplendor el máximo número de caras cristalinas posible.

Hay diversos factores que pueden ayudar a que los cristales se vean mejor. En primer lugar, la visibilidad de los cristales depende en gran parte de su aislamiento respecto de otros cristales del mismo mineral. Cuanto más individualizados estén los cristales, mejor mostrarán sus caras y tendrán un carácter más aéreo (Figura 82).

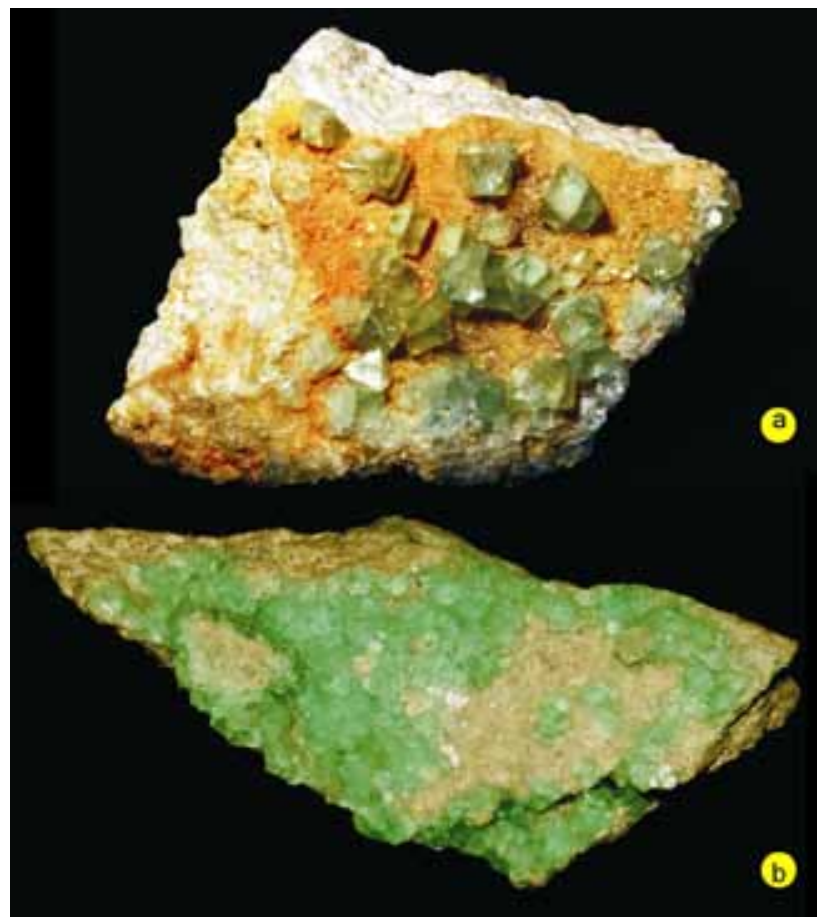

Figura 82. a) Cristales octaédricos de fluorita verde implantados sobre roca granítica. Esta muestra presenta los cristales aislados y facilita su contemplación b) ejemplar de fluorita de la misma localidad que aunque tiene un color más atractivo presenta los cristales menos definidos. El ejemplar "a" podría llegar a tener más valor presentando una coloración menos intensa. Cantera Berta, El Papiol, Cataluña.

Aunque los cristales no estén perfectamente aislados del resto, pueden haber cristales que tengan un tamaño mucho más grande que los de su alrededor $y$, en consecuencia, pueden llegar a tener una buena visibilidad (Figura 83).

En segundo lugar, si se cumple la condición anterior, la visibilidad de un cristal depende del tipo de matriz sobre la que crece. Si existe un fuerte contraste de color entre la matriz y los cristales, este factor ayuda a que los cristales destaquen mejor sobre la matriz y ayuda a mejorar el aspecto general de la pieza (Figuras 84,85 y 86 ).

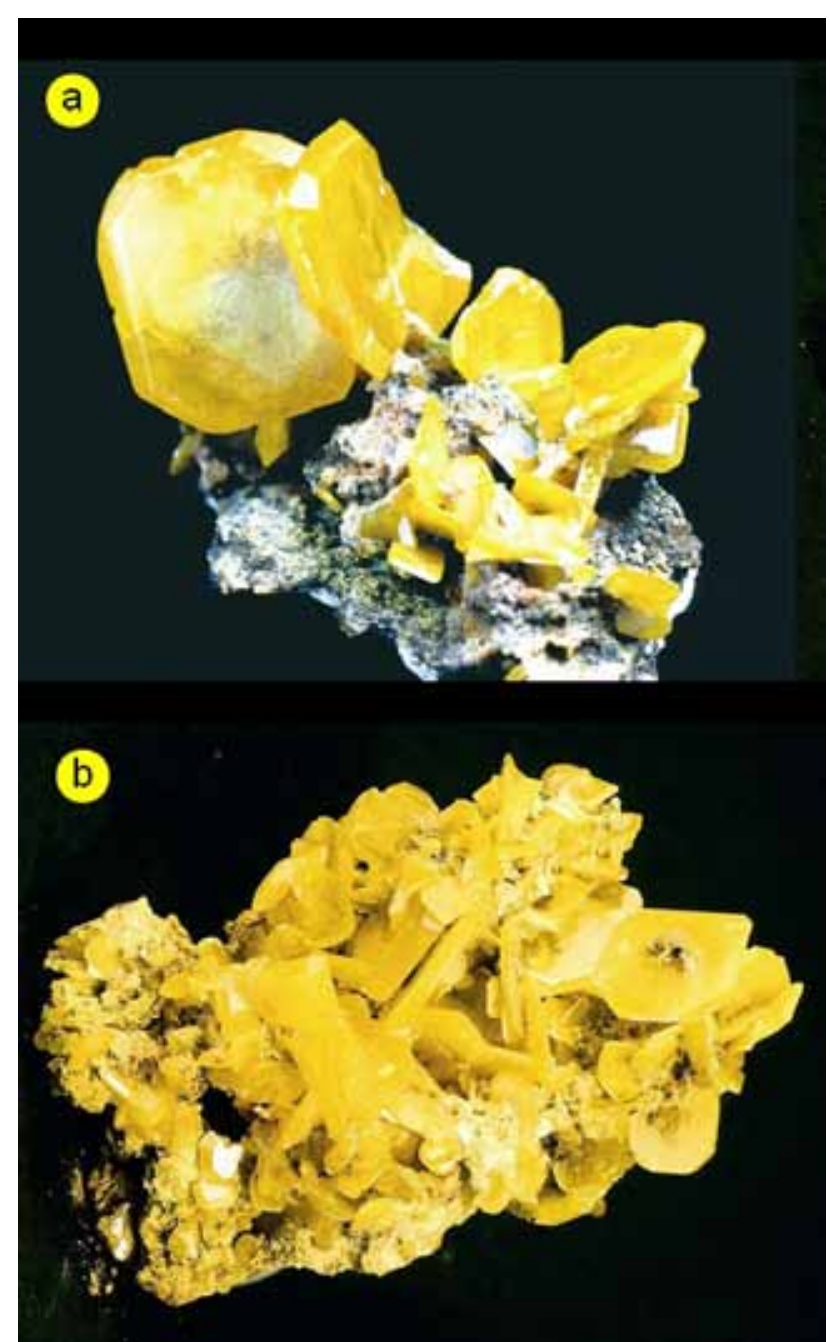

Figura 83. a) Muestra de wulfenita con los cristales bien aislados de manera que se puede ver la forma casi completa b) ejemplar de la misma localidad que presenta buen color pero cristales interpenetrados. La muestra "a" podría tener más valor.

\subsection{Dimensionalidad}

Aunque una superficie plana cargada de cristales puede tener su atractivo, la muestra puede ser más interesante si los cristales de la misma calidad se encuentran desarrollados sobre superficies muy irregulares, dando sensación de paisajes.

Las muestras más apreciadas serán siempre aquellas que puedan ser contempladas desde diferentes direcciones, especialmente si proporcionan al girarlas juegos de color, cambios de brillo espectaculares, o posibilidad de observar diferentes cristales en diferentes formas (Figura 87).

Las muestras deben tener proporciones adecuadas. No es lógico, por ejemplo, que haya un cristal pequeño en una muestra muy grande, aunque a veces la situación del cristal lo puede compensar (Figura 88). Un exceso de matriz puede reducir el valor estético de la muestra. Se tiene que procurar, por tanto, tener el máximo de superficie de la pieza ocupada por el mineral deseado. 


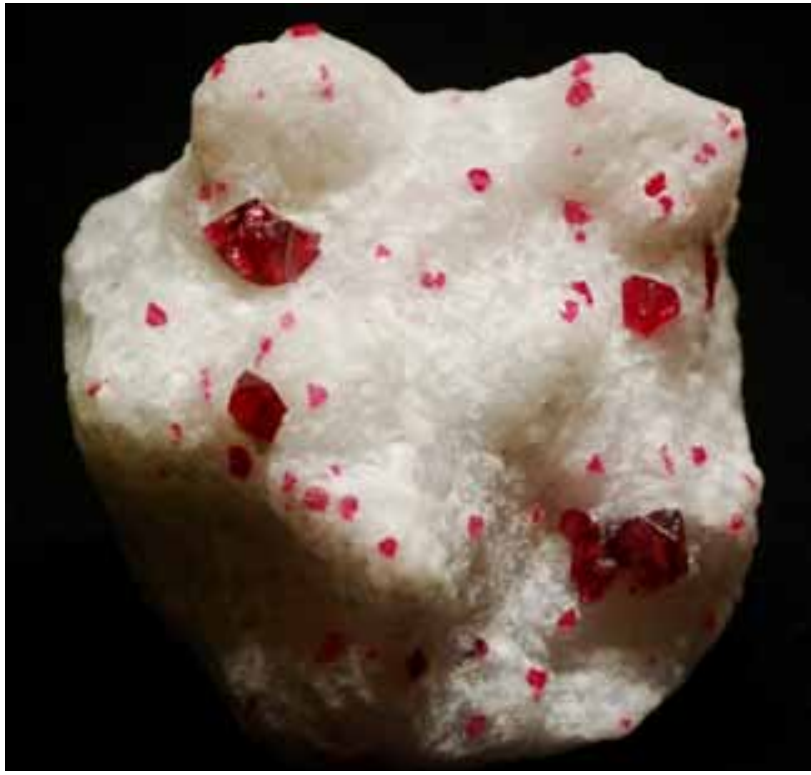

Figura 84. Cristales octaédricos de espinela (rojo) que destacan nítidamente al estar incluidos dentro de una matriz de calcita blanca. Vietnam.

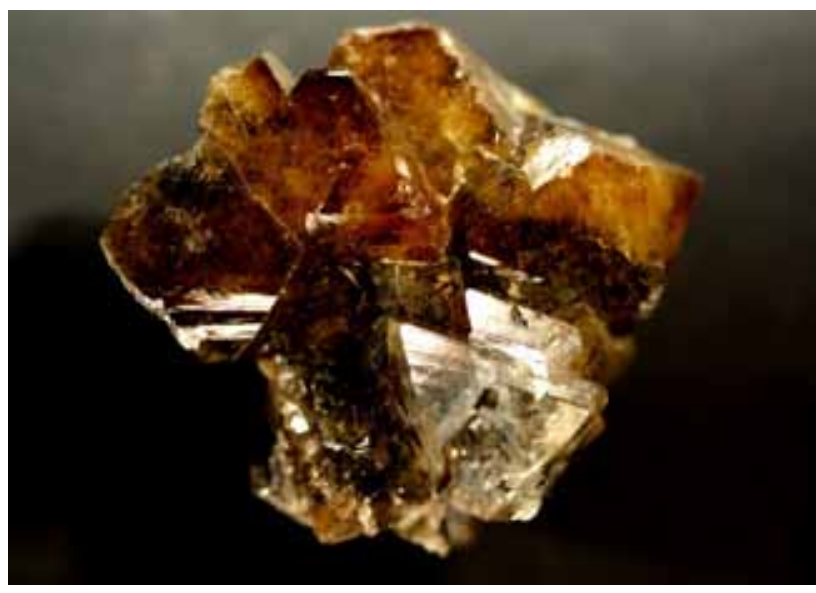

Figura 85. Agregado de cristales de scheelita. En este caso, la forma del agregado no deja apreciar bien la forma de los cristales. La muestra procede de la Mina Tae Wha, Corea del Sur.

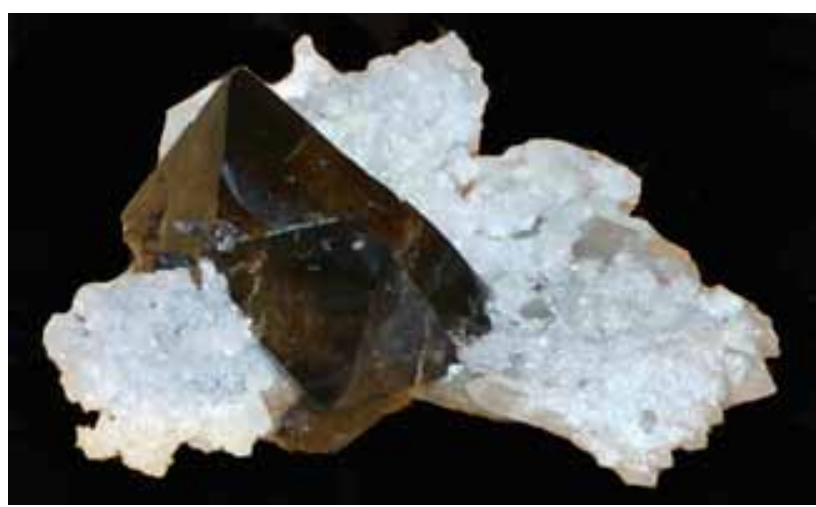

Figura 86. Cristal de scheelita procedente de la mina Yaogangxian, Hunan, China, sobre cuarzo. En este caso, los cristales de scheelita son mucho más visibles que en la Figura 85 y la matriz de cuarzo le da un buen contraste. Esta muestra podría ser más valorada que la anterior.

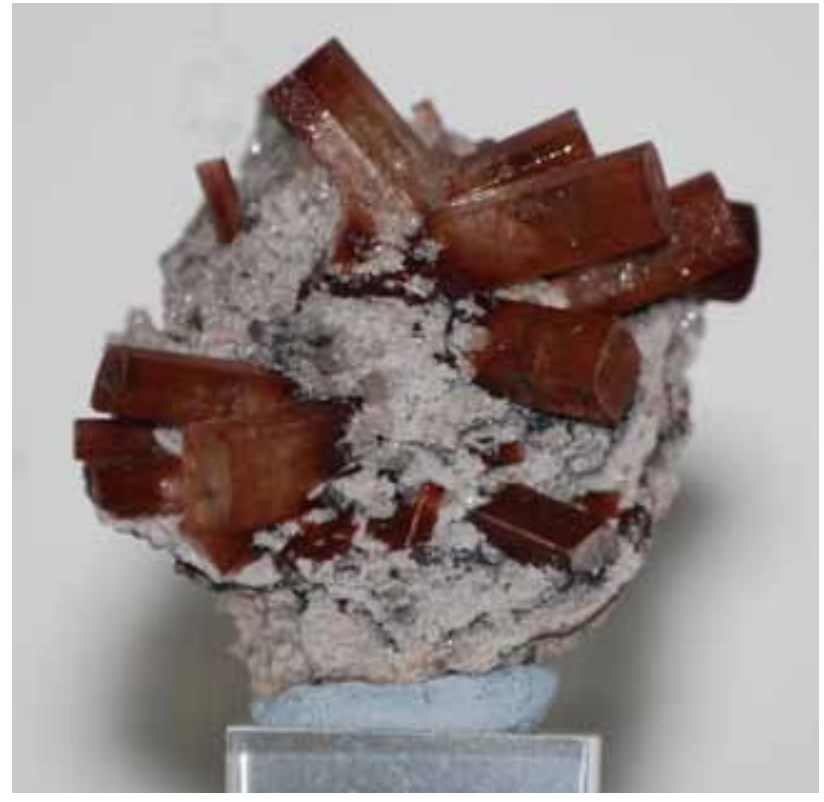

Figura 87. Cristales rojizos de topacio, orientados en diferentes direcciones y bien distribuidos en la muestra sobre una matriz clara. Tepetate, San Luis Potosí, México.

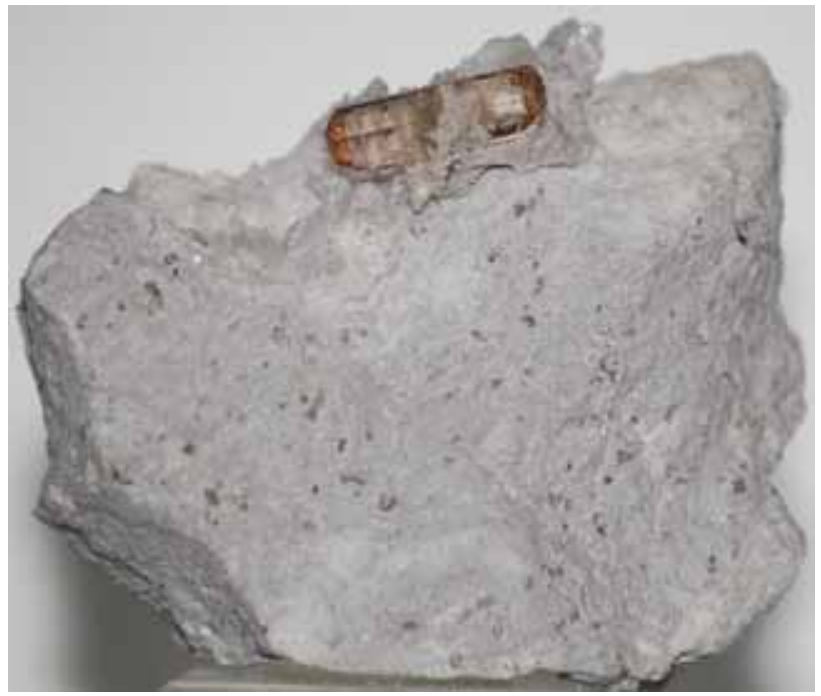

Figura 88. Cristales de topacio de color ámbar sobre una matriz clara, de buena calidad. Aunque hay una baja proporción de cristal/muestra, se compensa por la buena posición del cristal.

También puede ser interesante que la muestra se pueda colocar adecuadamente sobre un soporte y que pueda tener al menos una posición en que exhiba al máximo su belleza.

\subsection{Otros criterios}

Algunas propiedades físicas mejoran la valorización de la pieza.

Fluorescencia. Algunos minerales emiten luz visible de vivos colores cuando son iluminados, a oscuras, con 
una lámpara de luz ultravioleta. En el mercado hay lámparas a precios reducidos, portátiles y que funcionan con pilas. Algunos minerales exhiben bellísimos colores bajo la luz ultravioleta (Figura 89).

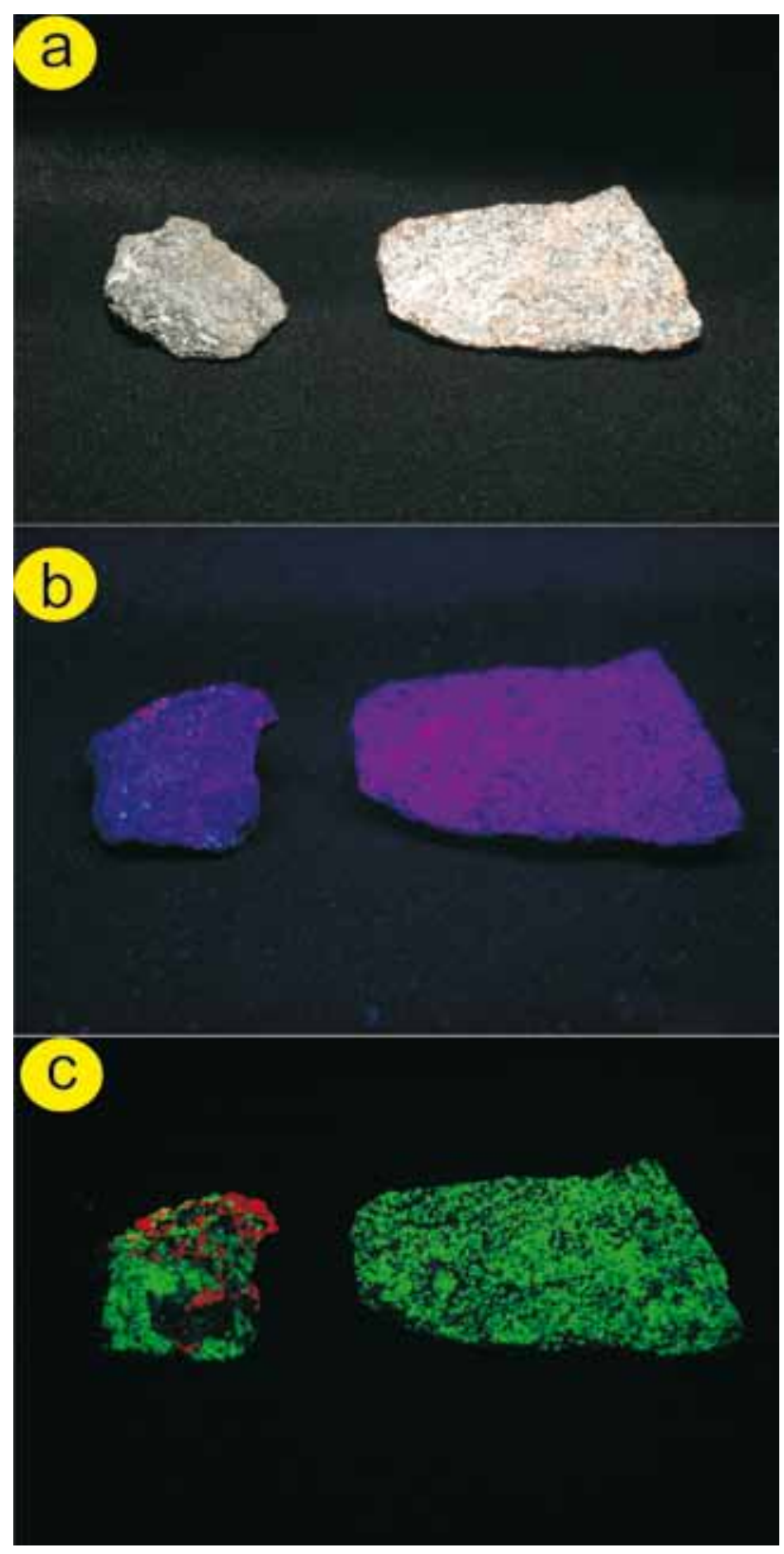

Figura 89. Agregado de cristales de franklinita, zincita y wilemita de Franklin, Nueva York (EUA). a) Con luz natural; b) con luz ultravioleta de longitud de onda corta; c) con luz ultravioleta de longitud de onda larga.

Se usan dos radiaciones ultravioletas, de longitud de onda corta y de onda larga. Algunos minerales fluorescentes presentan colores o intensidades de fluorescencia variada cuando son excitados por cada una de estas radiaciones, o bien sólo lo son por una de ellas.
Fosforescencia. Es la propiedad que tienen algunos minerales de continuar emitiendo fluorescencia durante un cierto tiempo una vez se ha apagado la lámpara ultravioleta que la emitía. Son ejemplo de este fenómeno algunos cristales de calcita o de yeso de algunas localidades.

Radioactividad. Algunos minerales que contienen elementos radioactivos emiten, por desintegración, partículas radioactivas. Esta propiedad puede ser detectada con un escintilómetro o contador Geiger (Figura 90). Por un lado, este aspecto despierta el interés de los aficionados especializados. Por otro lado, muchos de estos minerales son raros y de gran belleza y colorido. Con todo, se debe tener en cuenta que la radioactividad es una propiedad peligrosa que puede generar cáncer. Por tanto, estos minerales se deben tener aislados en lugares bien ventilados, en pequeñas cantidades y siempre lo más alejado posible de las personas. Cabe destacar que en algunos países hay restricciones muy severas para el tráfico de minerales de estas características.

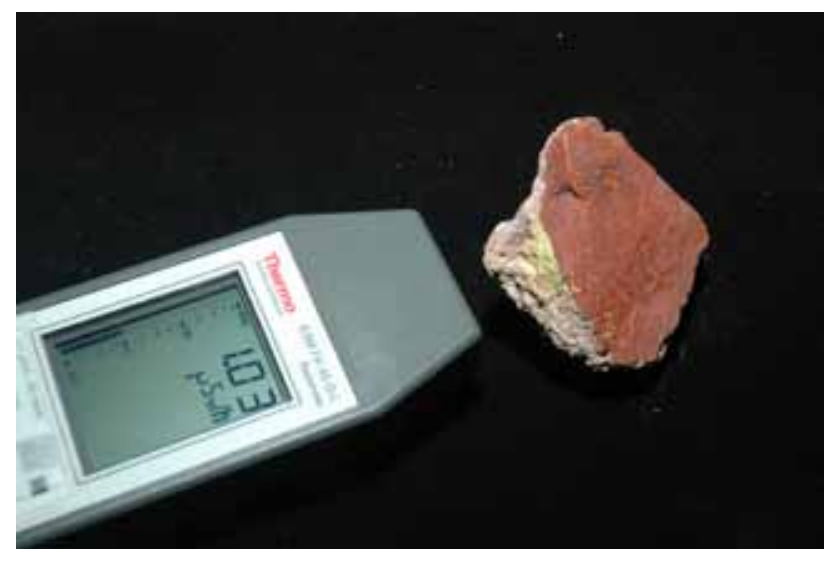

Figura 90. Radioactividad de una muestra de autunita (cristales amarillos) medida con la ayuda de un escintilómetro.

Magnetismo. La magnetita de algunas localidades es capaz de crear un campo magnético de suficiente fuerza como para atraer los objetos metálicos (piedra imán, Figura 91). Aún así, no todas las muestras de magnetita la tienen, y mucho menos aún otros minerales con un cierto magnetismo. De hecho, el magnetismo muchas veces sólo se manifiesta como la propiedad del mineral de orientarse bajo un campo magnético creado por un imán. Las muestras de magnetita más magnéticas son muy preciadas.

Pseudomorfismo. Un mineral puede haber sido reemplazado por otro que lo sustituye conservando la forma primitiva (Figuras 92 y 93). Esto es debido a que el mineral precursor, que se formó en unas condiciones determinadas, ha quedado fuera de su dominio de estabilidad y dentro del dominio de estabilidad del segundo mineral. Ciertos pseudomorfismos son muy preciados por los coleccionistas.

Fosilización. El material constitutivo de los restos de antiguos organismos vivos puede haber sido substituido 


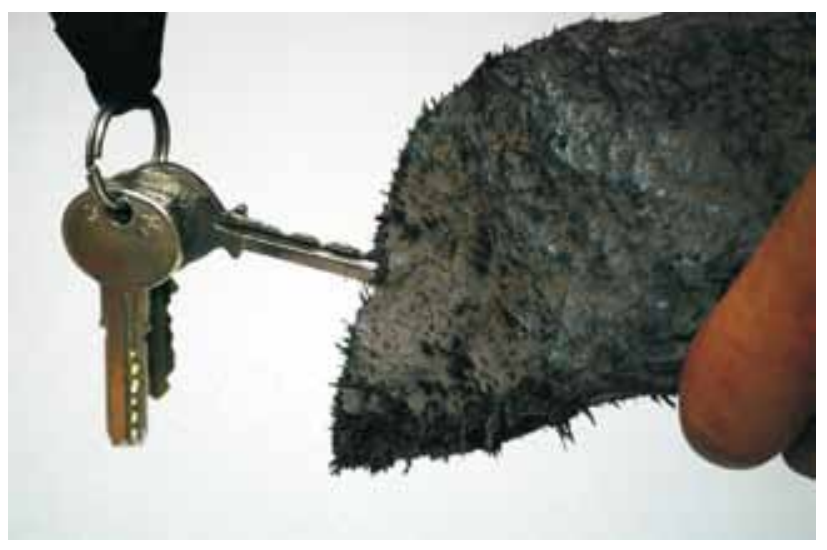

Figura 91. Agregado macizo de magnetita altamente magnética, que atrae objetos de hierro y polvo del mismo mineral. Kimzey Magnetite Mine, Magnet Cove, Hot Spring Co., Arkansas, E.U.A.

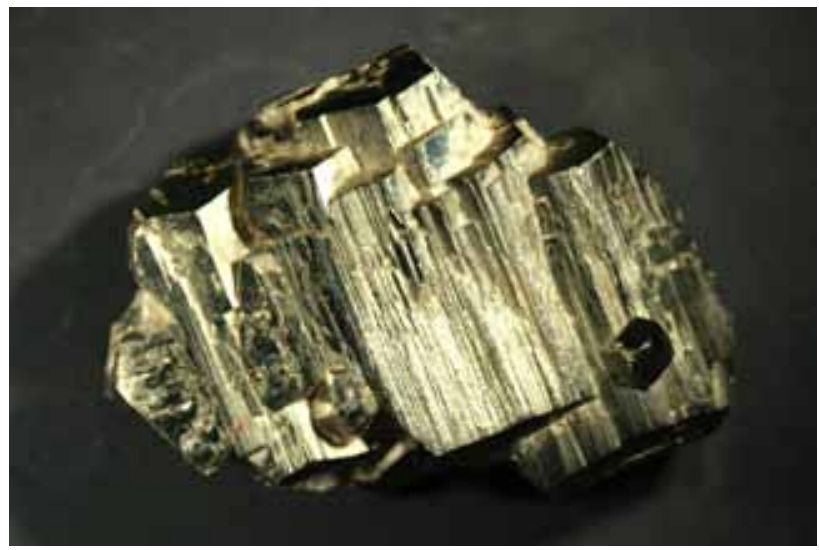

Figura 92. Cristales cúbicos de pirita, con brillo metálico y color latón.

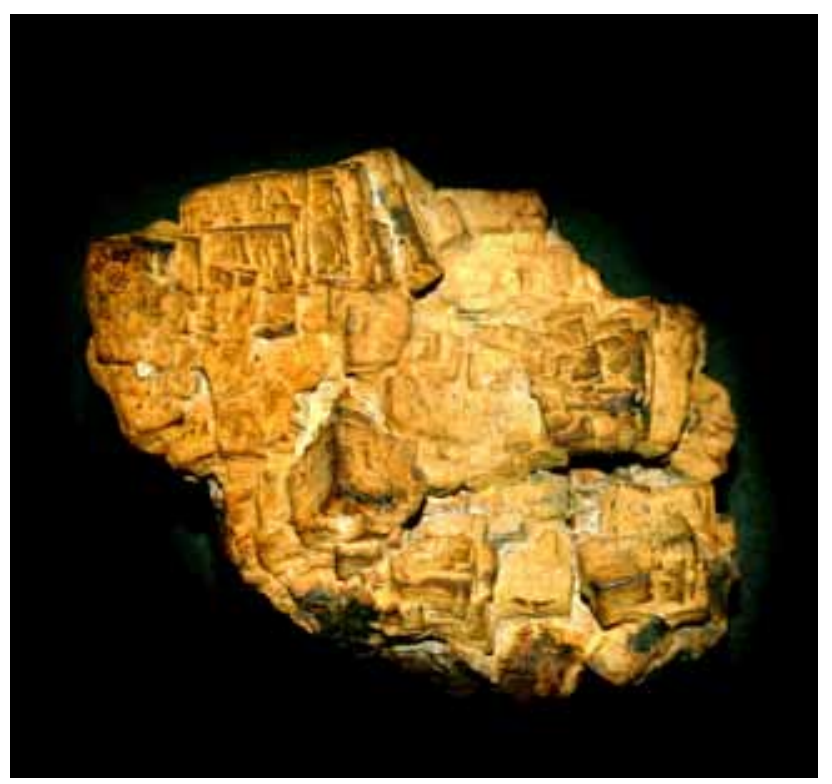

Figura 93. Cristales de pirita pseudomorfizados por agregados polvorientos de goethita, con brillo mate y color ocre. Montjuïc, Barcelona. por minerales de nueva formación, preservando su forma (Figura 94) como parte de los procesos de fosilización. Además de los carbonatos, algunos minerales que a menudo fosilizan organismos son el apatito, la turquesa, la pirita, la celestina, la barita, la goethita y el cuarzo y sus variedades, como la calcedonia y el ópalo.

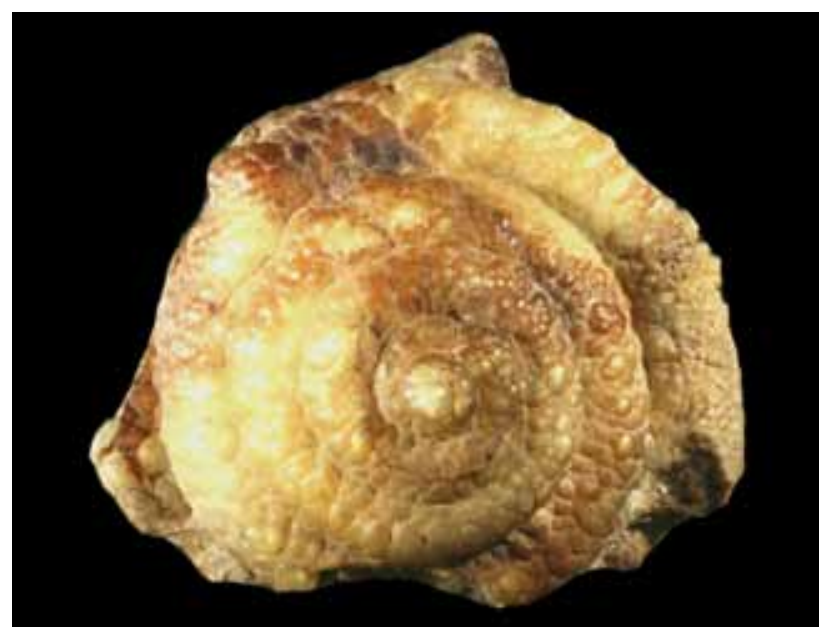

Figura 94. Agregados botrioidales de calcedonia fosilizando un gasterópodo.

\section{Pasos previos a la venta de las piezas}

\subsection{Los micromontajes}

Los micromontajes (micromounts) son muestras en las que el mineral interesante, de muy reducido tamaño, está montado sobre un soporte, de tal manera que queda orientado para favorecer su examen con una lupa o un microscopio binocular de gran aumento (Figura 95).

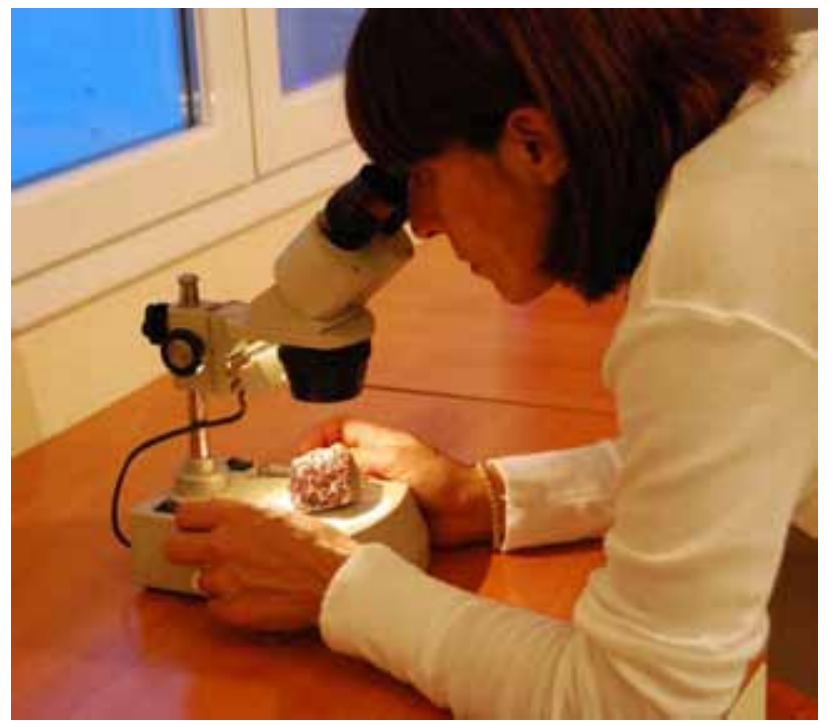

Figura 95. Examen de muestras con cristales de tamaño reducido con lupa binocular. 
Generalmente se trata de cristales muy pequeños pero muy perfectos (Figuras 96 a 103). De hecho, los cristales más perfectos acostumbran a ser los de tamaño más reducido. Disponer de una buena lupa o de un buen microscopio hace que el coleccionista de minerales pueda descubrir en cada muestra rincones de una gran belleza visual.

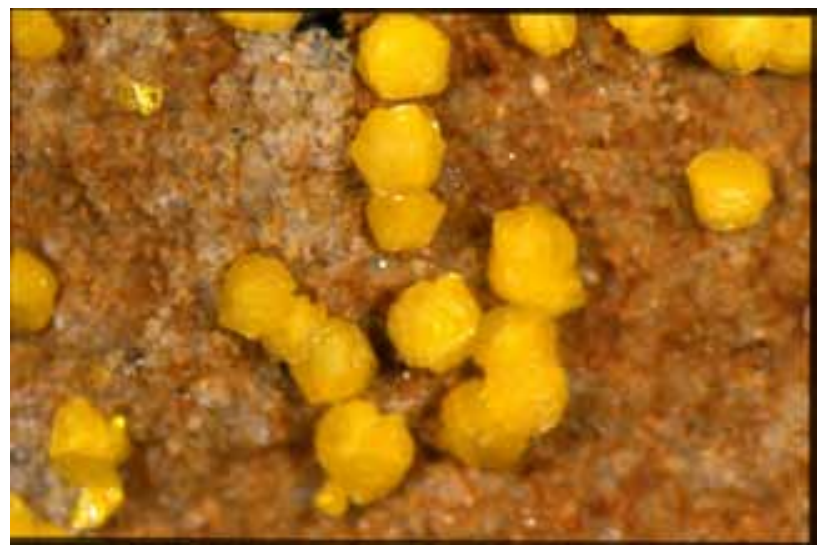

Figura 96. Agregados de cristales de carnotita de color amarillo fotografiados con una lupa binocular. Anchura real de la imagen: $1 \mathrm{~cm}$. E.U.A.

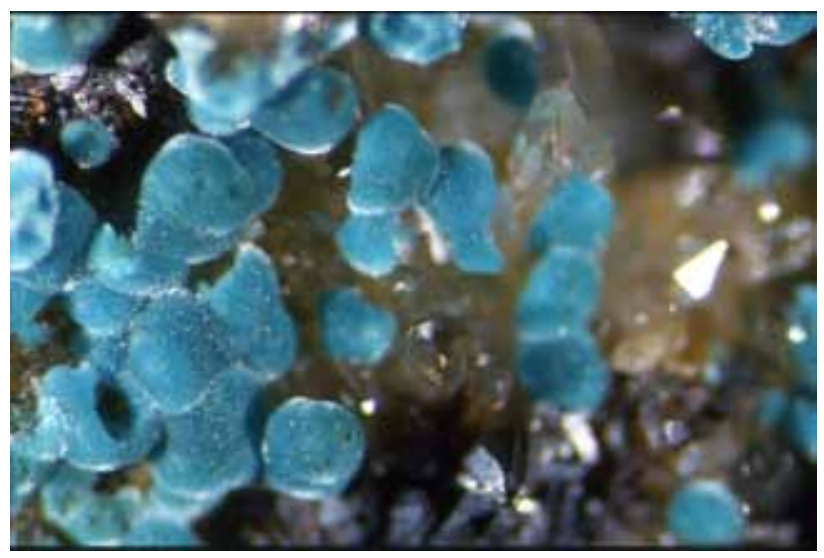

Figura 97. Micromontaje de agregados botroidales de auricalcita de color azul, fotografiados con lupa binocular. Anchura real de la imagen, $1 \mathrm{~cm}$. Cantera Berta, El Papiol, Cataluña.

El precio de un micromontaje varia desde menos de un euro en los casos de minerales más comunes a algunos centenares de euros en el caso de los minerales más raros. Algunos minerales raros sólo aparecen en forma de cristales muy pequeños, por lo que casi siempre se comercializan como micromontajes.

Naturalmente, hacer un micromontaje requiere tiempo y habilidad manual por parte del vendedor y por eso como mínimo debe haber una parte de coste del mineral que cubra el trabajo de quien fabrica el micromontaje.

Por otro lado, se trata de minerales que precisan a menudo un alto conocimiento de la Mineralogía y un buen equipo para su identificación.

Aún con estas dificultades, los micromontajes pueden

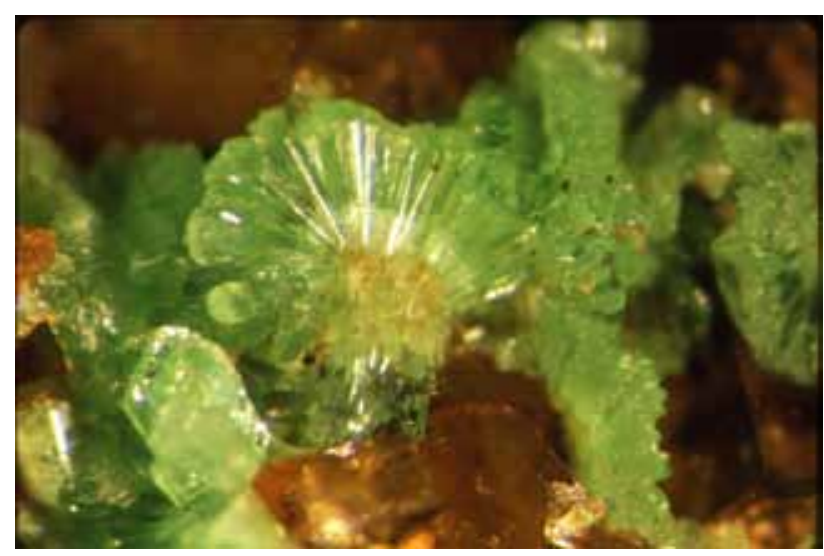

Figura 98. Micromontaje de agregados radiales de annabergita (verde) fotografiados con lupa binocular. Anchura real de la imagen, $1 \mathrm{~cm}$. Mina Atrevida, Vimbodí, Conca de Barberà, Cataluña.

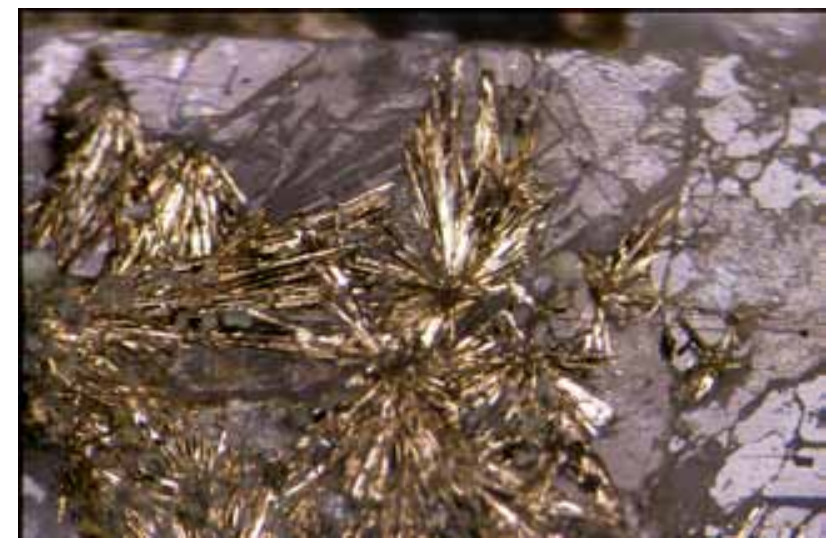

Figura 99. Micromontaje de agregados radiales de millerita de color dorado, fotografiados con lupa binocular. Anchura real de la imagen, $1 \mathrm{~cm}$. Mina Eugènia, Bellmunt del Priorat, El Priorat, Cataluña.

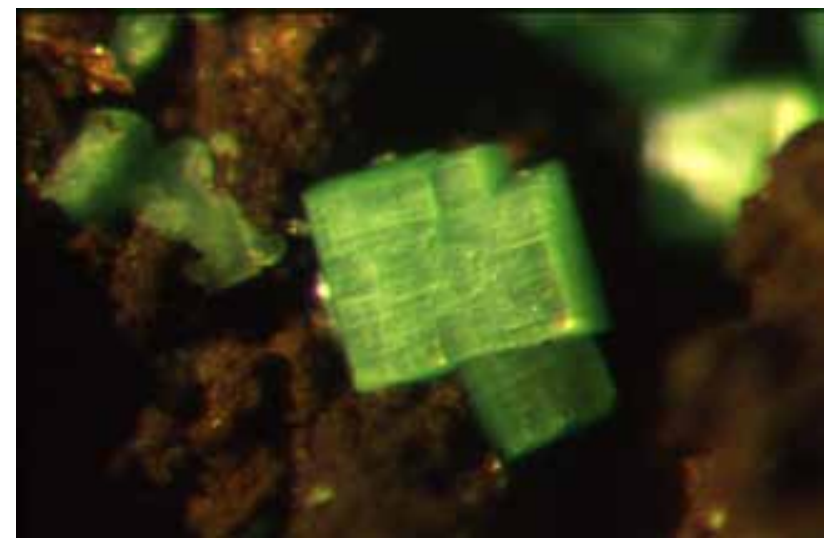

Figura 100. Micromontaje de cristales tabulares de torbernita de color verde fotografiados con lupa binocular. Anchura real de la imagen, $1 \mathrm{~cm}$. Andújar, Jaén, España.

ser un recurso importante especialmente en aquellos casos en que hay una minería operativa. Con un poco de capacidad de observación, cualquier minero puede localizar 


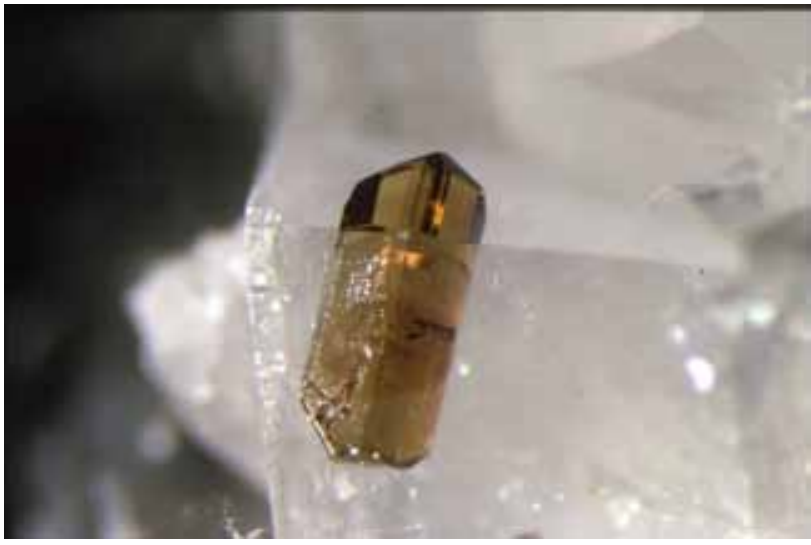

Figura 101. Micromontaje con un cristal de allanita de color miel dentro de dolomita incolora fotografiado con lupa binocular. Anchura real de la imagen, $1 \mathrm{~cm}$. Mina de talco de Luzenac, Francia.

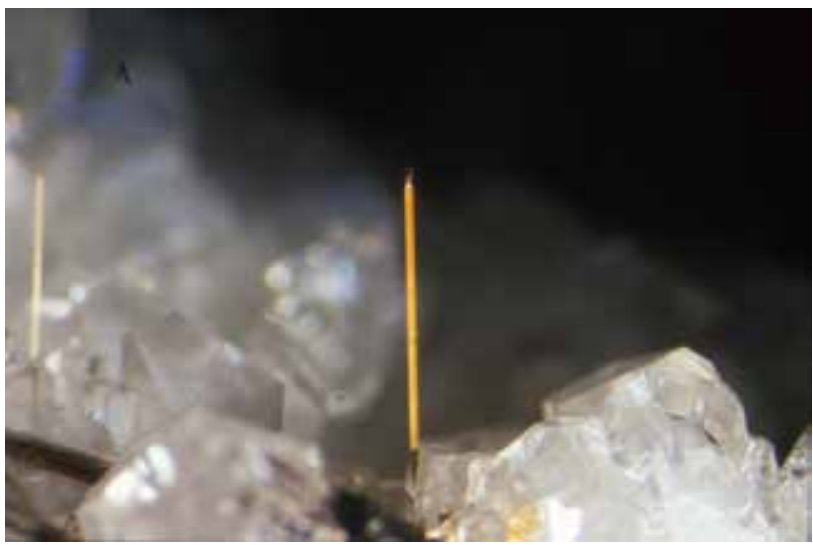

Figura 102. Micromontaje de un cristal acicular de rutilo de color amarillo, implantado sobre cristales incoloros de dolomita, fotografiado con lupa binocular. Anchura real de la imagen, $1 \mathrm{~cm}$. Mina de talco de Luzenac, Francia.

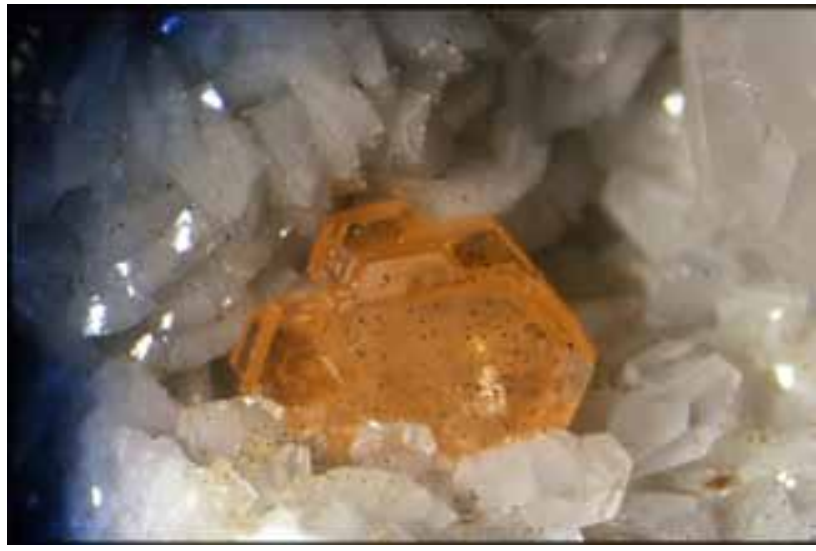

Figura 103. Micromontaje con cristales tabulares de bastnäsita implantados en una geoda de cristales de dolomita blanca, fotografiados con una lupa binocular. Anchura real de la imagen, $1 \mathrm{~cm}$. Mina de talco de Luzenac, Francia. este tipo de minerales. En localidades que tienen muchos minerales aptos para micromontajes, se pueden vender las piezas a peso a los compradores. En este caso, el precio unitario de las piezas sería obviamente más bajo.

Los minerales de micromontaje son muy delicados y, por tanto, se acostumbran a vender en pequeñas cajitas de plástico, protegidos de los golpes.

\subsection{Extracción}

En un yacimiento determinado las piezas de mejor calidad son las que se recogen directamente del interior de masas rocosas, donde las piezas están protegidas de los agentes atmosféricos.

Si las rocas son de baja dureza (e. g., arcilla, yeso) se pueden extraer los minerales con precaución, limpiando con paciencia los alrededores con un cuchillo (Figura 104, 105).

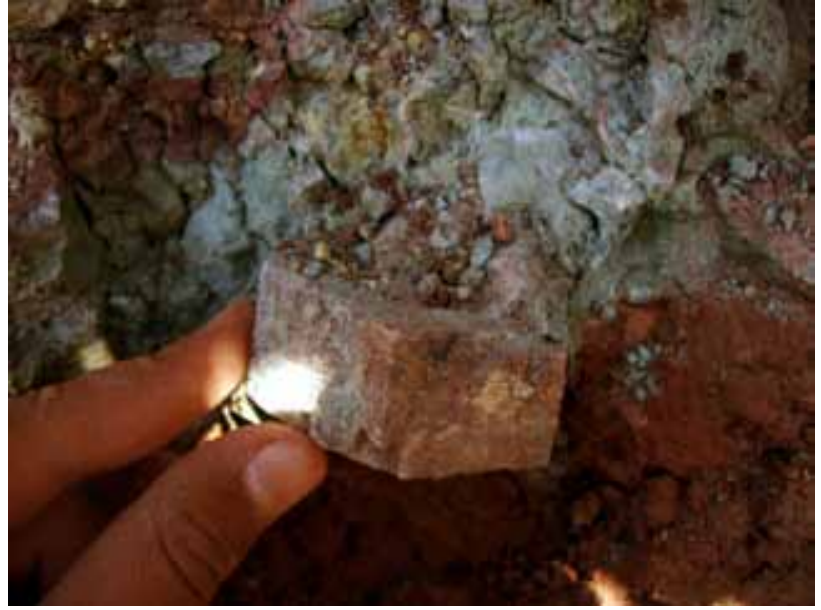

Figura 104. Extracción manual de aragonita cristalizada dentro de arcillas muy blandas. Villora, Cuenca, España.

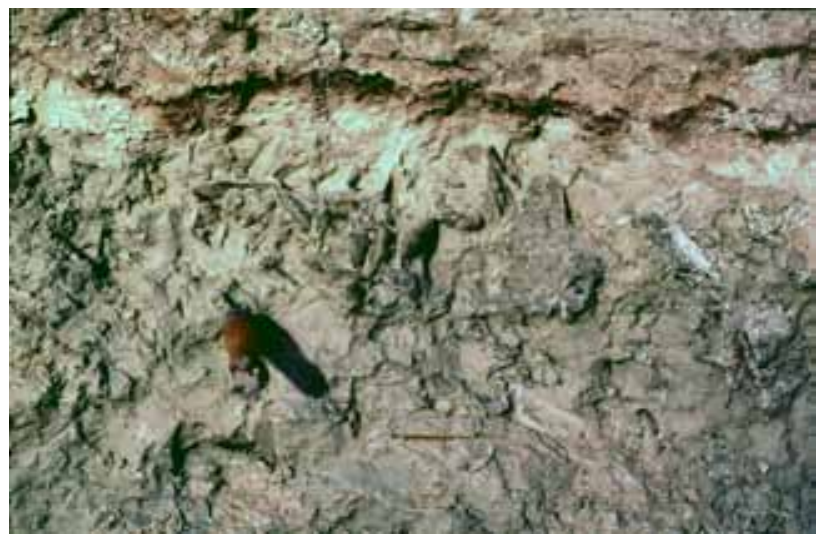

Figura 105. Extracción de cristales lenticulares de yeso del interior de margas grises con ayuda de un cuchillo. Bujaraloz, Zaragoza, España. 
Si las rocas son de alta dureza, probablemente para extraer las piezas se necesitarán martillos de diferentes tamaños y la ayuda de escarpas (Figuras 106 a 108).

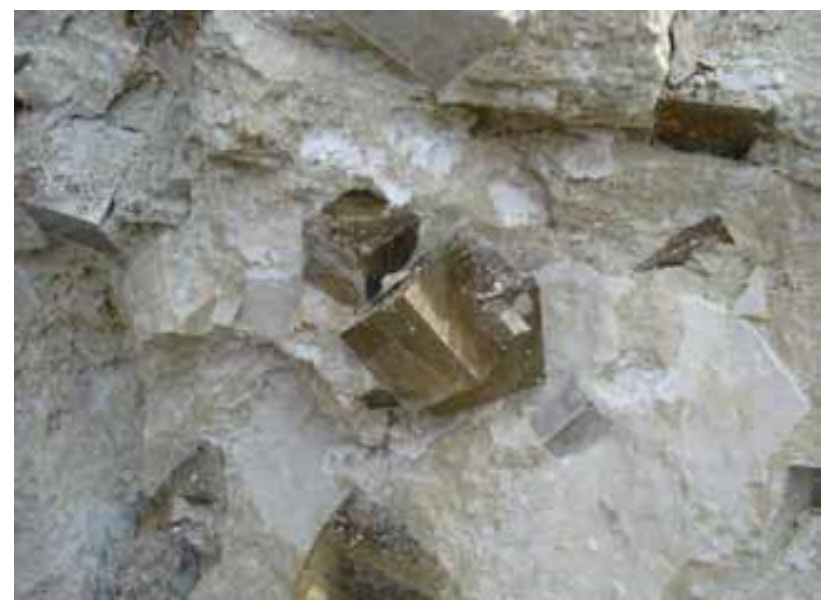

Figura 106. Cristales de pirita tal como aparecen en la mina dentro de una matriz dura. Minas de Navajún, la Rioja, España.

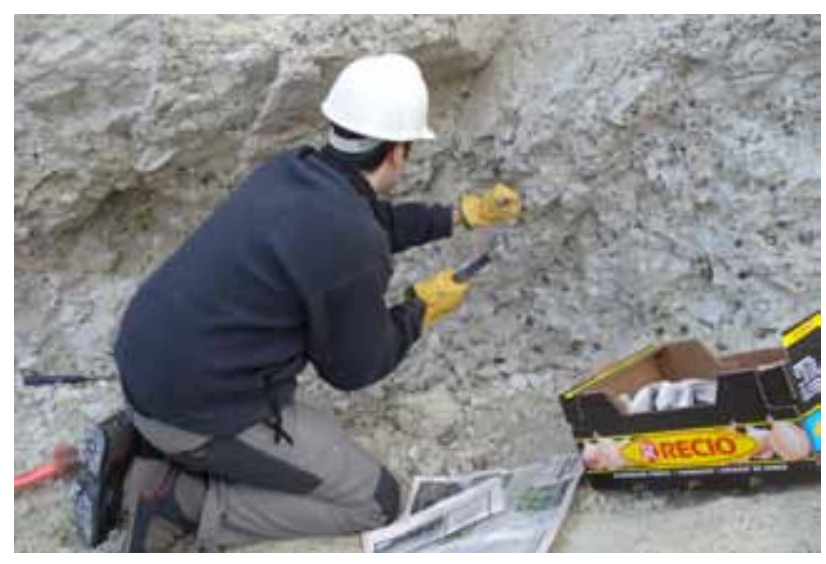

Figura 107. Extracción de los cristales de pirita de la imagen anterior con ayuda de escarpa y martillo.

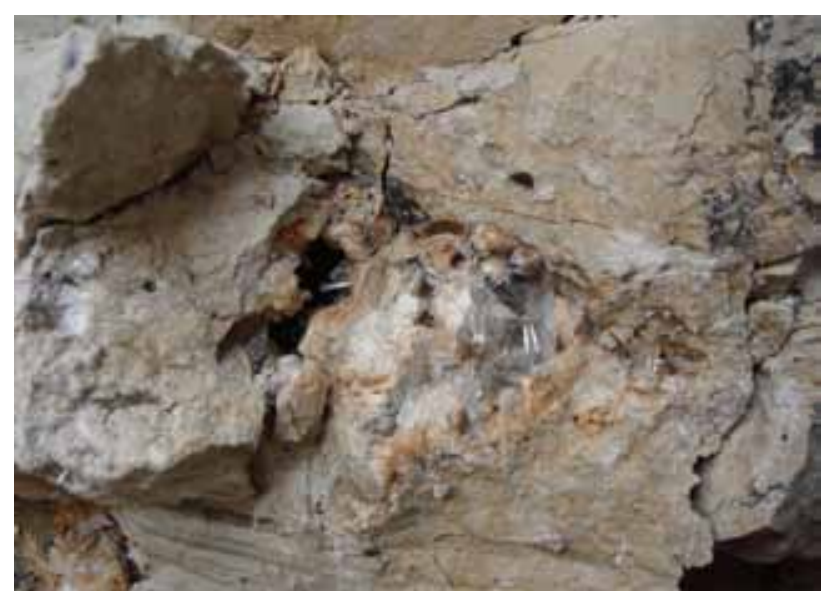

Figura 108. Extracción de geodas de celestina en roca caliza dura cerca de Torà, Cataluña. En este caso, se pueden aprovechar para la extracción las fracturas de la roca, introduciendo con mucha cura cuñas o escarpas.
En el caso de rocas muy duras y de grandes dimensiones, pero fisuradas, las arcillas expansivas pueden ser de gran ayuda. Se trata de arcillas que se expanden al absorber agua. Estas arcillas se reconocen en el campo, pues son las constituyentes de barros con un aspecto muy agrietado e hinchado. Estas pueden introducirse secas dentro de las grietas; a continuación se añade agua abundante a estas arcillas, que la absorberán y, expandiéndose poco a poco, romperán la roca. La extracción con explosivos es una equivocación, porque en este caso los cristales más delicados se rompen casi sin excepción, o quedan fracturados. Ello, además de conllevar una pérdida total del material vendible, implica una drástica reducción del valor del material restante.

El momento de la extracción es el más difícil y delicado y en ello interviene no tanto la suerte como la habilidad y la tenacidad del extractor. La extracción de este tipo de piezas se asemeja al trabajo de un escultor. Se debe tener muy claro que la extracción de una buena pieza puede ser un trabajo de muchas horas y que todas ellas se perderán si el ejemplar que se extrae al final queda dañado por fracturas o golpes. Si se encuentra una drusa o geoda en la que haya cristales frágiles, se debe proceder con sumo cuidado para que en el momento de la extracción los cristales no golpeen con la pared opuesta y se rompan. Se pueden evitar daños depositando barro (sin arena) sobre las caras de los cristales.

\subsection{Transporte al almacén}

Cada vez que movemos las muestras de lugar se corre el riesgo de dañarlas. Los golpes secos que pueden darse unas contra otras pueden llegar a estropearlas irremediablemente. Por tanto, es importante que, en previsión de que se puedan encontrar cristales, en el mismo lugar de extracción se disponga de elementos para proteger cada espécimen (e. g., papel, hierba, hojas caídas, barro). Las muestras deben estar convenientemente envueltas. Para su transporte es muy recomendable el uso de cajitas, a ser posible sin apilarlas y dejando un cojín de papel entre cada muestra que amortigüe sus movimientos (Figura 109). Se pueden utilizar cajas recicladas de las que se usan en el comercio; son muy prácticas, por ejemplo, las cajas de fruta.

\subsection{Reducción de las piezas}

Muy a menudo, la zona en que se encuentran los minerales de interés es pequeña, en cuyo caso será interesante reducir el tamaño de las piezas, eliminando las partes que no sean de interés. A veces, también una muestra excesivamente grande puede ser más estética y venderse a mejor precio si se parte estratégicamente en dos partes más pequeñas. Naturalmente, este proceso se llevará a cabo siempre que no conlleve el riesgo de dañar las piezas. 


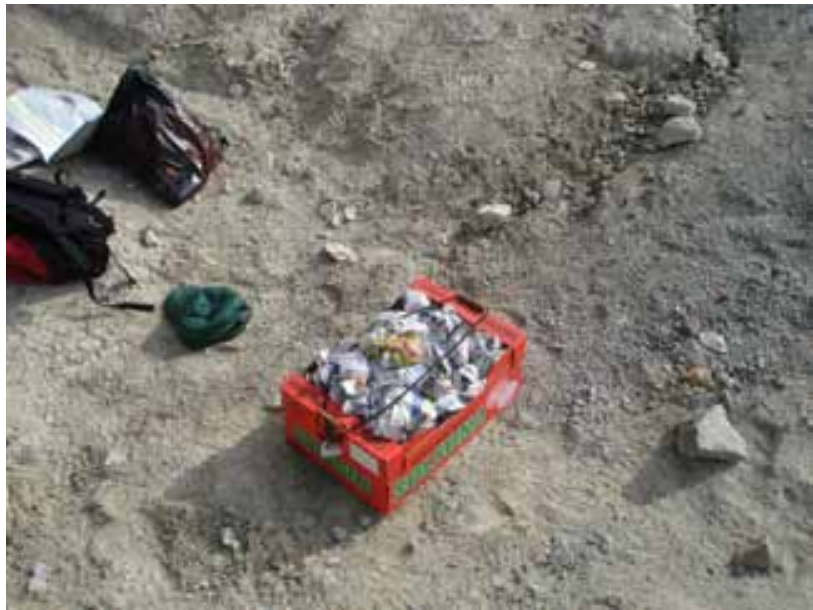

Figura 109. Preparación de las muestras para su transporte al almacén, envueltas y dentro de una caja.

La reducción de la muestra se debe efectuar con el equipo y en el lugar apropiados, como prensas hidráulicas (Figura 110). Estas prensas son sencillas, precisas y relativamente baratas y pueden ser imprescindibles para trocear muestras muy duras sin causar daños graves a las piezas. En algunos casos, para la partición de la muestra nos podemos ayudar de tenazas, mordazas u otros equipos.

Por otro lado, la reducción también se puede realizar de forma manual utilizando un martillo pequeño y escarpas. En cualquier caso, es importante que las zonas que deben recibir el impacto de la prensa o del martillo no sean las que tienen que quedar expuestas a la vista.

La reducción es otro apartado delicado y puede causar daños irreparables a la muestra. Sin embargo es muy necesario si el ejemplar es demasiado grande, pues los costes de transporte son también elevados. Además, es muy importante garantizar el equilibrio entre la superficie del mineral interesante y el volumen de la muestra.

\subsection{Acabados}

A menudo, los minerales más valiosos se presentan en la naturaleza recubiertos por otros minerales. Tales impurezas se pueden eliminar de diversas formas, dándole al mineral un valor mucho más alto que el que tendría en su estado natural, en bruto. La casuística es muy variada. El mineral interesante puede encontrarse recubierto por otros minerales que lo esconden, o queda en el interior de la muestra. En estos casos, lo que se debe hacer es intentar exponer al máximo el mineral que nos interesa. Esta operación se denomina acabado.

El acabado se puede hacer con la ayuda de pequeñas escarpas o agujas (son particularmente útiles los instrumentos de dentista), limpiando con paciencia la superficie del mineral de todas las impurezas que puedan estar adheridas, cuidando de no rayar o romper el mineral que nos interesa (Figura 111).

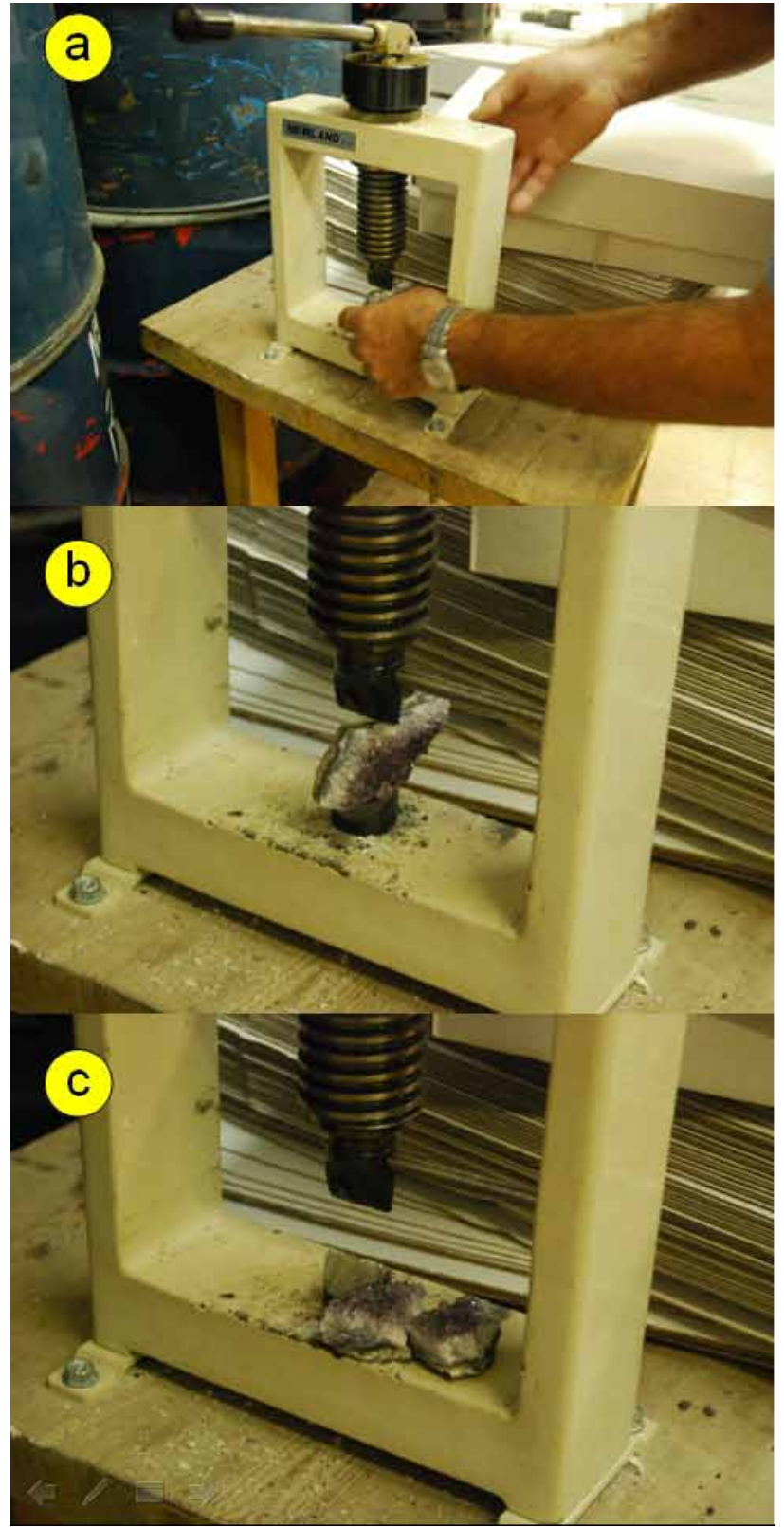

Figura 110. a) Prensa hidráulica para romper rocas. b) Disposición de la roca para partir una drusa de amatista. c) El resultado de la operación, con dos fragmentos de amatista de tamaño adecuado para la preparación de cajitas.

En algunos casos, cuando el mineral que nos interesa no sea atacable por ácidos y los minerales que lo impurifican sí, se puede recurrir a esta propiedad para hacer la limpieza (Figura 112). Un caso típico es en el que el mineral que nos interesa está englobado en calcita, o recubierto por ella. La calcita se disuelve muy fácilmente en ácido clorhídrico diluido (también denominado ácido muriático), que se puede adquirir con facilidad. Alternativamente, se podría utilizar vinagre. De todas formas, un ataque ácido puede dañar otros minerales o la estética de la roca, dándole un aspecto poco natural,de manera que se debe evaluar en cada caso si es interesante hacerlo. De hecho, muchos coleccionistas 


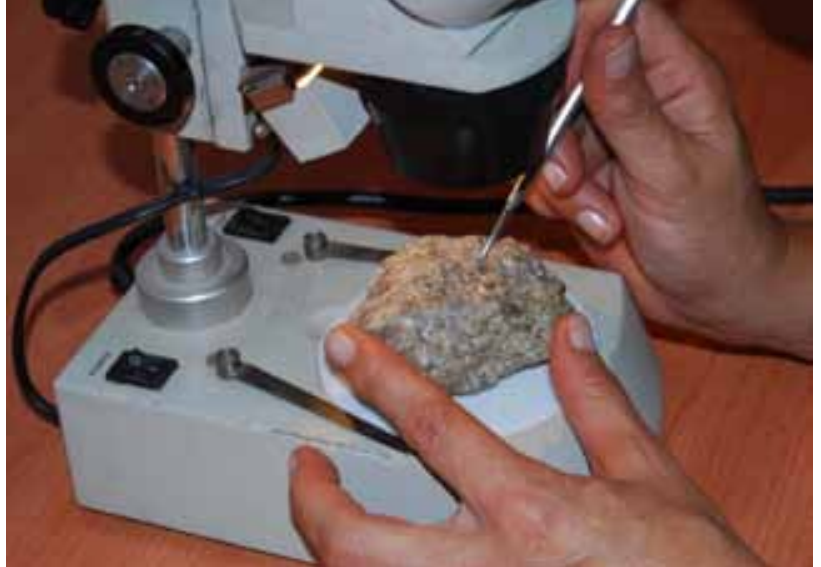

Figura 111. Limpieza de las impurezas de una muestra con la ayuda de un pequeño punzón.

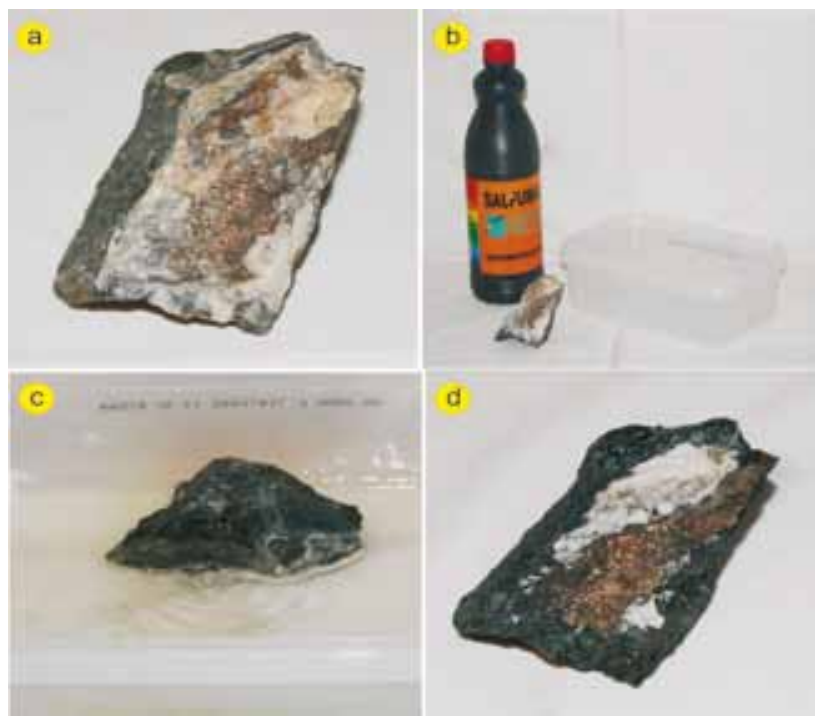

Figura 112. Limpieza de muestra rica en carbonatos con ayuda de ácido clorhídrico o salfumán. a) Imagen de la muestra natural donde hay pirrotina (de color bronce) incluida en calcita (blanco). b) Cubeta donde se hace el ataque ácido. c) Ataque con ácido de la muestra y destrucción de la calcita que desprende $\mathrm{CO} 2$, con efecto efervescente. d) Muestra ya atacada donde resalta mucho más la pirrotina.

rechazan las muestras atacadas con ácidos. En cualquier caso, el ataque con ácidos debe efectuarse en una zona bien aireada y con todas las precauciones necesarias que requiere el manejo de ácidos.

Cuando el mineral presenta recubrimientos ferruginosos, de color amarillento, estos pueden eliminarse dejando la muestra sumergida un día entero en un baño de ácido oxálico concentrado. Si al día siguiente el ácido (originalmente incoloro) ha quedado de color amarillo, quiere decir que el recubrimiento de la muestra ha sido atacado. Si el mineral de interés no experimenta daños, es recomendable que la muestra permanezca más tiempo bajo ataque hasta que la película de óxidos de hierro desaparezca por completo. En este momento es importante limpiar la muestra con agua abundante, para eliminar el ácido oxálico que resta e impedir la precipitación de costras blancas de oxalatos de calcio.

\subsection{Limpieza final}

Los minerales se deben presentar limpios para que puedan exhibir al máximo su brillo y coloración, pero una vez preparados es preciso evitar la acumulación de polvo sobre ellos. El polvo puede ser eliminado de muchas formas, la más común es con agua y jabón.

Un mecanismo de limpieza muy eficaz, si se dispone de ello, es un baño de ultrasonidos (Figura 113). En estos equipos se pone la muestra dentro de un recipiente lleno de agua sometida a ultrasonidos; en este contexto, las partículas de arcilla y otros minerales adheridas a la muestra son removidas.
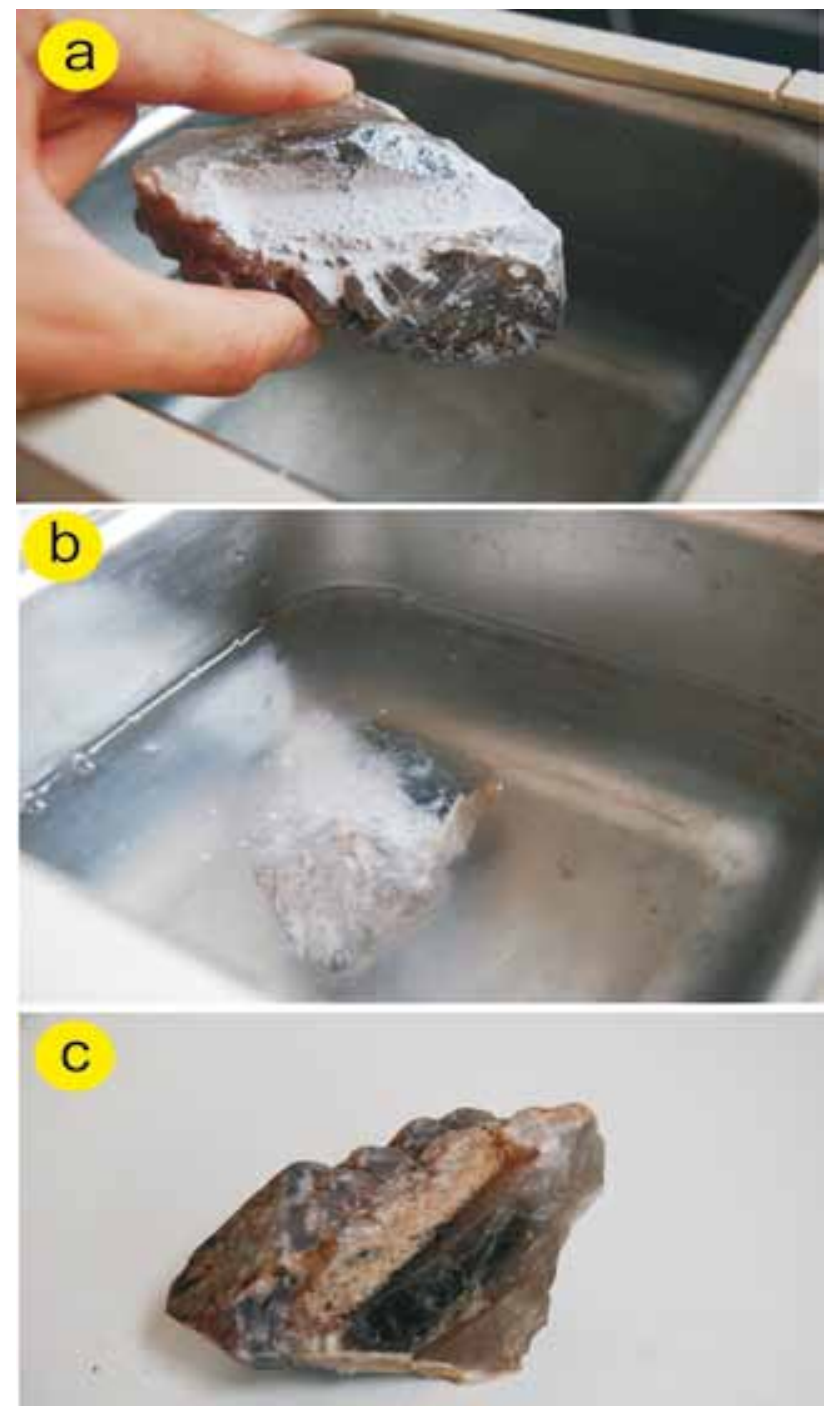

Figura 113. Limpieza de las impurezas de una muestra con la ayuda de una cubeta de ultrasonidos. a) Muestra inicial recubierta de polvo blanco; b) Limpieza dentro la cubeta con desprendimiento del polvo. c) El mineral una vez limpio; comparar con la primera imagen. 
Para la limpieza de recubrimientos de barro en muestras grandes se puede utilizar una manguera de agua a presión (Figura 114), mientras que para las más pequeñas lo más práctico es disponer de un pilón donde se pueda limpiar la muestra con un cepillo de dientes y agua y jabón. Sin embargo, se deben de tener en cuenta ciertas limitaciones.

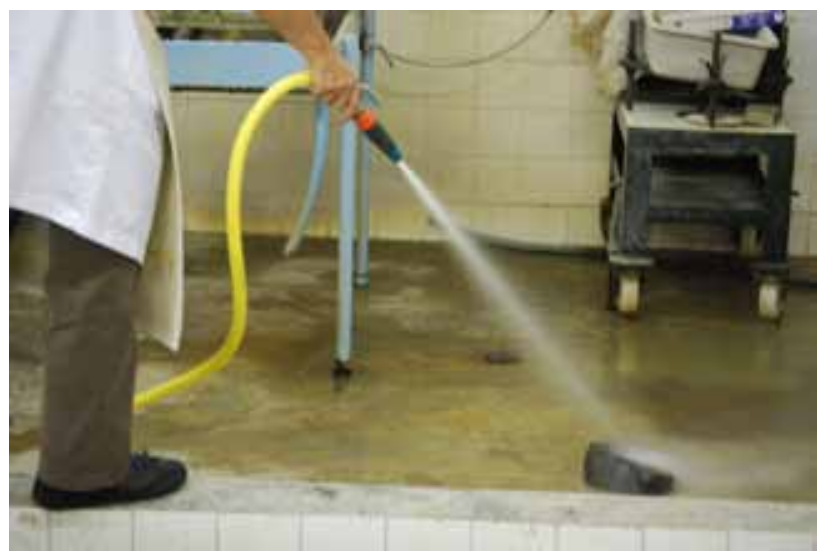

Figura 114. Limpieza de minerales con una manguera de agua a presión.

Hay algunos minerales que son solubles en agua y que por tanto, no pueden ser lavados con ella. Tal es el caso de las sales y de algunos sulfatos y carbonatos. Reconoceremos estos minerales porque tienen sabor. Además algunos minerales pueden reaccionar con los componentes del jabón.

Asimismo, algunos jabones contienen mezcladas partículas duras que se utilizan como abrasivo durante el proceso de lavado. Naturalmente, el uso de jabones de este tipo debe de evitarse.

Hay minerales blandos, como el talco o el yeso, que pueden ser rayados incluso por un cepillo de dientes: son aquellos minerales que se rayan con la uña.

Si el material es delicado o soluble en agua se puede trabajar con aire comprimido, pero solo si la muestra está seca (Figura 115).

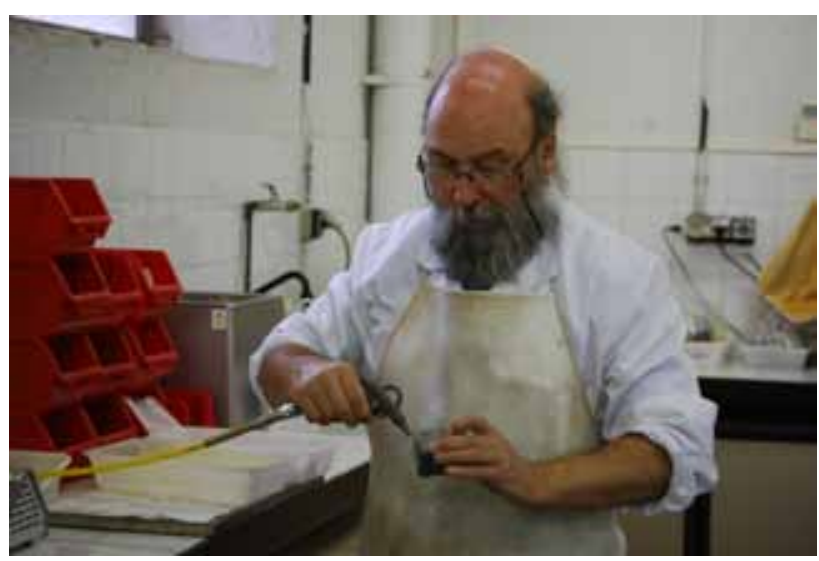

Figura 115. Limpieza de la muestra con una manguera de aire comprimido.

\subsection{Embalaje}

Es uno de los aspectos que más se debe cuidar para que los minerales no sufran daños, aunque este aspecto es desgraciadamente poco conocido por algunos exportadores de países en vías de desarrollo. Es muy frecuente que las muestras adquiridas por correo lleguen al destinatario en malas condiciones, fragmentadas o rayadas. A veces, completamente rotas. Eso se debe a un mal embalaje de los minerales y puede acarrear graves consecuencias para todos: para el comprador, que pierde dinero y las piezas, y para el vendedor, porque las transacciones insatisfactorias se difunden rápidamente por Internet y los vendedores descuidados perderán clientes y difícilmente podrán captarlos en lo sucesivo. Es muy importante que el vendedor tenga cuidado de asegurarse ventas posteriores, por eso necesita la satisfacción del cliente.

El mejor material de embalaje, tanto por sus propiedades como por su precio, es el papel de periódico (Figura 116). El papel de periódico se debe usar arrugado, de manera que ayude a hacer una bolsa de aire que amortigüe los posibles golpes que pueda recibir la pieza. Lo mejor es dar capas sucesivas de protección con diferentes páginas. Si se dispone de papel suave de embalar, también puede ser adecuado.

En la medida de lo posible, si los minerales se envían a destinaciones lejanas, se deben utilizar embalajes aislantes, amortiguadores de golpes y ligeros (para abaratar el transporte). El mejor material para ello es el poliestireno (denominado porexpand, unicell y de otras formas en diferentes países) o el plástico ligero (Figura 117).

Los minerales altamente frágiles pueden requerir ser embalados en una caja de cartón y protegidos con algodón (Figura 118).

\section{Otros usos que se pueden dar a los minerales}

Los minerales pueden ser utilizados también para usos decorativos y no sólo para los destinados propiamente al coleccionismo de minerales. Generalmente estas aplicaciones requieren un cierto trabajo y por tanto tienen un cierto valor añadido. Entre estas aplicaciones, que no necesitan un equipo demasiado complejo, destacan las siguientes: decoración, bisutería y recuerdos para turistas.

\subsection{Talla de las rocas y minerales}

Los minerales pueden ser tallados y pulidos de manera que puedan dar juegos de colores muy diversos. Este tipo de producción puede dar origen a microempresas de fácil sostenibilidad, siempre que se disponga de material abundante.

Como equipo básico es preciso disponer de una sierra diamantada para la talla de piezas, para darles las dimensiones y formas adecuadas. Estas sierras deben estar 

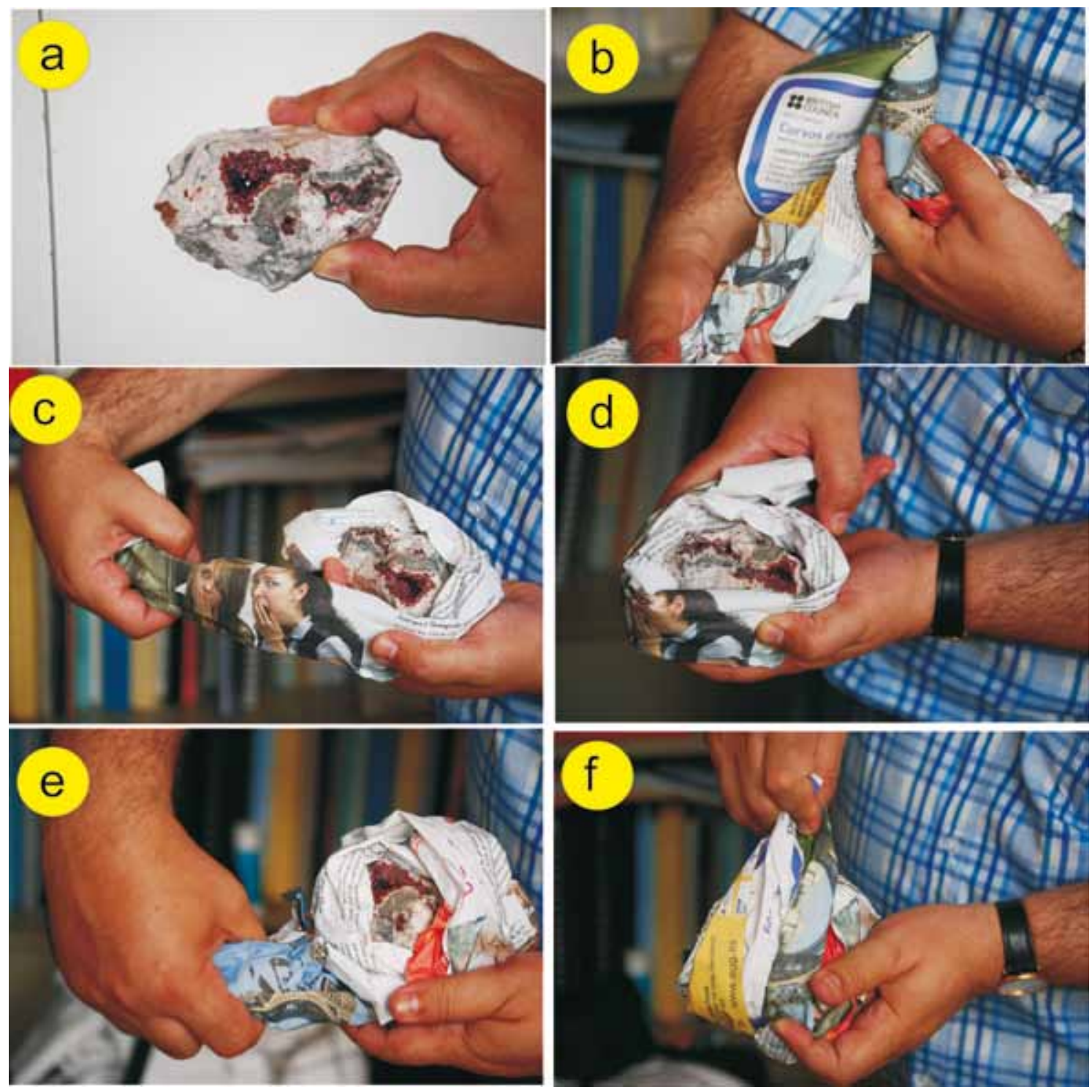

Figura 116. Embalaje de muestras. a) Pieza con una zona rica en cristales de roselita de color rosado en una matriz de calcita blanca, de Bou Azzer, Marruecos. b) Se arruga una hoja de papel de periódico hasta que queda alargada; de esta manera se fabrican cámaras de aire. c) y d) El papel de periódico se enrolla alrededor de la matriz de la pieza, protegiéndola de golpes. e) Con una nueva página arrugada de papel se repite la operación envolviendo el resto de la muestra. Cuantas más hojas de papel se utilicen más protegida estará la muestra.

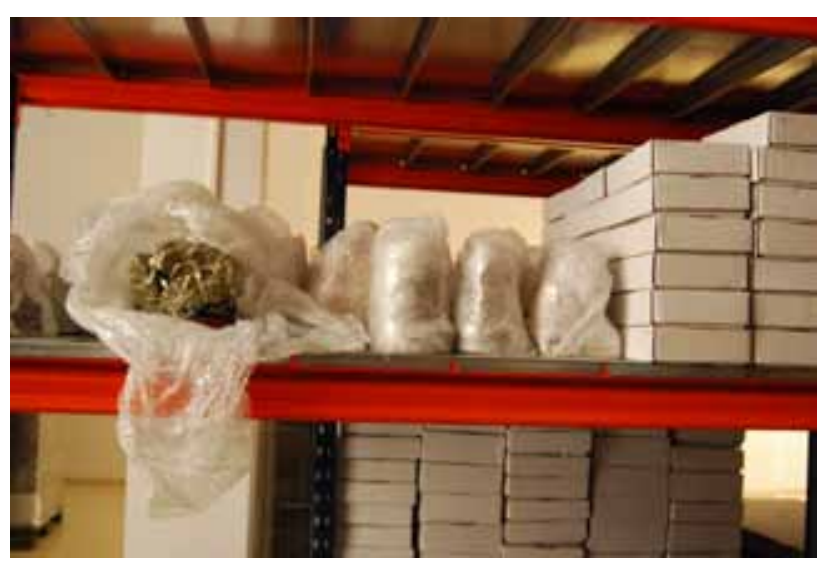

Figura 117. Muestras envueltas en plástico en un almacén. refrigeradas por agua y tener mecanismos de seguridad adecuados (Figura 119).

\subsection{Pulimentado de rocas y minerales}

Para el pulimentado de rocas y minerales se necesitan equipos fáciles de conseguir y con los abrasivos adecuados.

En una primera fase, llamada desbastado, se limpia la superficie del mineral de todas las irregularidades (fracturas, oxidaciones, cavidades, protuberancias) y se obtienen superficies más o menos lisas. En esta parte del proceso el abrasivo puede ser simplemente un papel de lija o incluso abrasivos naturales (arena de playa, gres cuarcítico, etc.). 


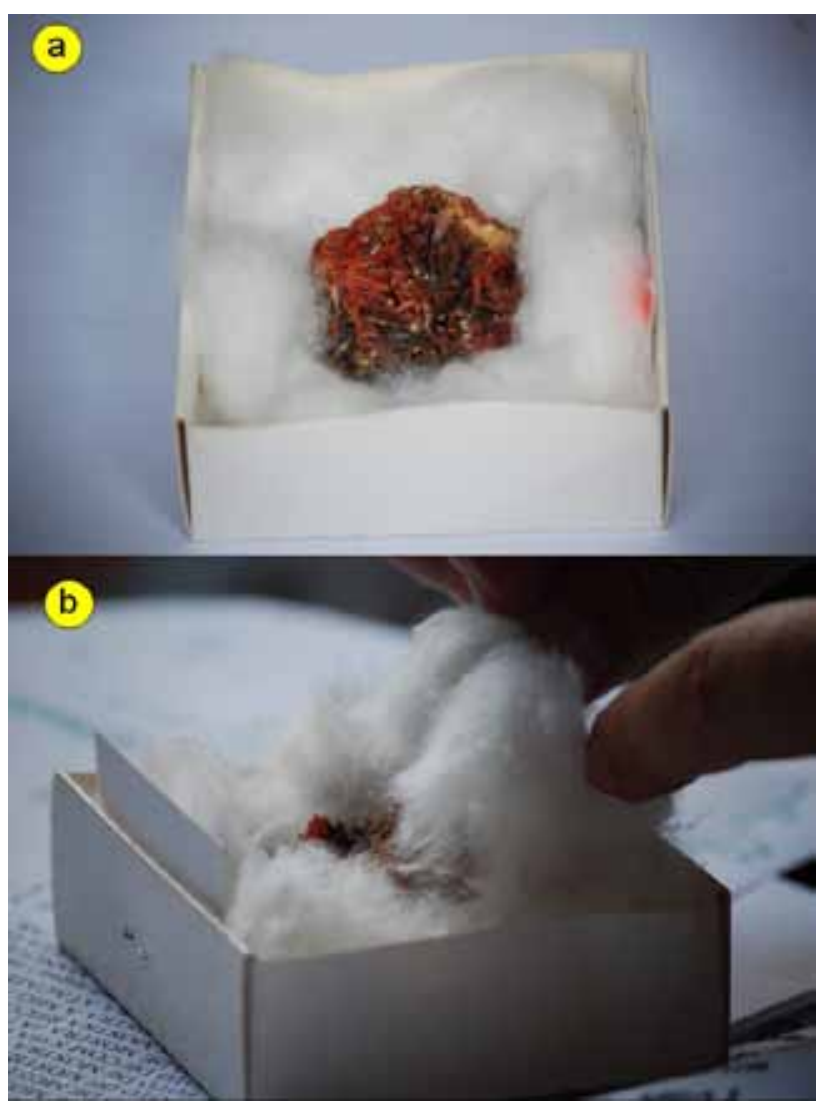

Figura 118. Envoltura de muestras muy delicadas con algodón. a) sentamiento de la pieza; b) recubrimiento previo al cierre de la caja. Crocoíta, Tasmania, Australia.

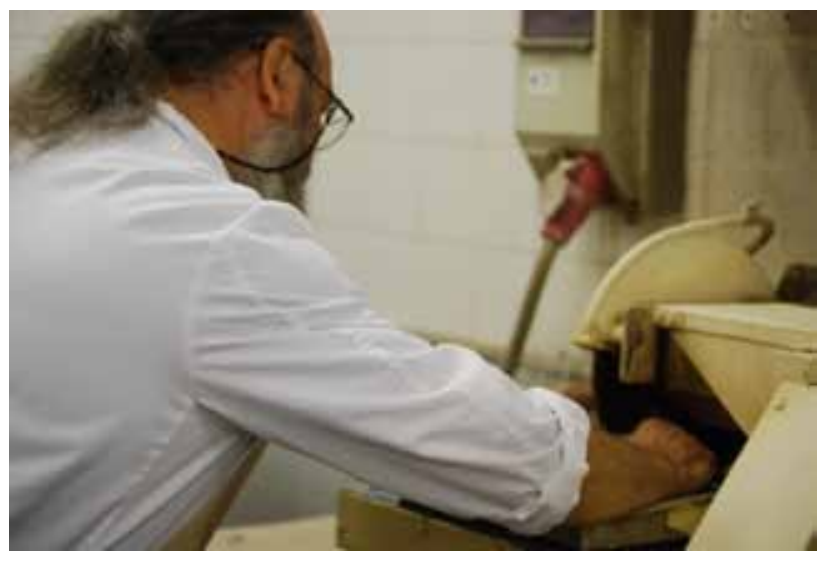

Figura 119. Talla de las muestras con una sierra diamantada.

La operación se puede hacer manualmente o con ayuda de platos giratorios (Figura 120), en los que se deposita el abrasivo y que se refrigeran con agua.

La segunda fase, la del pulimentado propiamente dicho, depende de la dureza del material a pulir. Se puede realizar con abrasivos como el carburundum u otros materiales duros como el óxido de cromo, o bien con pasta de diamante, aunque este último producto es muy caro.

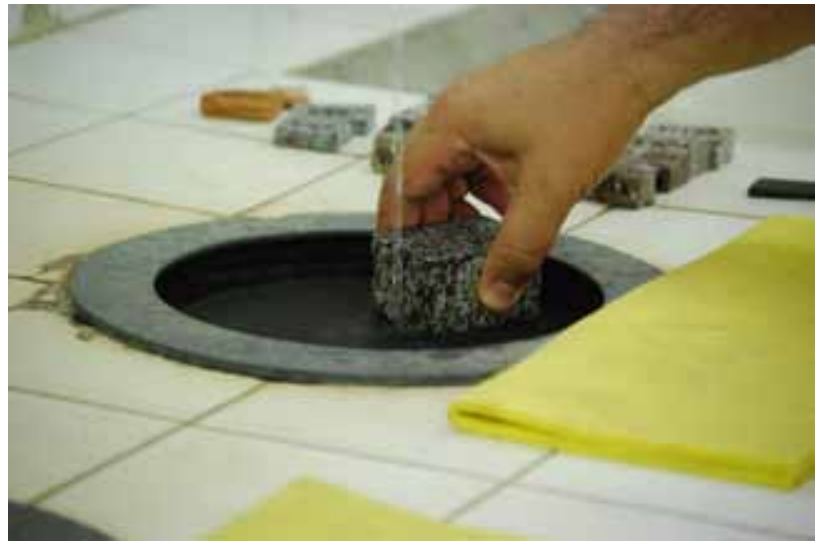

Figura 120. Desbastado de la muestra con ayuda de un plato giratorio refrigerado por agua en el que hay enganchado papel de lija.

El pulimentado se puede hacer con estos abrasivos en aparatos especializados, pero éstos se pueden también fabricar artesanalmente usando, por ejemplo, hormigoneras o lavadoras antiguas.

Una alternativa al pulido es aplicar un barnizado, lo que realza el color y el brillo de la pieza, a la vez que la puede preservar de algunos tipos de alteración. Este trabajo se puede hacer con barnices para madera o similares (Figura 121). Sin embargo, hay que tener en cuenta que esta operación no está indicada y es indebida para la gran mayoría de minerales de colección.

\subsection{Decoración}

Las posibilidades son infinitas en este ámbito, que se presta mucho a la creatividad. El producto puede ser un material simplemente decorativo (Figura 122) o tener alguna función.

Entre el material decorativo, a más de la roca simple, existen rocas montadas sobre soporte. Las clásicas geodas de amatista o las ágatas son un elemento decorativo muy preciado por el público en general que no conozca los minerales o no tenga interés en ellos.

Por otro lado, los minerales y las rocas, en tanto que se trata de objetos que generalmente duran mucho, pueden ser usados en la elaboración de objetos domésticos. Entre ellos, destacan las bases de relojes de mesa o pared (Figura 123), a menudo hechas con ágata o troncos silicificados, pero también mesas o sillas. Muchos objetos pueden hacerse con rocas o minerales pulidos, con muy poco trabajo. Los más típicos son ceniceros y bases para velas (Figura 124).

Cuando el mineral es blando e inalterable por los ácidos e insoluble en agua, como la mayor parte de los silicatos, puede ser usado para fabricar utensilios que estén en contacto con alimentos o bebidas (Figura 125). De esta manera, actualmente se fabrican con esteatita barriles para almacenar bebidas o líquidos. 

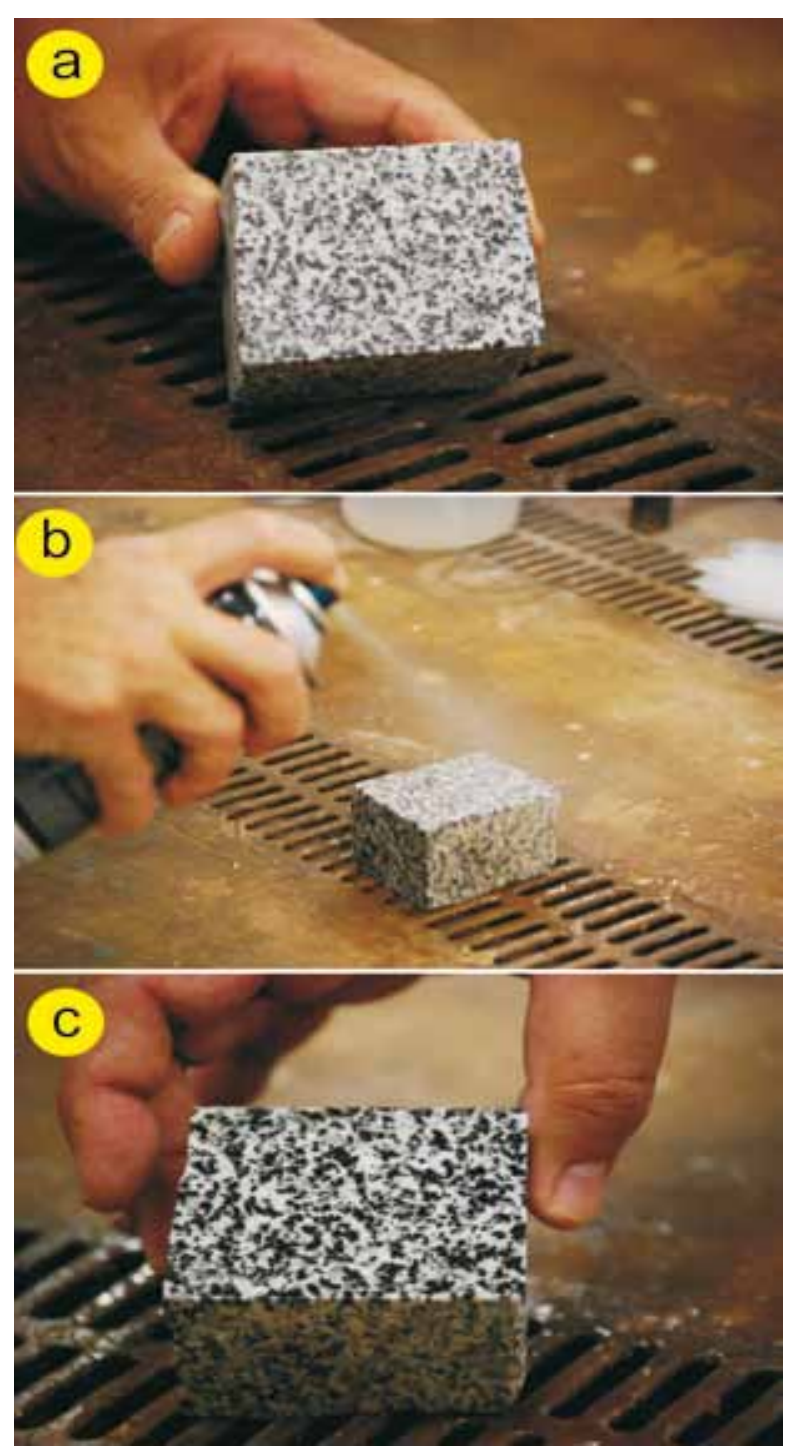

Fgura 121. Variación de las propiedades de la muestra al aplicarle barniz. a) Muestra tallada y con un ligero desbastado; b) aplicación de barniz con un spray; c) la muestra un a vez barnizada, a remarcar la mejora del color y el brillo.

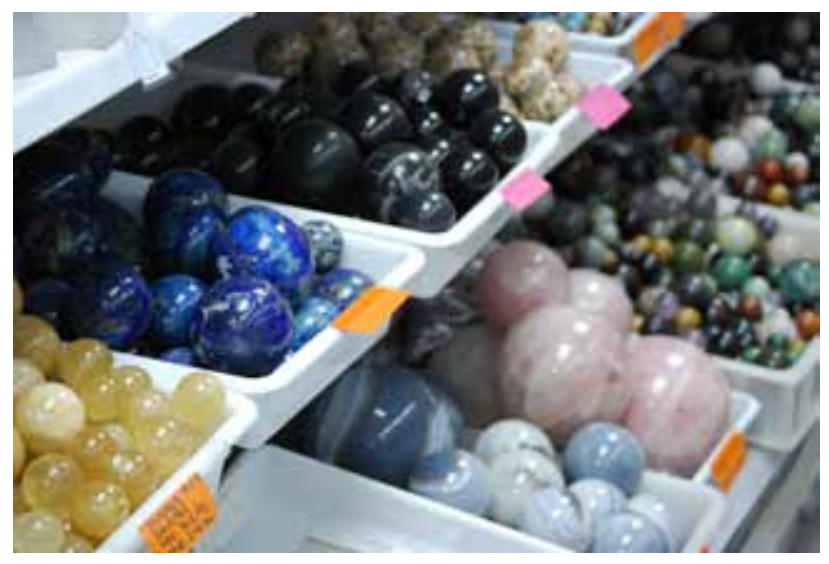

Figura 122. Ejemplos de minerales de colores pulidos y usados por a fabricar objetos de decoración.

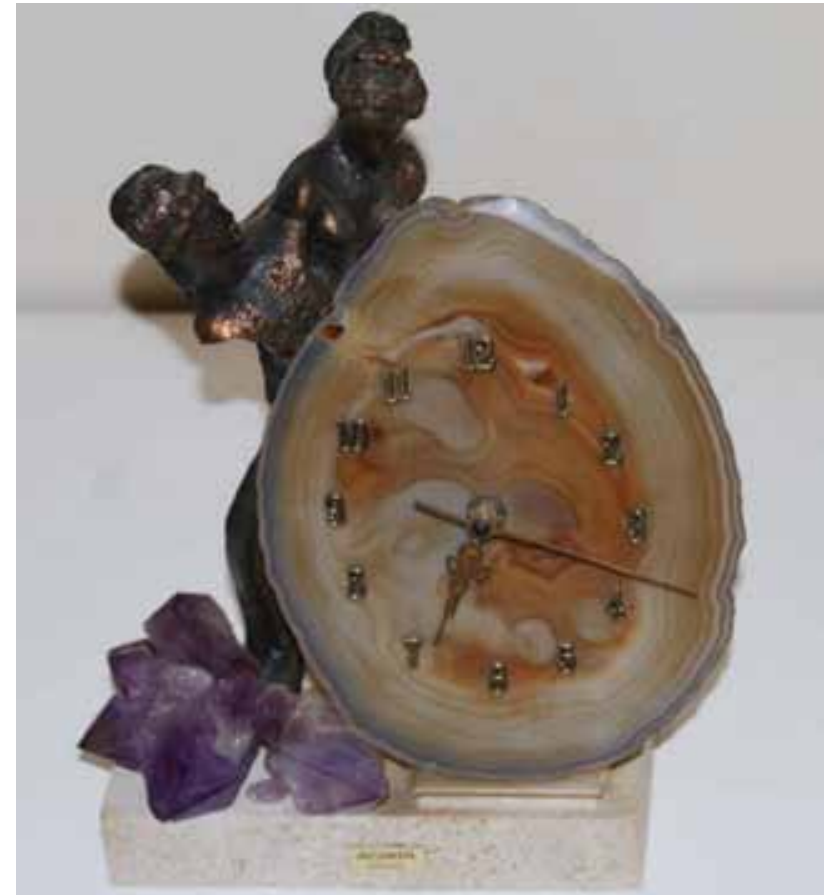

Figura 123. Base de un reloj elaborada con una sección de ágata.

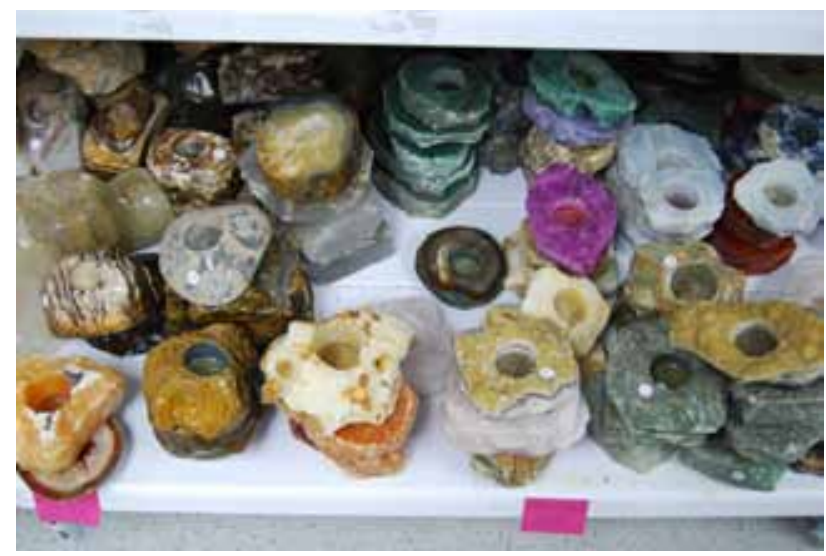

Figura 124. Ceniceros y bases de velas elaborados a partir de ónice.

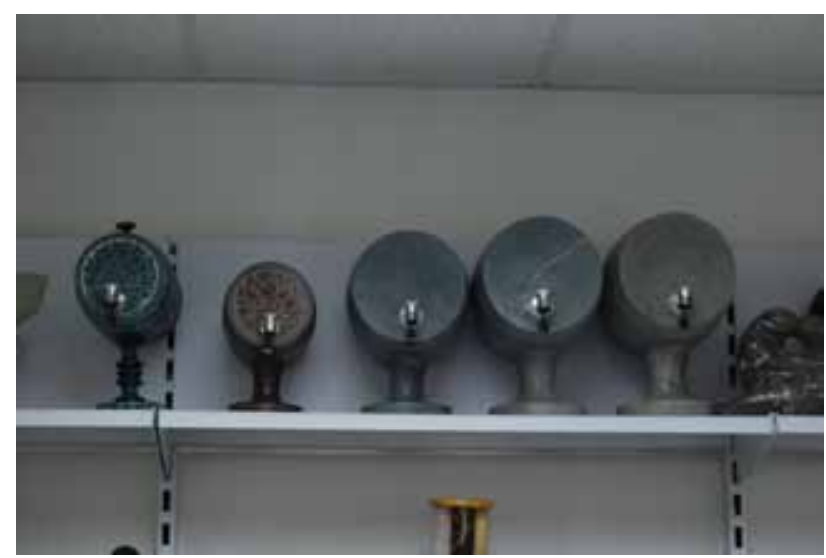

Figura 125. Recipientes para conservar bebidas fabricados con esteatita. 
En el caso que el mineral sea transparente y criptocristalino, especialmente si es un material blando (halita, yeso, etc.) puede usarse para la fabricación de lámparas (Figura 126). En este caso, la bombilla se pone dentro de la lámpara mineral y emite una luz muy difusa que da sensación de intimidad.

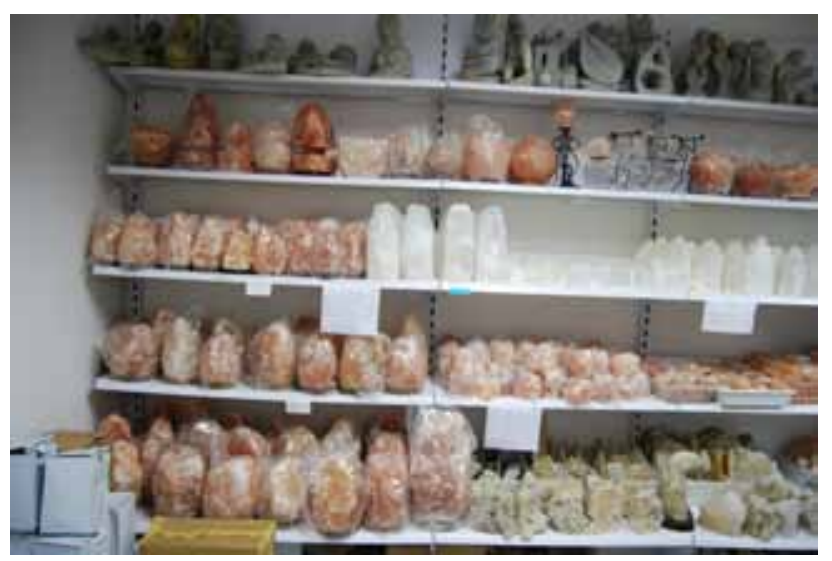

Figura 126. Lámparas hechas con sal gema de color rosado o con yeso de color blanco.

\subsection{Escultura sobre rocas y minerales}

Algunos materiales se prestan extraordinariamente a ser tallados y pulidos, incluso sin usar herramientas demasiado complejas. Este es el caso de minerales como el talco o el yeso, o incluso la sal. Si se hace una inversión de dinero superior, se puede llegar a disponer de máquinas que ejecuten directamente estas esculturas o grabados (Figura 127).

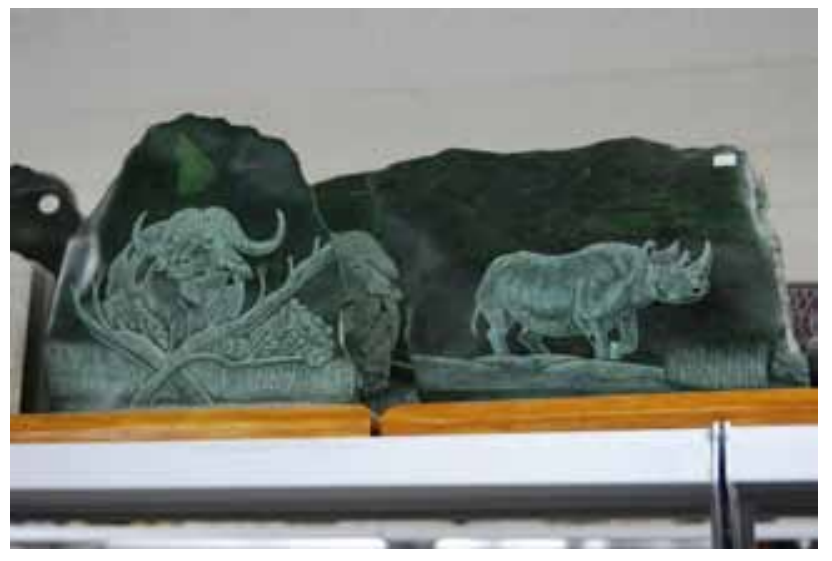

Figura 127. Bajos relieves elaborados a partir de fragmentos de esteatita.

7.5. Objetos decorativos elaborados con fragmentos pequeños de rocas y minerales

Las posibilidades de preparar objetos de decoración con un coste bajo, pero con un elevado valor añadido son muy grandes. Todo depende de las características del material original y de la capacidad artística del artesano.

Algunos ejemplos pueden ser la realización de árboles a partir de fragmentos rodados de minerales de diferentes colores (Figura 128) o bien la realización de mosaicos.

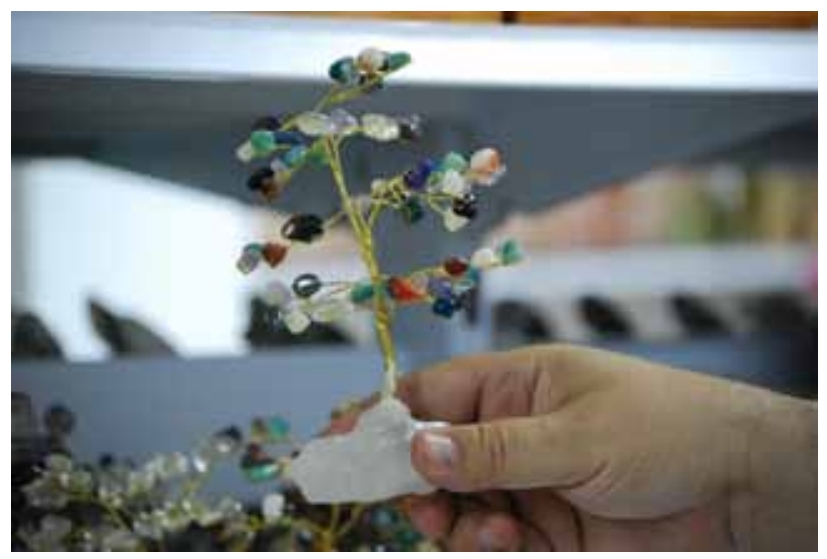

Figura 128. Otros objetos ornamentales fabricados con piedras pulimentadas de colores: un árbol.

\subsection{Material esotérico}

Existen sectores importantes de la población que creen en las propiedades curativas de los minerales. Aunque esto es una creencia sin ningún tipo de fundamento, la demanda de este material es relativamente elevada. En la mayoría de los casos, el material demandado estará convenientemente pulido, inclusive imitando morfologías típicas de algunos minerales (Figura 129), que no tienen por qué ser morfologías correspondientes al mineral que es tallado y pulido. Así, se pueden encontrar minerales como la labradorita o la turquesa, o bien algunas rocas o vidrio volcánico, tallados con forma de cristales de cuarzo.

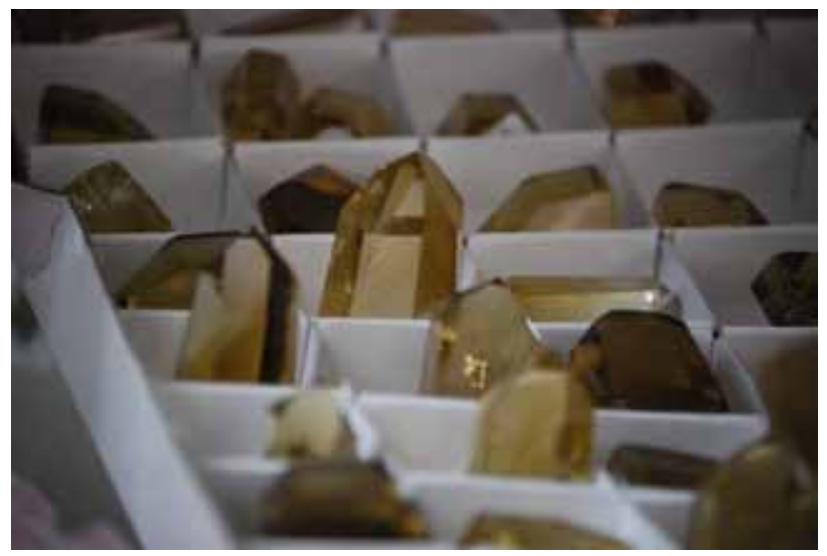

Figura 129. Cristales de cuarzo pulidos artificialmente para usarse por sus presuntas propiedades curativas. 


\subsection{Bisutería}

Algunos minerales se prestan a un fácil pulido y tallado y pueden ser usados para la producción de objetos de bisutería, como collares, pulseras, etc. (Figura 130). La preparación puede ser sencilla con herramientas muy rudimentarias. De hecho si los minerales son blandos (fluorita, calcita, turquesa, etc.) se pueden utilizar sistemas de producción conocidos ya desde el Neolítico. Sólo se necesita un equipo para la producción de piezas pulidas y un poco de imaginación y de capacidad de diseño. Hay que considerar que en algunos países constituye un floreciente negocio la simple producción de cuentas, a la venta en tiendas especializadas y dirigidas a terceros que son los que elaboran las piezas de bisutería.

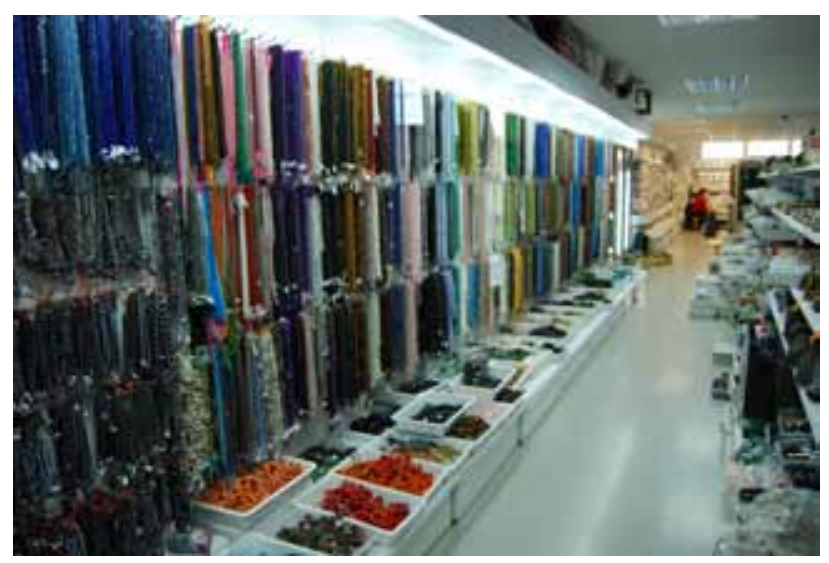

Figura 130. Objetos de bisutería (collares y pulseras) elaborados a partir de minerales coloreados.

\subsection{Recuerdos para turistas}

Algunos minerales o rocas comunes, característicos de una región y bien conocidos por los turistas, suelen ser utilizados para la confección de recuerdos. Normalmente se trata de pequeños objetos fácilmente transportables, de 4-5 cm de diámetro, que constarían de una peana de madera o metacrilato sobre la cual se adhiere el mineral o roca (labrado o en crudo) con silicona o pegamento. En este caso, en la peana debería constar el nombre del mineral y la expresión "recuerdo de..." con el nombre de la localidad (Figura 131).

\section{Selección de los minerales de una región determinada con interés comercial}

Hay diversas bases de datos en las que aparecen descripciones de minerales y en algunas de ellas se indican las localidades para cada país. Las más interesantes están listadas en el anexo. En alguna de ellas, como la de mindat. com, se indican incluso las coordenadas geográficas del lugar. Estos lugares, sin embargo, acostumbran a ser minas

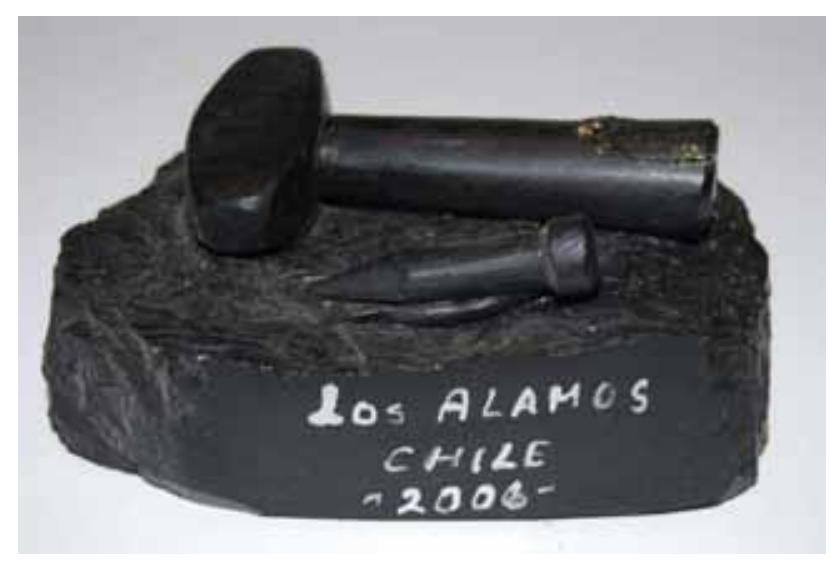

Figura 131. Objeto de recuerdo para turistas fabricado a partir de carbón.

activas o, al menos, con un propietario o concesionario. En muchas de estas minas no se ponen impedimentos para el acceso, pero en cualquier caso se debe de solicitar la autorización pertinente. Ello, por el hecho de que las zonas mineras activas encierran diversos peligros relacionados con dicha actividad y las empresas deben garantizar la seguridad tanto de su propia persona como de sus visitantes. Por otro lado, puede que a los propietarios les disguste o incomode la presencia de intrusos en sus propiedades y menos quienes pretenden lucrar con materiales extraídos de su propiedad o concesión. Por eso suele ser menos problemático trabajar en zonas libres donde haya minería antigua, en cuyo caso se debe tener presente que las zonas con antiguas explotaciones pueden ser inestables y su acceso es peligroso.

Otra fuente de información son las revistas de los propios coleccionistas de minerales, en las que se hallan abundantes datos sobre las características de los minerales más apreciados de las localidades mineralógicas más conocidas. Sería importante que estas revistas estuvieran al alcance todo el mundo, idealmente en bibliotecas públicas y escuelas, en zonas cercanas a localidades mineralógicas.

Finalmente, los servicios geológicos publican mapas geológicos, la lectura de los cuales puede dar indicaciones sobre las zonas en que potencialmente podría aparecer algún mineral interesante.

\subsection{Identificación de los minerales}

El reconocimiento de minerales se puede realizar directamente en el lugar de origen a simple vista (visu) gracias a sus propiedades físicas (forma, brillo, color, dureza, exfoliación, translucencia, fluorescencia, etc.) y químicas (reacción con ácidos, etc.). Hay muchos manuales de mineralogía que explican como efectuar la identificación (Ramdohr, 1960; Hurlbut, 1992; Gaines et al., 1995, entre muchos otros). Buena parte de los minerales más comunes se pueden identificar con la ayuda de una lupa de bolsillo, una navaja, una moneda de cobre, un pequeño imán y un 
frasquito de ácido clorhídrico o, en su defecto, jugo de limón o vinagre. Disponer de lámparas de luz ultravioleta puede ser de gran ayuda. Algunas de estas lámparas son relativamente baratas, portátiles y robustas y pueden servir además para la localización de muchos minerales. Como alternativa a las lámparas más sofisticadas, se pueden utilizar luces germicidas a menudo usadas en agricultura. En el caso que haya minerales radiactivos, un escintilómetro es imprescindible; actualmente los hay muy asequibles.

El problema reside especialmente en la identificación de los minerales más raros o de tamaño de grano más fino. En este caso, para una completa identificación hace falta un análisis mineralógico mediante difracción de polvo de rayos $\mathrm{X}$, microscopio electrónico de barrido con analizador de energías de rayos X (SEM-EDS-BSE), microsonda electrónica (EPMA) o microsonda Raman, entre otras técnicas. Estas técnicas son más o menos caras y sólo se realizan en laboratorios especializados, pero muchos de ellos se encuentran en universidades públicas. Por tanto, se puede acceder fácilmente a acuerdos para poder hacer una investigación a bajo coste o incluso sin coste alguno. En el anexo 1 se ofrece una lista de lugares en los que se pueden efectuar análisis mineralógicos mediante las técnicas antes mencionadas.

\section{Mecanismos de venta de minerales}

A la hora de vender una determinada pieza, para el cálculo del precio deben tenerse en cuenta los parámetros que se han comentado anteriormente. Así, las piezas de precio más alto serán las que cumplan a la vez todos los requisitos citados anteriormente. No obstante, y muy especialmente en el caso de los minerales más raros no deben desestimarse piezas que no cumplan con alguno de los requisitos citados, pues pueden seguir siendo muy valiosos para el comprador.

El valor de un espécimen determinado, como en todo, siempre dependerá de lo que determine el mercado. Por tanto, un futuro vendedor de minerales debería estudiar cuáles son los precios que alcanzan en el mercado muestras similares a las suyas, por ejemplo, a través de Internet. No obstante, debe tenerse en cuenta que muchos vendedores de Internet venden su material a precios caros.

Existen muchas posibilidades de venta, pero básicamente hay dos según el grado de iniciativa empresarial que se tenga: vender los minerales directamente o hacerlo a través de intermediarios. En el primer caso, en la práctica lo que hace falta es iniciativa empresarial para crear microempresas, inclusive mediante el apoyo de diversas agencias de las diferentes administraciones públicas (federales, nacionales, estatales, etc.) según sea el ordenamiento territorial establecido en cada país. La segunda opción es la más sencilla pero hay que valorar, en cada caso, que las ganancias a largo plazo pueden ser menores, si bien quizás pueda llegarse a un mayor abanico de posibles compradores al poder hacer llegar el material a puntos más lejanos.
9.1. Venta propia en mercados de artesanías y productos regionales

En primer lugar, se puede organizar la venta en la propia región productora o país de extracción de los minerales. Ello puede realizarse directamente en tiendas o ferias de objetos artesanales en general o de productos regionales, especialmente para el caso de las piezas de mayor belleza o de los objetos ornamentales elaborados con minerales o rocas.

Los ejemplares que aparecen en una región determinada, además de ser objeto de especial interés por parte de los coleccionistas o museos locales, pueden ser interesantes para un público local mucho más general. Tal es el caso de los objetos ornamentales en general o de uso doméstico. En ese sentido, no es desdeñable la oportunidad que otorga la existencia de un turismo organizado. Efectivamente, los turistas pueden también adquirir estos minerales por las mismas razones y con mayor facilidad que los consumidores locales. Por ejemplo, en Madagascar y en Brasil existe un comercio importantísimo de minerales en mercados especializados.

Los minerales pueden presentar incluso características decorativas suficientes como para poder venderse con éxito en ferias artesanales en otros países. Tal es el caso, nuevamente, de las amatistas brasileñas, o de los minerales y fósiles de Marruecos (Figura 132).

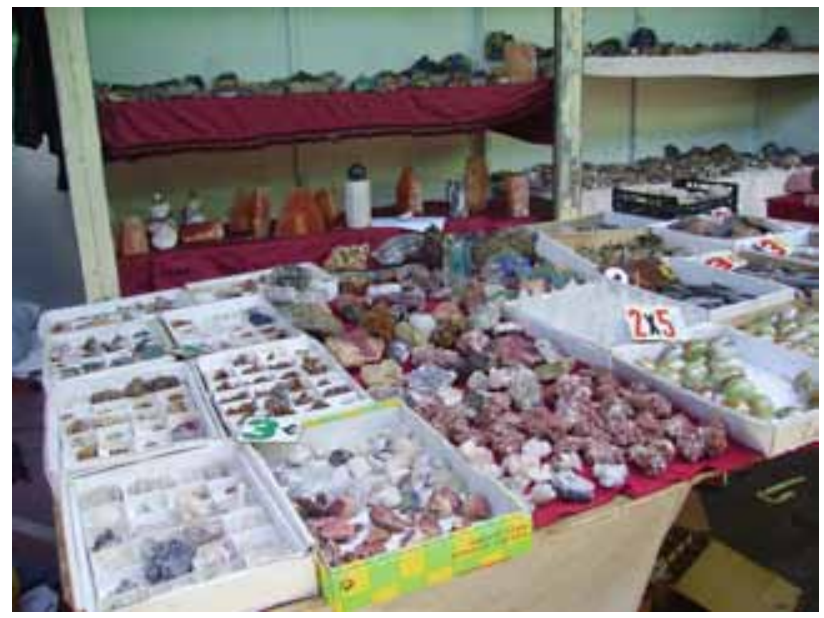

Figura 132. Puesto de venta de minerales de Marruecos en un mercado de productos artesanales en Barcelona.

\subsection{Venta propia por Internet}

Se pueden crear microempresas encargadas de vender los minerales por Internet. Para eso sólo hace falta disponer de una computadora conectada a la red, una cámara digital y contar con un grupo de gente (puede ser una familia) con un trabajo bien estructurado. Así, una parte del grupo se puede encargar de la extracción, otra de la promoción por Internet y otra de preparar el material para 
su exportación por correo o mensajería internacional. Para dar una idea de cuál es la estructura y los contenidos de las páginas web dedicadas a la venta directa de minerales, en el anexo se presenta un listado de algunas de las páginas $w e b$ de venta directa de minerales de todo el mundo. Como se puede constatar, muchas de las webs pertenecen a microempresas de países en vías de desarrollo o emergentes (e. g., Brasil, Pakistán, India, China, Uruguay, Perú, Bolivia o Marruecos).

La promoción del material por Internet constituye una labor exigente. La forma más eficaz de hacerlo es colocar en la página web una o más fotos de buena calidad y en color del mineral para que los posibles compradores tengan una idea precisa de las propiedades de la pieza. Es importante indicar el tamaño del mineral, o colocar a su lado una regla u objeto que sirva de escala $\mathrm{y}$, no menos importante, su precio en las divisas más comunes (dólares americanos o euros). Se debe informar claramente a los compradores de las condiciones de venta de las piezas, lo cual incluye el transporte. En este aspecto es importante seguir una política de estricta honestidad: los compradores consideran un abuso que el transporte sea más costoso que la propia pieza. En ocasiones, la particular situación político-social de un país o la remota ubicación del puesto de venta y envío pueden conllevar un coste extra en el transporte. De ser así, los compradores potenciales deben de estar informados de forma precisa de los riesgos o costes adicionales que conlleva realizar envíos internacionales. Como estrategia comercial óptima, siempre es preferible perder una venta eventual a perder un cliente de forma definitiva.

El sistema de venta por Internet puede ser directo o a través de subastas. En el primer caso es preciso que el vendedor se prepare su propia página web y en ella ponga sus minerales a la venta. De acuerdo con estas premisas, el vendedor establece un precio fijo y si a algún comprador de cualquier parte del mundo le interesa la pieza, la compra (Figura 133).

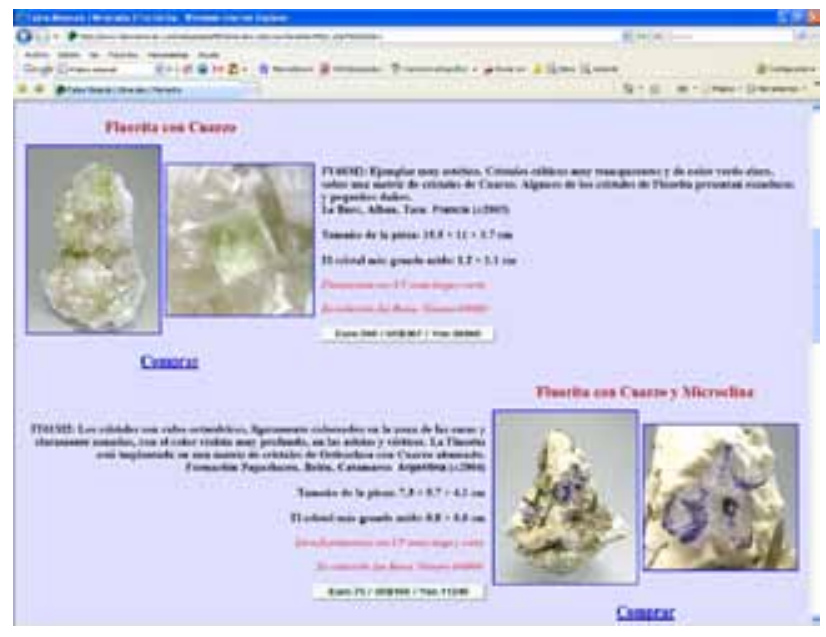

Figura 133. Ejemplo de una página web de venta de minerales (Fabre Minerals).
En el segundo caso, el vendedor pone la pieza a subasta por un tiempo limitado, de manera que los diferentes compradores proponen precios cada vez más altos y el subastador que ha propuesto el precio más alto en el tiempo establecido es el que gana la subasta (Figura 134). Las reglas en detalle las establece cada empresa de subastas en Internet. La más importante de todas en volumen de negocio, así como en variedad, cantidad y calidad de la oferta es ebay.com, pero hay muchas otras (ver anexo 4). En cualquier caso, el pago se puede realizar electrónicamente (vía paypal.com u otros sistemas de pago en línea) o por otros tipos de mecanismos (transferencia bancaria, cheque, etc.).

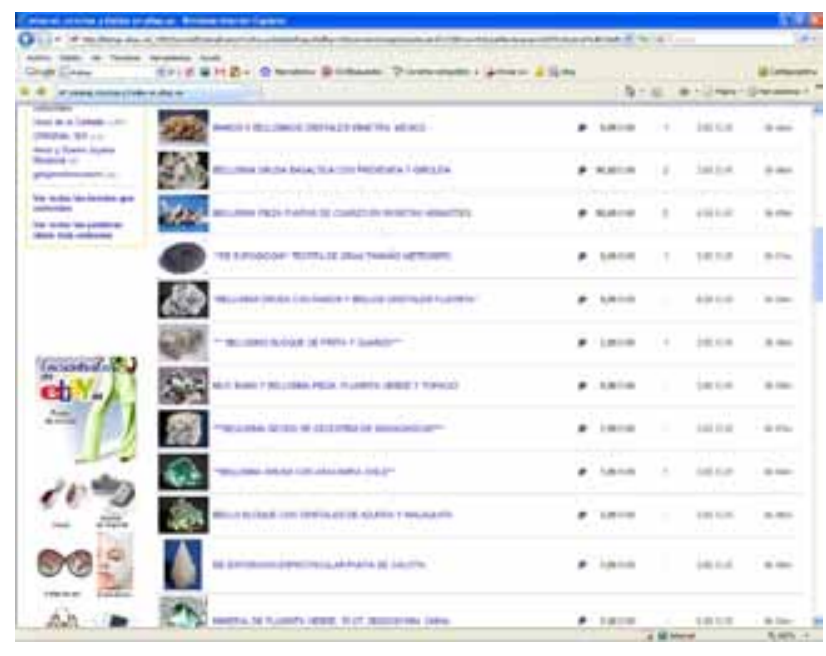

Figura 134. Ejemplo de una página web de subasta de minerales.

\subsection{Venta propia en ferias de minerales}

Algunas ferias de minerales son de carácter internacional. En Europa y en los EUA cada año se celebran muchas de ellas, y las más famosas son las de Munich (Alemania, Figura 135), Sainte Marie aux Mines (Francia) y Tucson (Arizona, EUA).

Algunas ferias dan facilidades para que una microempresa nueva pueda montar un puesto de venta. Estas ferias las visitan miles de compradores con la intención de encontrar novedades a buen precio. Por tanto, en el caso que el material fuera de suficiente calidad (se debería contar con asesoramiento apropiado) y con potencial para obtener buenas ventas, podría ser interesante disponer de un espacio de exposición.

Se debe tener presente, no obstante, que una empresa de estas características es arriesgada, porque los gastos son numerosos: boletos de avión, el transporte del material (que puede ser costoso porque los minerales son pesados), costes de preparación del espacio de exposición y venta, alojamiento, etc.

En las ferias, los minerales se pueden vender al detalle (a los compradores que la visitan) o a al mayoreo (a otros 


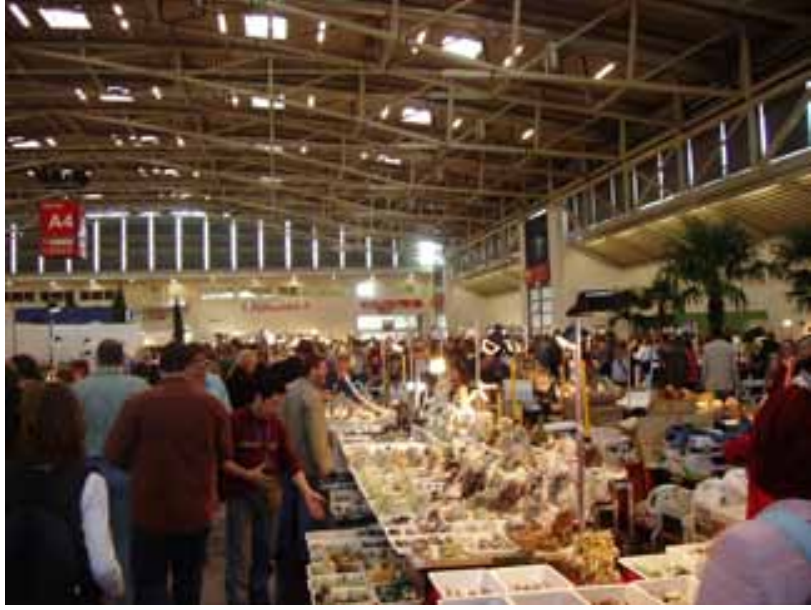

Figura 135. Sala de la feria internacional de minerales en Munich, Alemania.

comerciantes que haya en la feria). Es importante vender todo el material, de manera que no se haya de volver a llevarse nada de vuelta al país de origen.

Las ferias son una buena oportunidad para dar a conocer y promocionar los productos, de manera que pueden ayudar a tener más ventas en el futuro. Son también una oportunidad para conocer personalmente a otros comerciantes y a los compradores, hecho que permitirá que se establezca entre todos una mejor relación de confianza a nivel personal y comercial.

Normalmente lo que más se presta para a este tipo de venta son minerales de buena calidad, con mucho valor añadido, como por ejemplo minerales de calidad gema, o algunos ejemplares muy raros.

\subsection{Exportación mediante intermediarios}

Es un mecanismo fácil para vender las muestras, porque el comerciante es quien se encarga del transporte. Existen en todo el mundo numerosos mayoristas que se dedican a importar minerales y en el anexo-5 se presenta una lista de los más importantes.

Algunos de los principales mayoristas compran minerales en grandes cantidades al mismo vendedor y ellos después lo venden a otros comerciantes que revenden las piezas en pequeñas tiendas o ferias. Por tanto, este tipo de operaciones implica vender grandes cantidades de minerales pero a bajo precio, aunque el volumen total de la venta pueda llegar a ser muy elevado.

Es un mecanismo seguro de venta, porque el vendedor se asegura de vender en una sola operación lotes muy grandes que, previo trato, pueden contener muy diversas calidades de mineral.

\subsection{Exportación directa de las muestras}

Como cuestión previa, se debe tener en consideración que cada país tiene su propia regulación en relación a la exportación y se deberá comprobar que se disponga de las licencias necesarias para el envío de las muestras al extranjero. En algunos países, sin embargo, existen agencias gubernamentales dedicadas a fomentar la exportación aportando, inclusive, parte del capital necesario para ello (e. g., Bancomext en México). Por ello, el exportador potencial puede ver atenuados los costes que conlleva la exportación y puede contar con asesoría profesional, siempre que existan tales agencias en su país, el exportador cumpla con los requisitos oficiales y se formalice la exportación.

Una vez se pueda proceder a la exportación, se deben preparar las muestras adecuadamente para asegurarse que lleguen a su destino en las mejores condiciones posibles. Se debe de tener en cuenta que si tienen desperfectos perderán su valor y el comprador podría rechazar la mercancía.

En el caso de que se trate de una venta al detalle, es decir, de una o pocas piezas, se pueden enviar en forma de paquete postal, convenientemente envueltas de acuerdo con los criterios ya descritos y colocando un cojín de materiales blandos entre las muestras. No se pueden utilizar plantas, paja o restos orgánicos porque complicarían los trámites de exportación.

En el caso de que se trate de una venta al mayoreo, de decenas de kilos, el proceso es más complejo. De entrada, el peso de los minerales puede deteriorar la mayor parte de los recipientes. Lo más práctico es enviarlos en bidones resistentes, como por ejemplo bidones metálicos o de plástico reciclados que antes contuvieron hidrocarburos o productos químicos (Figuras 136 a 139), convenientemente limpiados.

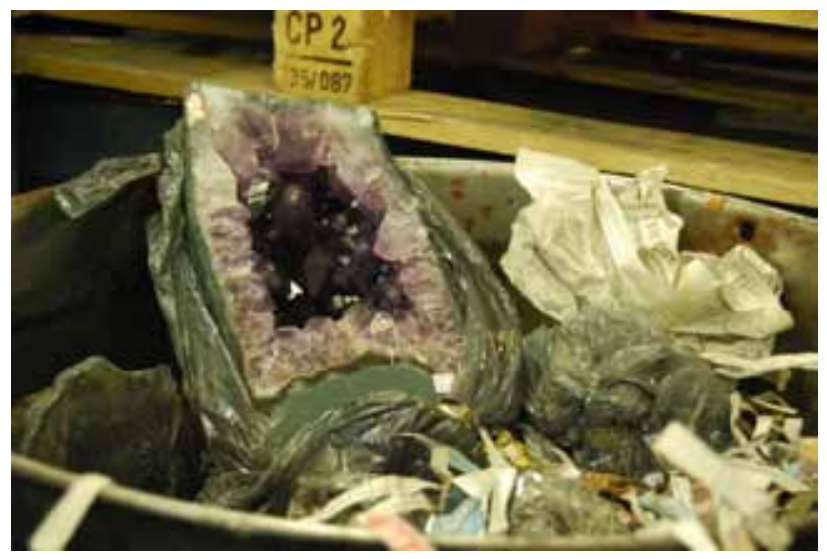

Figura 136. Preparación del envío de muestras. Se llena un bidón con las muestras convenientemente envueltas, dejando un cojín entre ellas, en este caso, recortes de papel de periódico.

Debe evitarse a toda costa que una muestra pueda deteriorarse a causa de choques contra las otras muestras durante el transporte. Así pues, es importante que las muestras queden fijas durante el transporte, por lo que su recipiente debe quedar lleno al máximo. 


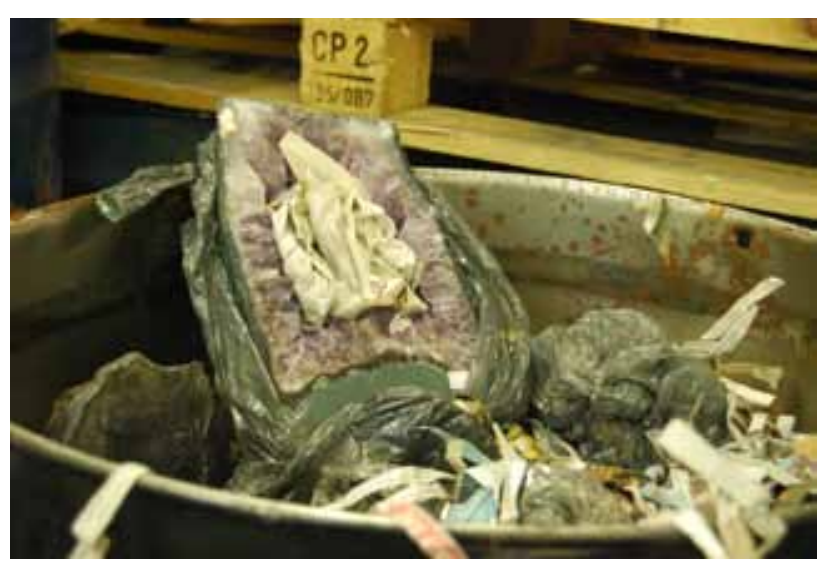

Figura 137. Preparación de la geoda de la Figura anterior para su envío. Es conveniente poner papel de periódico en el interior para que los cristales no reciban golpes. A continuación se envuelve la pieza

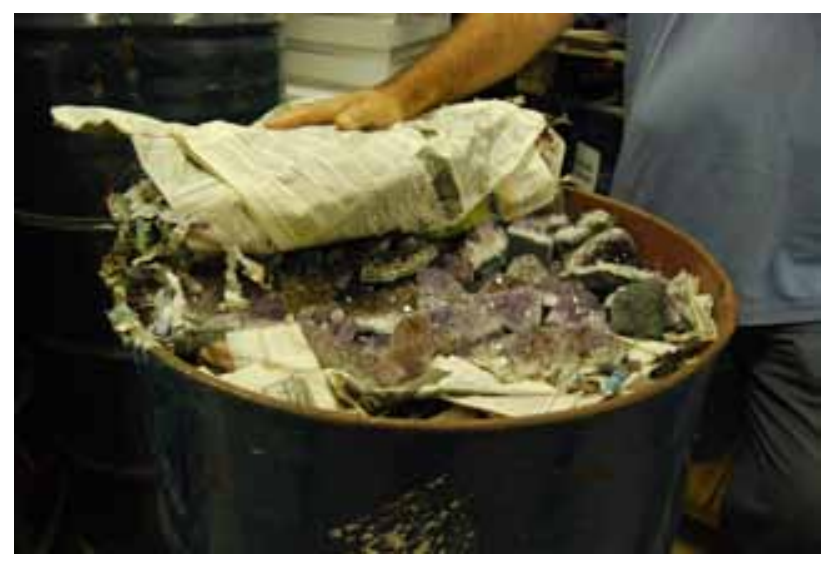

Figura 138. Preparación de drusas de amatista para su envío. Se pueden hacer sándwiches de capas de minerales entre capas de papel. En este caso, como el mineral es duro, no hace falta.

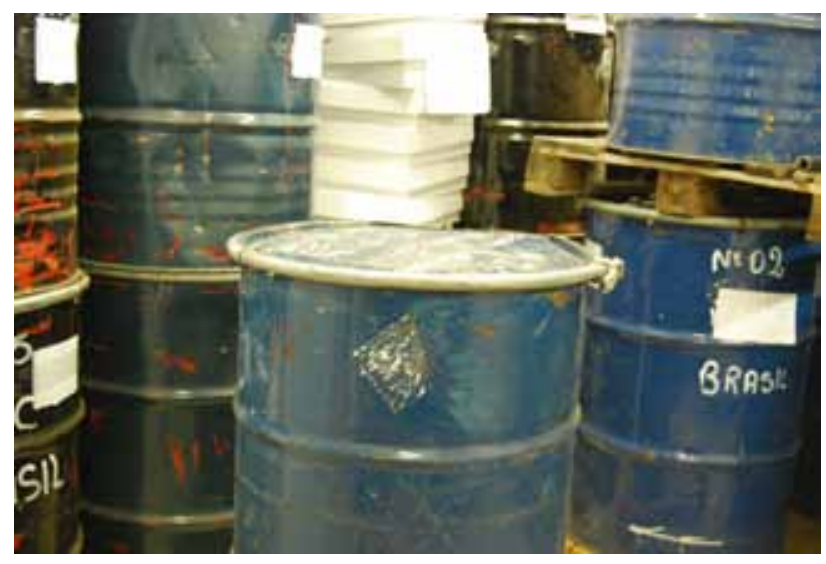

Figura 139 Cierre del bidón con precinto extraíble por los agentes de aduanas.

\section{Presentación de las muestras para su venta}

Es un mecanismo seguro de venta, porque el vendedor se asegura vender en una sola operación lotes muy grandes en los que, previo trato, puede haber diferentes calidades de piezas.

La manera de exponer los minerales para su venta puede ser decisiva para que el comprador se decida a adquirir la pieza. Es muy importante que la muestra esté bien limpia y bien presentada. Se debe tener diseñada la presentación para que el comprador se fije en la muestra. Eso pasa por que los siguientes aspectos sean los adecuados:

\subsection{Embalaje de la muestra}

Se debe presentar el mineral dentro de una cajita de cartón, con un fondo de algodón si la pieza es frágil, o dentro de una cajita de plástico transparente. Ello da al comprador la idea de que la muestra ha tenido un tratamiento experto y cuidadoso (Figura 140). Además, disponer de estas cajitas facilitará el transporte, son baratas y se pueden adquirir fácilmente en grandes cantidades.

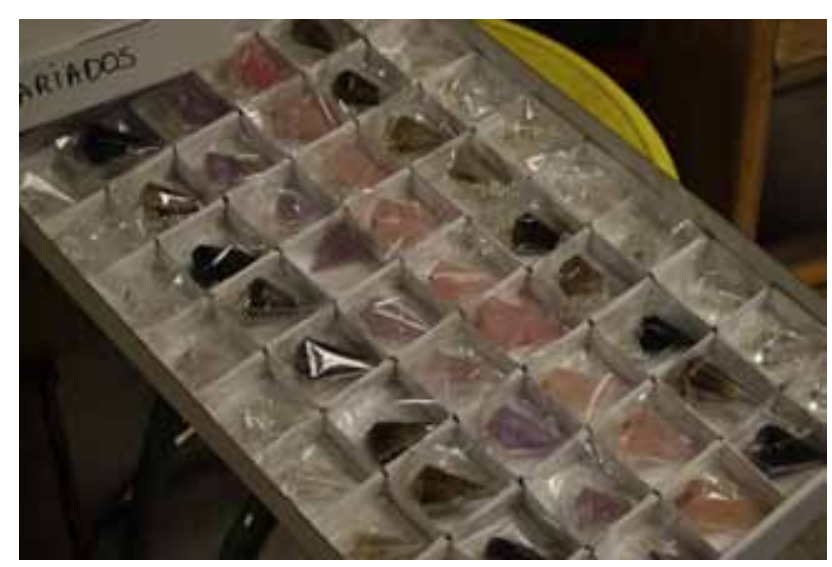

Figura 140. Presentación de minerales para su venta en cajitas de cartón.

\subsection{Orientación de la muestra}

La muestra tiene que estar situada con la parte más interesante dirigida hacia el posible comprador.

\subsection{Colocación de la muestra}

La muestra puede estar montada sobre un soporte, tanto si es un micromontaje como si es una muestra de mano. En el caso de que se trate de minerales para recuerdo para la venta a turistas, o piezas de gran belleza, es esencial que la muestra esté montada sobre un soporte (de plástico o de madera, Figura 141).

Una buena presentación, además de ayudar a llamar la atención del comprador potencial, sugiere que el vendedor 


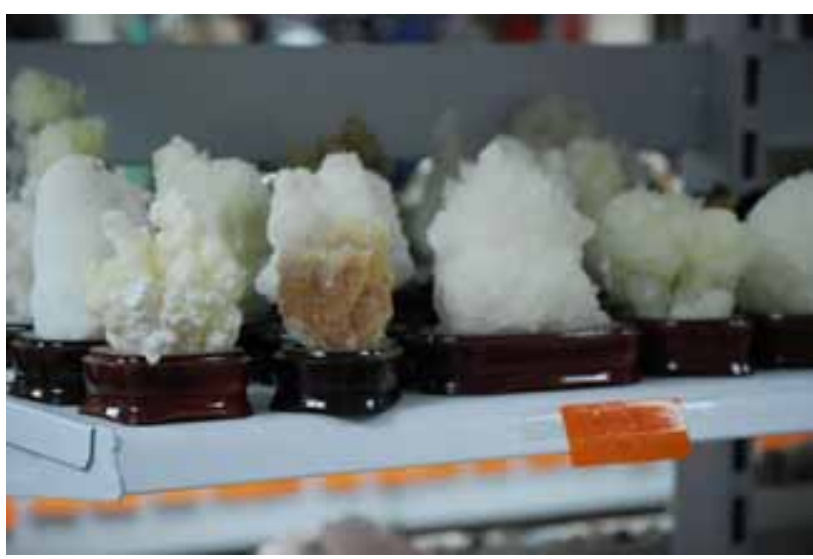

Figura 141. Presentación de la muestra sobre soportes de madera.

ha manipulado la muestra cuidadosamente durante las etapas anteriores.

Si se quiere vender piezas de cierta calidad, debe evitarse que se amontonen o queden mal colocadas sin mostrar su parte más interesante. En el caso de que un visitante toque la muestra y cambie su posición correcta, el vendedor debe asegurarse de situar de nuevo la muestra en su posición más favorable.

\subsection{Iluminación de la muestra}

Es importante que el punto de venta disponga de lámparas que emitan una buena luz sobre los minerales, para realzar los aspectos de brillo y transparencia (Figura 142). De todas maneras, se debe recordar que algunos minerales pueden sufrir efectos negativos al ser expuestos a la luz.

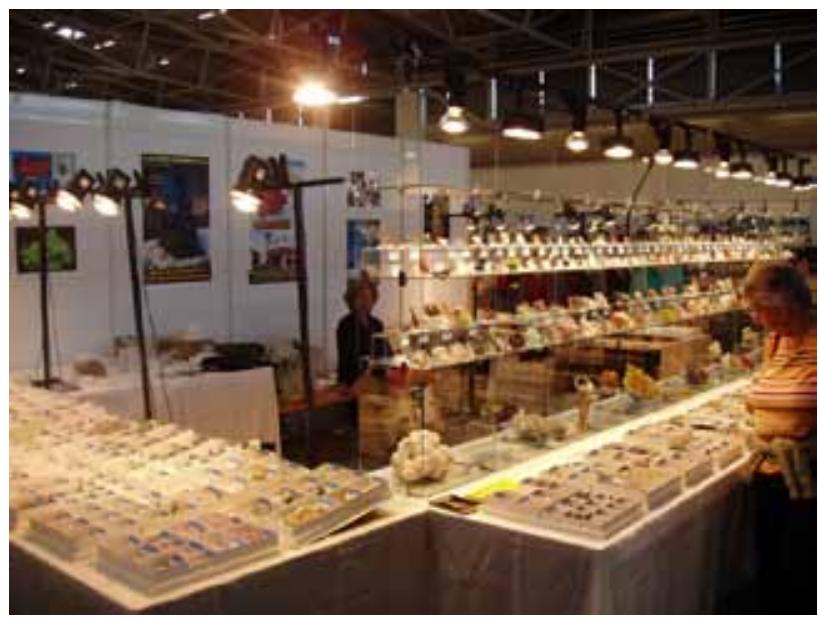

Figura 142.Iluminación de las piezas en una zona de venta de minerales en un stand de la feria de Munich (Alemania).

\subsection{Etiquetaje del mineral}

Es esencial que el mineral cuente con una etiqueta con todos los detalles que lo identifican (Figura 143): nombre del mineral y, si se presta, de su variedad, fórmula química y localidad de procedencia detallada (es poco serio indicar solamente el nombre del país). Algunos vendedores añaden su nombre y datos de contacto. La etiqueta debería estar cuidadosamente realizada. Si se dispone de computadora e impresora, se pueden diseñar etiquetas bien hechas y la elaboración de decenas de etiquetas de un mismo mineral puede ser un trabajo sencillo.

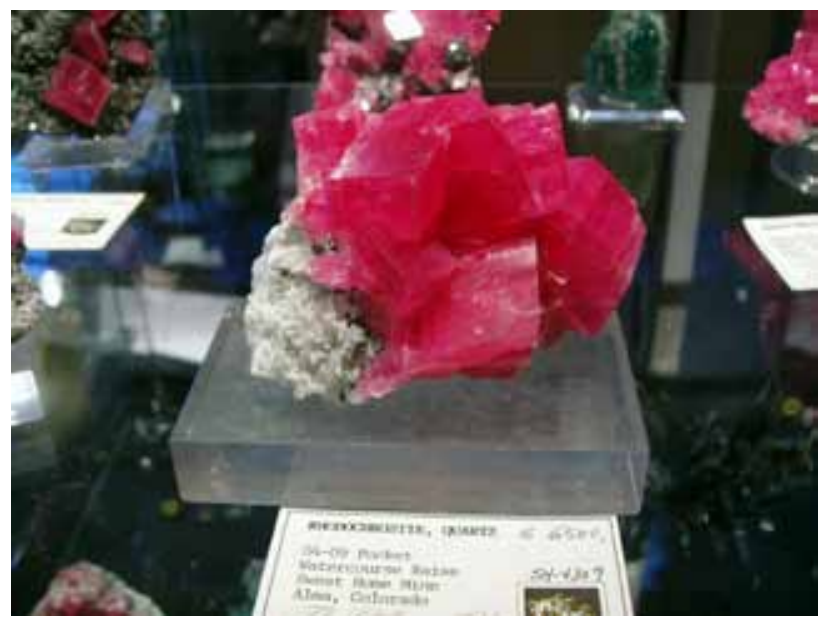

Figura 143. Etiquetaje de una muestra de rodocrosita.

\section{Agradecimientos}

A los siguientes museos por facilitarnos fotografiar muchas de sus piezas: Museo Mollfulleda de Mineralogía (Arenys de Mar, Barcelona), Museu de Ciències Naturals de Barcelona (Ajuntament de Barcelona / ICUB), Museu de Geologia Valentí Masachs (Universitat Politècnica de Catalunya, Manresa), Colección de Mineralogia sistemática del Departament de Cristal-lografia, Mineralogia i Dipòsits Minerals de la Universitat de Barcelona. Gracias igualmente a Sergio Evangelio y Joan Barrera por facilitarnos diversas fotografías de minerales. Al personal del Servei de Làmina Prima de la Universitat de Barcelona que nos ayudaron en la obtención de fotos del pulido de material. Las imágenes de aplicaciones de minerales y de muchas muestras fueron facilitadas por PROMINER, S.L. (Sr. J.M. Jurado). Este trabajo ha sido mejorado gracias a los comentarios y sugerencias de A. Camprubí y J.A. Proenza. 


\section{Bibliografía}

Bariand, P., Cesbron, F., Geffroy, J., 1977, Les minéraux, leurs gisements, leurs associations: París, Francia, Editions Minéraux et Fossiles BRGM.

Berry, L.G., Masson, B., 1963, Mineralogía: Madrid, España, Aguilar, Betejtin, A. 1970, Curso de Mineralogía, Moscú, Rusia, Mir.

Canet, C., Camprubí, A., Flores-Castro, K., Victoria-Morales, A., Ostroumov, M., 2004, Mineralogía, en Alaniz-Álvarez, S.A., NietoSamaniego, A.F., Tolson, G. (eds.), Léxico Geológico Mexicano: México, D.F., Sociedad Geológica Mexicana, 21-28.

Deer, W.A., Howie, R. S., Zussman, J., 1992, An Introduction to the Rock-forming Minerals: London, U.K., Longman.

Hurlbut, C.S., Klein, C., 1987, Manual de Mineralogía de Dana: Barcelona, España, Reverté.

Kirsch, H., 1980, Mineralogía aplicada para ingenieros, técnicos y estudiantes: Buenos Aires, Argentina, Editorial Universitaria.

Klockmann, F., Ramdohr, P., 1955, Tratado de Mineralogía: Barcelona, España, Gustavo Gili.

Kostov, Y., 1958, Mineralogy: London, U. K., Oliver \& Boyd.

Mata Perelló, J.M., Sanz Balagué, J., 1988, Guia d'identificació dels minerals (Països Catalans i d'altres): Manresa, España, Edicions Selectes.

Mata Perelló, J.M., Sanz Balagué, J., 1988, Guía de identificación de minerales adaptada fundamentalmente a la Península Ibérica: Manresa, España, Parcir Edicions Selectes.

Mata Perelló, J.M., Sanz Balagué, J., 2006, Guia d'identificació de minerals: Barcelona, España, Edicions UPC.

Putnis, A., 1993, Introduction to mineral sciences: Cambridge, U.K., Cambridge University Press.

Zoltai, T., Stout, J.H., 1984, Mineralogy. Concepts and Principles: Minneapolis, E.U.A., Burgess Publishing Company.

\section{Anexos}

11.1. Anexo 1: Algunos laboratorios de apoyo en la caracterización de minerales

Grup de Recursos Minerals: yacimientos, aplicaciones y sostenibilidad. (Caracterización de visu, microscopia óptica de luz transmitida y reflejada, difracción de polvo de rayos X, difracción de monocristal, microdifracción, microscopia electrónica de rastreo con análisis de energías de rayos $\mathrm{X}$, microsonda electrónica, microsonda Raman, microscopia infrarrojo). Coordinador: Joan Carles Melgarejo y Draper. Departament de Cristal-lografia, Mineralogia i Dipòsits Minerals de la Facultat de Geologia de la Universitat de Barcelona, c/Martí y Franquès s/n 08028 Barcelona. Tel. (34)93-4021344. Mail: joan.carles.melgarejo.draper@ub.edu. Con este grupo colabora además el Dr. Joan Viñals Olia (jvinalsvinals@ub.edu), quien desarrolla habitualmente trabajos de caracterización de minerales con museos y particulares.

Instituto de Geología / Instituto de Geofisica, Universidad Nacional Autónoma de México. (Caracterización de visu, microscopía óptica de luz transmitida y reflejada, difracción de polvo de rayos $X$, microscopía electrónica de barrido con análisis de energías de rayos $\mathrm{X}$, microsonda electrónica, microsonda Raman, microscopía infrarrojo, ICP-MS). Contactos: Antoni Camprubí (taga@geologia. unam.mx), Carles Canet (ccanet@geofisica.unam.mx),
Carlos Linares (linaresc@geofisica.unam.mx), Rufino Lozano (rufino@servidor.unam.mx), Teresa Pi (difracrx@ geologia.unam.mx), Margarita Reyes (adelars@servidor. unam.mx).

\subsection{Anexo 2: Páginas web de mineralogía interesantes}

http://un2sg4.unige.ch/athena/mineral/mineral.html Base de datos de la Universidad de Génève, muy completa, mecanismo de búsqueda por la fórmula química (inglés).

http://www.mindat.org/index.php Descripción de minerales, conexión con vendedores de minerales de todo el mundo (inglés).

http://webmineral.com/ Descripción de minerales (inglés, con entradas de nombres de minerales en alemán y castellano).

http://www.minerant.org/educational.html. Listado de recursos de mineralogía en Internet (inglés).

http://rruff.info/ Una base de datos muy actualizada de las propiedades de los minerales (inglés).

http://euromin.w3sites.net/ Base de datos de propiedades de minerales (francés).

11.3. Anexo 3: Páginas web con direcciones de comerciantes de minerales

http://www.geo.uw.edu.pl/HOBBY/DEALER/dealer. $\mathrm{htm}$ Base de datos muy completa de vendedores de minerales (inglés).

http://www.minerant.org/dealersMIN.html Base de datos muy completa de vendedores de minerales (inglés).

\subsection{Anexo 4: Páginas web de subastas de minerales}

http://www.ebay.com Subastas de minerales y de todo tipo de productos, que pone a la venda productos con destino a todo el mundo, pero que también cuenta con páginas de diferentes países, entre ellos España, E.U.A., Francia, Canadá, Brasil, Reino Unido, Alemania.

http://coleccionismo.delcampe.net. Subasta de minerales y de todo tipo de objetos, de ámbito europeo.

http://www.thevug.com/vug/vugauctions.html Un listado actualizado de algunos de los más famosos lugares de subastas especializadas en minerales

11.5. Anexo 5: Páginas web de mayoristas de minerales

http://www.prominersl.com (España).

11.6. Anexo 6: Páginas web de comercio de micromontajes

http://www.micromineral-forum.com http://www.micromineral-market.com 
11.7. Anexo 7: Páginas web de museos de mineralogía

http://se.geocities.com/museudelguix/catala.html Museo del yeso, enfocado a las diversas formas de este mineral, así como sus usos.

http://www.geomuseu.upc.edu

http://www.mnactec.cat/museum/museo_de_las_mines_de_bellmunt_del_priorat.htm

Recibido: 02/06/2008

Recibido corregido: 06/09/2008

Aceptado: 02/10/2008 